\title{
Total Synthesis and Biological Evaluation of the Potent HIV Latency- Reversing Agent Ansellone A and its Analogues
}

Mizushi Yanagihara $^{\mathrm{a}}$, Kenichi Murai ${ }^{\mathrm{a} *}$, Naoki Kishimoto ${ }^{\mathrm{b}}$, Towa Abe $^{\mathrm{b}}$, Shogo Misumi ${ }^{\mathrm{b}}$, Mitsuhiro Arisawa $^{\mathrm{a} *}$

${ }^{a}$ Graduate School of Pharmaceutical Sciences, Osaka University, Suita, Osaka, 565-0871, Japan

${ }^{b}$ Department of Environmental and Molecular Health Sciences, Faculty of Medical and Pharmaceutical Sciences, Kumamoto University, Kumamoto 862-0973, Japan

E-mail:murai@phs.osaka-u.ac.jp,arisaw@phs.osaka-u.ac.jp

Supporting Information

Table of Contents

1. Page S2

2. Page S2

3. Page S14

4. Page S17

5. Page S20

6. Page S21

7. Page S22

8. Page S33

9. Page S35

10. Page S36

\section{General}

Synthesis of ansellone A

Synthesis of ansellone $A$ analogs

Study of Prins cyclization with 1a and 1c

Optimization of Prins cyclization with $1 \mathrm{~b}$

Tong's synthesis of ansellone A (for comparison)

Computational study

Biological assay

References

${ }^{1} \mathrm{H}$ and ${ }^{13} \mathrm{C}$ NMR Data 


\section{General}

Melting points were measured by BÜCHI B-545 and all melting points were uncorrected. ${ }^{1} \mathrm{H}-\mathrm{NMR}$ and ${ }^{13} \mathrm{C}-\mathrm{NMR}$ spectra were measured by JEOL JNM-ECS 400, JEOL ECS 300 or JEOL JNM-LA 500 spectrometers with tetramethylsilane as an internal standard. IR spectra were recorded by Shimadzu FTIR 8400 (ATR). High resolution mass spectra and elemental analysis were performed by the Elemental Analysis Section of Osaka University. Column chromatography was performed with $\mathrm{SiO}_{2}$ (Merck Silica Gel 60 (230-400 mesh) or Kanto Chemical Silicagel 60 (spherical, 63-210 $\mu \mathrm{m})$. Unless otherwise noted, materials were purchased from Aldrich Inc., Tokyo Chemical Industry, Kanto Kagaku, Wako Chemicals, and other commercial suppliers and were used without purification. All heating experiments were performed using an oil bath.

\section{Synthesis of ansellone $A$}

\section{Preparation of 3}<smiles>C=C(C)C1CC=C(C)C(=O)C1</smiles>

(R)-carvone<smiles>C=C(C)[C@H]1CC(=O)C(C)=C[C@H]1O</smiles>

S1

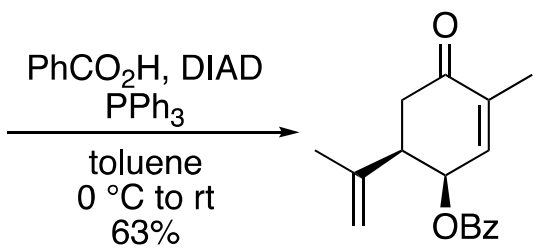

S2<smiles>C=C(CO[Na])[C@H]1CC(=O)C(C)=C[C@H]1O</smiles>

3

\section{Compound S2}<smiles>C=C(C)C1CC(=O)C(C)=CC1OC(C)(C)C</smiles>

Diisopropyl azodicarboxylate $(7.20 \mathrm{~mL}, 36.9 \mathrm{mmol})$ was added dropwise to a solution of known compound $\mathbf{S 1}^{1}$ (2.04 g, $\left.12.3 \mathrm{mmol}\right)$, benzoic acid (4.51 g, 36.9 $\mathrm{mmol})$, and $\mathrm{PPh}_{3}(9.68 \mathrm{~g}, 36.9 \mathrm{mmol})$ in toluene $(30.0 \mathrm{~mL})$ at $0{ }^{\circ} \mathrm{C}$ under $\mathrm{N}_{2}$ atmosphere. After stirring overnight at room temperature, the resulting solution was diluted with EtOAc, and washed with saturated $\mathrm{NaHCO}_{3}$ aq. and brine. The organic layer was dried over $\mathrm{Na}_{2} \mathrm{SO}_{4}$, filtered, and concentrated under reduced pressure. The residue was purified by flash column chromatography on silica gel $\left(1^{\text {st }}\right.$ time: $n$-hexane-EtOAc $(9: 1), 2^{\text {nd }}$ time: $n$-hexane- $\left.\mathrm{CHCl}_{3}(1: 1)\right)$ to give compound $\mathbf{S 2}(2.08 \mathrm{~g}, 7.69 \mathrm{mmol}, 63 \%)$ as a yellow solid. MP 
109.2-109.3 ${ }^{\circ} \mathrm{C} ;[\alpha]_{\mathrm{D}}^{24}=-376.9\left(\mathrm{c} 0.63, \mathrm{CHCl}_{3}\right) ;{ }^{1} \mathrm{H}-\mathrm{NMR}\left(500 \mathrm{MHz}, \mathrm{CDCl}_{3}\right)$ 8: $7.98(2 \mathrm{H}, \mathrm{dd}, J=7.7$, $1.2 \mathrm{~Hz}), 7.56(1 \mathrm{H}, \mathrm{dd}, J=7.7,7.7 \mathrm{~Hz}), 7.43(2 \mathrm{H}, \mathrm{dd}, J=7.7,7.7 \mathrm{~Hz}), 6.91(1 \mathrm{H}, \mathrm{dd}, J=5.4,1.7 \mathrm{~Hz})$, $5.77(1 \mathrm{H}, \mathrm{d}, J=5.4 \mathrm{~Hz}), 4.95(1 \mathrm{H}, \mathrm{s}), 4.83(1 \mathrm{H}, \mathrm{s}), 3.02-2.94(2 \mathrm{H}, \mathrm{m}), 2.67-2.60(1 \mathrm{H}, \mathrm{m}), 1.85(3 \mathrm{H}$, s), $1.82(3 \mathrm{H}, \mathrm{s}) ;{ }^{13} \mathrm{C}-\mathrm{NMR}\left(125 \mathrm{MHz}, \mathrm{CDCl}_{3}\right) \delta: 199.2,165.8,142.9,139.0,138.7,133.2,129.8$, 129.7, 128.4, 113.0, 66.8, 44.4, 38.0, 21.9, 15.6; HRMS (ESI-TOF) calcd for $\mathrm{C}_{17} \mathrm{H}_{28} \mathrm{O}_{3} \mathrm{Na}[\mathrm{M}+\mathrm{Na}]^{+}$: 293.1154, found 293.1166 .

\section{Compound $3^{2}$}<smiles>C=C(C)[C@H]1CC(=O)C(C)=C[C@H]1O</smiles>

Compound S2 (491 mg, $1.81 \mathrm{mmol}$ ) was added to a solution of $\mathrm{NaOH}$ (508 mg, $12.7 \mathrm{mmol})$ in $\mathrm{MeOH}(73.0 \mathrm{~mL})$ at room temperature. The mixture was stirred at room temperature for $1.5 \mathrm{~h} . \mathrm{H}_{2} \mathrm{O}$ was added to the resulting solution, and the resulting mixture was extracted with $\mathrm{CHCl}_{3}$. The combined organic layer was washed with brine, dried over $\mathrm{Na}_{2} \mathrm{SO}_{4}$, and concentrated under reduced pressure. The residue was purified by column chromatography on silica gel using $n$-hexane-EtOAc (3:1) to give compound 3 (291 mg, $1.75 \mathrm{mmol}, 96 \%)$ as a pale yellow oil; ${ }^{1} \mathrm{H}-\mathrm{NMR}\left(500 \mathrm{MHz}, \mathrm{CDCl}_{3}\right) \delta: 6.74-6.72(1 \mathrm{H}, \mathrm{m})$, $5.02(1 \mathrm{H}, \mathrm{s}), 4.77(1 \mathrm{H}, \mathrm{s}), 4.37-4.35(1 \mathrm{H}, \mathrm{m}), 2.79-2.73(1 \mathrm{H}, \mathrm{m}), 2.70-2.66(1 \mathrm{H}, \mathrm{m}), 2.34(1 \mathrm{H}, \mathrm{dd}, J$ $=15.5,4.0 \mathrm{~Hz}), 2.31(1 \mathrm{H}, \mathrm{s}), 1.78(3 \mathrm{H}, \mathrm{s}), 1.75(3 \mathrm{H}, \mathrm{s}) ;{ }^{13} \mathrm{C}-\mathrm{NMR}\left(125 \mathrm{MHz}, \mathrm{CDCl}_{3}\right) \delta: 199.9$, 143.6, 142.2, 136.9, 113.3, 63.4, 45.8, 36.8, 21.9, 15.4 . 


\section{Synthesis of ansellone A}

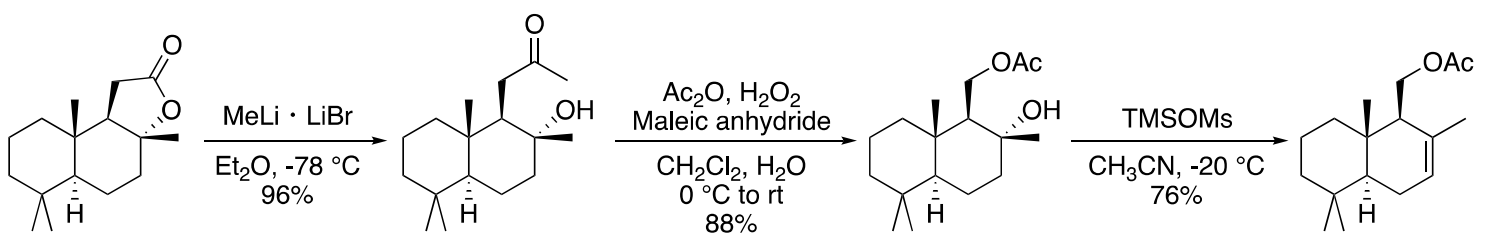

(+)-sclareolide
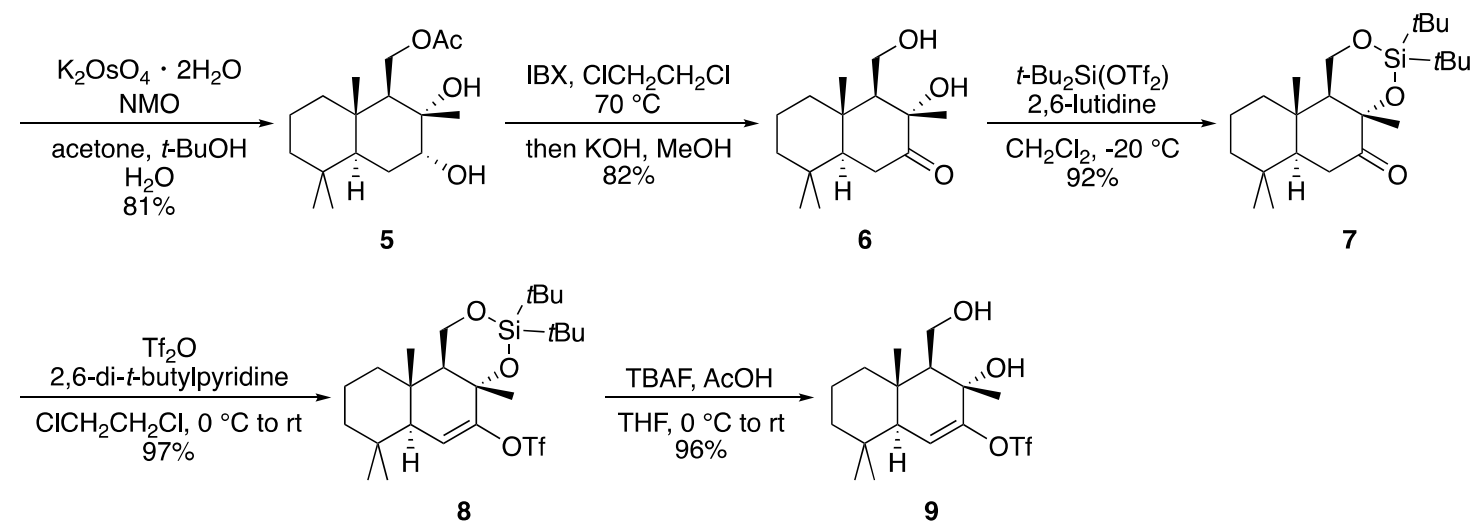

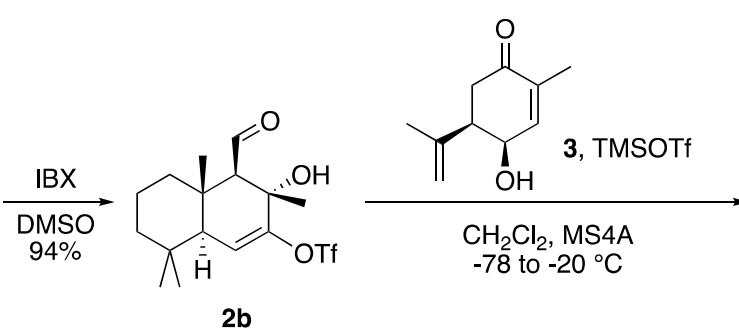

$2 b$

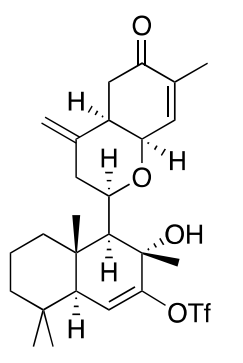

10a (exo)<smiles>CC1=CC2C(CC1=O)C(C)CC1OC3C=C(C)C(C)C3C=C(O)C(O)C12</smiles>

10b (endo)

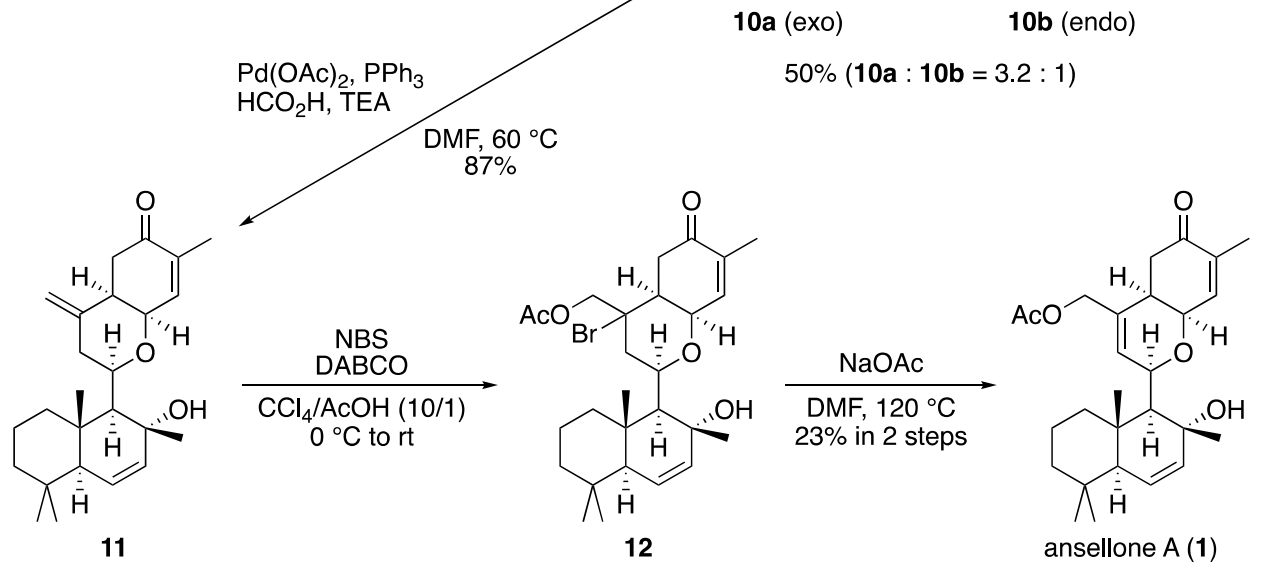




\section{Compound $3^{3}$}

Compound S3 was prepared according to the literature procedure ${ }^{3}$ as follows:
$1.5 \mathrm{M} \mathrm{MeLi}$ solution in $\mathrm{Et}_{2} \mathrm{O}(40.0 \mathrm{~mL}, 60.0 \mathrm{mmol})$ was added dropwise to a
solution of $(+)$-sclareolide $(7.51 \mathrm{~g}, 30.0 \mathrm{mmol})$ in $\mathrm{Et}_{2} \mathrm{O}(225 \mathrm{~mL})$ at $-78^{\circ} \mathrm{C}$ under
$\mathrm{N}_{2}$ atmosphere. After stirring for $1 \mathrm{~h} \mathrm{at}-78{ }^{\circ} \mathrm{C}$, the reaction was quenched with
$\mathrm{H}_{2} \mathrm{O}$ and warmed to room temperature. The resulting mixture was extracted with EtOAc. The combined organic layer was dried over $\mathrm{Na}_{2} \mathrm{SO}_{4}$, filtered, and concentrated under reduced pressure. The residue was purified by column chromatography on silica gel using n-hexane-EtOAc (3:1) to give compound S3 (7.65 g, $28.7 \mathrm{mmol}, 96 \%)$ as a colorless solid; ${ }^{1} \mathrm{H}-\mathrm{NMR}$ $\left(400 \mathrm{MHz}, \mathrm{CDCl}_{3}\right) \delta: 2.53(1 \mathrm{H}, \mathrm{dd}, J=17.5,5.5 \mathrm{~Hz}), 2.44(1 \mathrm{H}, \mathrm{dd}, J=17.5,4.3 \mathrm{~Hz}), 2.20(3 \mathrm{H}, \mathrm{s})$, $1.95-1.90(2 \mathrm{H}, \mathrm{m}), 1.71-1.65(1 \mathrm{H}, \mathrm{m}), 1.62-1.50(1 \mathrm{H}, \mathrm{m}), 1.46-1.21(6 \mathrm{H}, \mathrm{m}), 1.17-1.13(1 \mathrm{H}, \mathrm{m}), 1.10$ $(3 \mathrm{H}, \mathrm{s}), 1.01(1 \mathrm{H}, \mathrm{dd}, J=11.9,2.3 \mathrm{~Hz}), 0.93-0.89(1 \mathrm{H}, \mathrm{m}), 0.87(3 \mathrm{H}, \mathrm{s}), 0.78(6 \mathrm{H}, \mathrm{s})$.

\section{Compound S4}<smiles>CC(=O)OC[C@H]1[C@@H](C)CC[C@H]2C(C)(C)CCC[C@]12C</smiles>

Compound S4 was prepared according to the literature procedure ${ }^{4}$ as follows: $\mathrm{H}_{2} \mathrm{O}_{2}\left(30 \%\right.$ in $\left.\mathrm{H}_{2} \mathrm{O}, 15.8 \mathrm{~mL}, 155 \mathrm{mmol}\right)$ was added to a solution of $\mathrm{Ac}_{2} \mathrm{O}$ (16.9 $\mathrm{mL}, 179 \mathrm{mmol})$ in $\mathrm{CH}_{2} \mathrm{Cl}_{2}(23.0 \mathrm{~mL})$ at $5{ }^{\circ} \mathrm{C}$ under $\mathrm{N}_{2}$ atmosphere. The mixture was stirred at $5{ }^{\circ} \mathrm{C}$ for $1 \mathrm{~h}$. Maleic anhydride $(10.2 \mathrm{~g}, 104 \mathrm{mmol})$ was then added in portions over $50 \mathrm{~min}$ at $8{ }^{\circ} \mathrm{C}$. The mixture was stirred at $8{ }^{\circ} \mathrm{C}$ for $1 \mathrm{~h}$ before warming to room temperature and stirring for another 1 hour. Compound $\mathbf{S} 3(3.60 \mathrm{~g}, 13.5 \mathrm{mmol})$ in $\mathrm{CH}_{2} \mathrm{Cl}_{2}(13.5 \mathrm{~mL})$ was then added dropwise at room temperature. The reaction mixture was stirred at room temperature for $16 \mathrm{~h}$. The mixture was diluted with $\mathrm{CH}_{2} \mathrm{Cl}_{2}$. The organic phase was washed sequentially with $\mathrm{H}_{2} \mathrm{O}$, saturated $\mathrm{NaHCO}_{3}$ aq. for 3 times and brine, dried over $\mathrm{Na}_{2} \mathrm{SO}_{4}$, filtered and concentrated under reduced pressure. The residue was purified by column chromatography on silica gel using $n$-hexane-EtOAc (4:1) to give compound S4 (3.37 g, $11.9 \mathrm{mmol}, 88 \%)$ as a colorless solid; ${ }^{1} \mathrm{H}-\mathrm{NMR}\left(300 \mathrm{MHz}, \mathrm{CDCl}_{3}\right) \delta: 4.35(1 \mathrm{H}, \mathrm{dd}, J=11.7,4.4 \mathrm{~Hz}), 4.23(1 \mathrm{H}, \mathrm{dd}, J=11.7,5.3 \mathrm{~Hz}), 2.40$ (1H, brs), $2.05(3 \mathrm{H}, \mathrm{s}), 1.89(1 \mathrm{H}, \mathrm{dt}, J=12.4,3.2 \mathrm{~Hz}), 1.68-1.36(7 \mathrm{H}, \mathrm{m}), 1.28-1.03(6 \mathrm{H}, \mathrm{m}), 0.95$ $(1 \mathrm{H}, \mathrm{dd}, J=12.2,2.1 \mathrm{~Hz}), 0.88(3 \mathrm{H}, \mathrm{s}), 0.86(3 \mathrm{H}, \mathrm{s}), 0.80(3 \mathrm{H}, \mathrm{s})$.

\section{Compound $55^{5}$}<smiles>CC(=O)OC[C@H]1C(C)=CC[C@H]2C(C)CCC[C@@]21C</smiles>

Compound S5 was prepared according to the literature procedure ${ }^{5}$ as follows: TMSOMs $(0.18 \mathrm{~mL}, 0.88 \mathrm{mmol})$ was added to a solution of compound $\mathbf{S 4}(49.4$ $\mathrm{mg}, 0.18 \mathrm{mmol})$ in $\mathrm{CH}_{3} \mathrm{CN}(0.50 \mathrm{~mL})$ at room temperature under $\mathrm{N}_{2}$ atmosphere. After stirring for $10 \mathrm{~min}$ at room temperature, the resulting mixture was diluted with $\mathrm{H}_{2} \mathrm{O}$, and extracted with $\mathrm{Et}_{2} \mathrm{O}$. The organic layer was washed with saturated $\mathrm{NaHCO}_{3}$ aq., dried over $\mathrm{Na}_{2} \mathrm{SO}_{4}$, filtered, and concentrated under reduced pressure. The residue was 
purified by column chromatography on silica gel using $n$-hexane only to $n$-hexane- $\mathrm{Et}_{2} \mathrm{O}$ (49:1) to give compound S5 (35.3 mg, $0.134 \mathrm{mmol}, 76 \%)$ as a colorless solid; ${ }^{1} \mathrm{H}-\mathrm{NMR}\left(400 \mathrm{MHz}, \mathrm{CDCl}_{3}\right) \delta$ : $5.50(1 \mathrm{H}, \mathrm{brs}), 4.24(1 \mathrm{H}, \mathrm{dd}, J=11.7,3.2 \mathrm{~Hz}), 4.08(1 \mathrm{H}, \mathrm{dd}, J=11.7,6.4 \mathrm{~Hz}), 2.04-1.86(4 \mathrm{H}, \mathrm{m})$, $2.03(3 \mathrm{H}, \mathrm{s}), 1.66(3 \mathrm{H}, \mathrm{s}), 1.57-1.40(3 \mathrm{H}, \mathrm{m}), 1.26-1.05(3 \mathrm{H}, \mathrm{m}), 0.88(3 \mathrm{H}, \mathrm{s}), 0.86(3 \mathrm{H}, \mathrm{s}), 0.81(3 \mathrm{H}$, s).

\section{Compound $5^{6}$}<smiles>CC(=O)OC[C@H]1[C@@H](O)C[C@H]2C(C)(C)CCC[C@]2(C)[C@H]1O</smiles>

Compound 5 was prepared according to the literature procedure ${ }^{6}$ as follows: $\mathrm{N}$-Methylmorpholine $\mathrm{N}$-oxide $(0.879 \mathrm{~g}, 7.50 \mathrm{mmol})$ was added to a solution of compound S5 $(1.65 \mathrm{~g}, 6.22 \mathrm{mmol})$ in acetone $(2.0 \mathrm{~mL})$ and $t-\mathrm{BuOH}(2.7 \mathrm{~mL})$, $\mathrm{H}_{2} \mathrm{O}(2.7 \mathrm{~mL})$ at room temperature under $\mathrm{N}_{2}$ atmosphere. After stirring for 10 minutes, potassium osmate (VI) dihydrate $(0.114 \mathrm{mg}, 0.310 \mathrm{mmol})$ was added to the resulting mixture. The reaction was complete after stirring for 8 days. Saturated sodium thiosulfate aq. was added to the reaction mixture, and the resulting mixture was extracted with $\mathrm{CHCl}_{3}$. The organic layer was dried over $\mathrm{Na}_{2} \mathrm{SO}_{4}$, filtered, and concentrated under reduced pressure. The residue was purified by flash column chromatography on silica gel using $n$-hexane-EtOAc (3:1) to give compound $5(1.50 \mathrm{~g}, 5.02 \mathrm{mmol}, 81 \%)$ as a colorless solid; ${ }^{1} \mathrm{H}-\mathrm{NMR}\left(400 \mathrm{MHz}, \mathrm{CDCl}_{3}\right) \delta$ : 4.39 (1H, dd, $J=11.9,3.4 \mathrm{~Hz}), 4.15(1 \mathrm{H}, \mathrm{dd}, J=11.9,5.8 \mathrm{~Hz}), 3.75(1 \mathrm{H}, \mathrm{s}), 3.65-3.64(1 \mathrm{H}, \mathrm{m}), 2.93$ $(1 \mathrm{H}, \mathrm{m}), 2.06(3 \mathrm{H}, \mathrm{s}), 1.89-1.86(1 \mathrm{H}, \mathrm{m}), 1.75(1 \mathrm{H}, \mathrm{dd}, J=5.5,3.7 \mathrm{~Hz}), 1.65-1.37(6 \mathrm{H}, \mathrm{m})$, 1.24-1.15 (1H, m), $1.15(3 \mathrm{H}, \mathrm{s}), 1.10-1.02(1 \mathrm{H}, \mathrm{m}), 0.88(3 \mathrm{H}, \mathrm{s}), 0.85(3 \mathrm{H}, \mathrm{s}), 0.80(3 \mathrm{H}, \mathrm{s})$.

\section{Compound $6^{6}$}<smiles>CC1(C)CCC[C@]2(C)[C@H]1CC(=O)[C@@H](O)[C@H]2CO</smiles>

2-Iodoxybezoic acid (299 $\mathrm{mg}, 1.07 \mathrm{mmol})$ was added to a solution of compound 5 (104 mg, $0.347 \mathrm{mmol})$ in 1,2-dichloroethane $(1.70 \mathrm{~mL})$ at room temperature under $\mathrm{N}_{2}$ atmosphere. After stirring for $13 \mathrm{~h}$ at $70{ }^{\circ} \mathrm{C}$, the resulting solution was cooled to room temperature. After adding sat. sodium thiosulfate aq. $(1.0 \mathrm{~mL})$, methanol $(2.0 \mathrm{~mL})$, and $\mathrm{KOH}(67.2 \mathrm{mg}, 1.2 \mathrm{mmol})$ to the mixture, the resulting mixture was stirred for $1.5 \mathrm{~h}$. The resulting mixture was diluted with $\mathrm{H}_{2} \mathrm{O}$, and then extracted with $\mathrm{CH}_{2} \mathrm{Cl}_{2}$. The organic layer was dried over $\mathrm{Na}_{2} \mathrm{SO}_{4}$, filtered, and concentrated under reduced pressure. The residue was purified by column chromatography on silica gel using $n$-hexane-EtOAc (1-1) to give compound 6 (72.3 mg, $0.284 \mathrm{mmol}, 82 \%$ ) as a colorless solid; ${ }^{1} \mathrm{H}-\mathrm{NMR}\left(400 \mathrm{MHz}, \mathrm{CDCl}_{3}\right) \delta$ : $4.39(1 \mathrm{H}, \mathrm{s}), 4.04-3.99(1 \mathrm{H}, \mathrm{m}), 3.90-3.84(1 \mathrm{H}, \mathrm{m}), 3.40(1 \mathrm{H}, \mathrm{d}, J=9.2 \mathrm{~Hz}), 2.61-2.52(2 \mathrm{H}, \mathrm{m})$, 1.88-1.84 (1H, m), 1.68-1.57 (2H, m), 1.54-1.45 (2H, m), $1.44(3 \mathrm{H}, \mathrm{s}), 1.30(1 \mathrm{H}, \mathrm{dd}, J=12.2,4.9$ $\mathrm{Hz}), 1.25-1.20(1 \mathrm{H}, \mathrm{m}), 1.17-1.10(1 \mathrm{H}, \mathrm{m}), 1.01(3 \mathrm{H}, \mathrm{s}), 0.90(3 \mathrm{H}, \mathrm{s}), 0.86(3 \mathrm{H}, \mathrm{s}) ;{ }^{13} \mathrm{C}-\mathrm{NMR}(125$ $\left.\mathrm{MHz}, \mathrm{CDCl}_{3}\right) \delta: 213.2,79.5,62.5,59.0,56.1,41.3,39.7,37.5,34.9,34.0,32.8,22.3,21.0,18.1$, 15.4; HRMS (MALDI-TOF) calcd for $\mathrm{C}_{15} \mathrm{H}_{26} \mathrm{O}_{3} \mathrm{Na}[\mathrm{M}+\mathrm{Na}]^{+}: 277.1774$, found 277.1771. 


\section{Compound 7}<smiles>CC1(C)CCC[C@]2(C)C1CC(=O)[C@]1(C)O[Si](C(C)(C)C)(C(C)(C)C)OC[C@H]12</smiles>

2,6-Lutidine $\quad(1.90 \quad \mathrm{~mL}, \quad 16.4 \quad \mathrm{mmol}) \quad$ and di-t-butylsilyl bis(trifluoromethanesulfonate) $(2.10 \mathrm{~mL}, 6.45 \mathrm{mmol})$ were added to a solution of compound 6 ( $1.38 \mathrm{~g}, 5.44 \mathrm{mmol})$ in $\mathrm{CH}_{2} \mathrm{Cl}_{2}(54.0 \mathrm{~mL})$ at $-20{ }^{\circ} \mathrm{C}$ under $\mathrm{N}_{2}$ atmosphere. The resulting mixture was stirred at room temperature for $19 \mathrm{~h}$. Saturated $\mathrm{NaHCO}_{3}$ aq. was added to the reaction mixture, and the resulting mixture was extracted with $\mathrm{CH}_{2} \mathrm{Cl}_{2}$. The combined organic layer was dried over $\mathrm{Na}_{2} \mathrm{SO}_{4}$, filtered, and concentrated under reduced pressure. The residue was purified by column chromatography on silica gel using $n$-hexane-EtOAc (12:1) to give compound 7 (1.97 g, $4.99 \mathrm{mmol}$, $92 \%$ ) as a colorless solid. MP 129.3-129.4 ${ }^{\circ} \mathrm{C} ;[\alpha]_{\mathrm{D}}^{20}=-23.3\left(\mathrm{c} 0.53, \mathrm{CHCl}_{3}\right) ;{ }^{1} \mathrm{H}-\mathrm{NMR}(300 \mathrm{MHz}$, $\left.\mathrm{CDCl}_{3}\right) \delta: 4.13(2 \mathrm{H}, \mathrm{d}, J=6.9 \mathrm{~Hz}), 2.60-2.42(2 \mathrm{H}, \mathrm{m}), 1.99(1 \mathrm{H}, \mathrm{t}, J=6.9 \mathrm{~Hz}), 1.79-1.75(1 \mathrm{H}, \mathrm{m})$, $1.68-1.43(3 \mathrm{H}, \mathrm{m}), 1.58(3 \mathrm{H}, \mathrm{s}), 1.28(1 \mathrm{H}, \mathrm{dd}, J=13.9,3.3 \mathrm{~Hz}), 1.21-1.16(1 \mathrm{H}, \mathrm{m}), 1.13-1.07(1 \mathrm{H}$, m), $1.02(9 \mathrm{H}, \mathrm{s}), 1.00(9 \mathrm{H}, \mathrm{s}), 0.99(3 \mathrm{H}, \mathrm{s}), 0.87(3 \mathrm{H}, \mathrm{s}), 0.83(3 \mathrm{H}, \mathrm{s}) ;{ }^{13} \mathrm{C}-\mathrm{NMR}\left(75 \mathrm{MHz}, \mathrm{CDCl}_{3}\right) \delta$ : 209.4, 81.1, 60.8, 59.7, 56.7, 41.4, 39.7, 37.3, 36.4, 33.8, 32.7, 27.8, 27.6, 23.8, 21.3, 20.8, 20.6, 18.3, 16.0; HRMS (MALDI-TOF) calcd for $\mathrm{C}_{23} \mathrm{H}_{42} \mathrm{O}_{3} \mathrm{SiNa}[\mathrm{M}+\mathrm{Na}]^{+}:$417.2795, found 417.2795.

\section{Compound 8}<smiles>CCC[Si]1(CC(C)(C)C)OC[C@@H]2[C@](C)(O1)C(O)=CC1C(C)(C)CCC[C@]12C</smiles>
$\mathrm{Tf}_{2} \mathrm{O}(340 \mu \mathrm{L}, 2.02 \mathrm{mmol})$ was added to a solution of compound 7 (400 mg, $1.01 \mathrm{mmol})$ and 2,6-di-t-butylpyridine $(0.87 \mathrm{~mL}, 4.02 \mathrm{mmol})$ in 1,2-dichloroethane $(5.0 \mathrm{~mL})$ at $0{ }^{\circ} \mathrm{C}$ under $\mathrm{N}_{2}$ atmosphere. The resulting solution was stirred at room temperature for $11 \mathrm{~h} . \mathrm{H}_{2} \mathrm{O}$ was added to the resulting solution, and the resulting mixture was extracted with $\mathrm{Et}_{2} \mathrm{O}$. The combined organic layer was washed with saturated $\mathrm{NaHCO}_{3}$ aq., dried over $\mathrm{Na}_{2} \mathrm{SO}_{4}$, and concentrated under reduced pressure. The residue was purified by column chromatography on silica gel using $n$-hexane only to $n$-hexane-EtOAc (10:1) to give compound 8 (517 mg, $0.982 \mathrm{mmol}, 97 \%)$ as a colorless solid. MP 90.2-90.3 ${ }^{\circ} \mathrm{C} ;[\alpha]_{\mathrm{D}}^{25}=-12.9\left(\mathrm{c} 0.53, \mathrm{CHCl}_{3}\right) ;{ }^{1} \mathrm{H}-\mathrm{NMR}\left(300 \mathrm{MHz}, \mathrm{CDCl}_{3}\right) \delta$ : $5.68(1 \mathrm{H}, \mathrm{d}, J=1.8 \mathrm{~Hz}), 4.16-4.02(2 \mathrm{H}, \mathrm{m}), 2.59(1 \mathrm{H}, \mathrm{dd}, J=11.9,5.0 \mathrm{~Hz}), 2.11(1 \mathrm{H}, \mathrm{d}, J=1.8 \mathrm{~Hz})$, 1.69-1.44 (4H, m), $1.63(3 \mathrm{H}, \mathrm{s}), 1.26-1.08(2 \mathrm{H}, \mathrm{m}), 1.04(9 \mathrm{H}, \mathrm{s}), 1.02(9 \mathrm{H}, \mathrm{s}), 0.93(3 \mathrm{H}, \mathrm{s}), 0.90(3 \mathrm{H}$, s), $0.84(3 \mathrm{H}, \mathrm{s}) ;{ }^{13} \mathrm{C}-\mathrm{NMR}\left(75 \mathrm{MHz}, \mathrm{CDCl}_{3}\right) \delta: 150.9,118.5\left(\mathrm{q}, J_{\mathrm{CF} 3}=320 \mathrm{~Hz}\right), 117.8,73.8,60.7$, 57.6, 55.9, 40.5, 38.0, 36.5, 32.8, 32.5, 28.2, 27.9, 23.5, 21.8, 21.2, 20.8, 18.1, 16.8; HRMS (FAB-DF) calcd for $\mathrm{C}_{24} \mathrm{H}_{41} \mathrm{~F}_{3} \mathrm{O}_{5} \mathrm{SSiNa}[\mathrm{M}+\mathrm{Na}]^{+}:$549.2294, found 549.2282. 


\section{Compound 9}<smiles>CC1(C)CCC[C@@]2(C)[C@H](CO)[C@H](O)C(Br)=C[C@H]12</smiles>

AcOH $(180 \mu \mathrm{L}, 3.14 \mathrm{mmol})$ and TBAF solution in THF $(1.0 \mathrm{M}, 2.20 \mathrm{~mL}, 2.20$ mmol) were added to a solution of compound $8(517 \mathrm{mg}, 0.982 \mathrm{mmol})$ in THF $(4.90 \mathrm{~mL})$ at $0{ }^{\circ} \mathrm{C}$ under $\mathrm{N}_{2}$ atmosphere. The mixture was stirred at room temperature for $1 \mathrm{~h}$. Saturated $\mathrm{NH}_{4} \mathrm{Cl}$ aq. was added to the solution, and the resulting mixture was extracted with EtOAc. The combined organic layer was dried over $\mathrm{Na}_{2} \mathrm{SO}_{4}$, filtered, and concentrated under reduced pressure. The residue was purified by column chromatography on silica gel using $n$-hexane-EtOAc (2:1) to give compound 9 (365 $\mathrm{mg}$, $0.945 \mathrm{mmol}, 96 \%)$ as a colorless solid. MP 90.0-90.5 ${ }^{\circ} \mathrm{C}$; $[\alpha]_{\mathrm{D}}^{28}=-2.1\left(\mathrm{c} 0.67, \mathrm{CHCl}_{3}\right) ;{ }^{1} \mathrm{H}-\mathrm{NMR}$ $\left(500 \mathrm{MHz}, \mathrm{CDCl}_{3}\right) \delta: 5.80(1 \mathrm{H}, \mathrm{d}, J=2.3 \mathrm{~Hz}), 3.97(1 \mathrm{H}, \mathrm{dd}, J=10.4,4.6 \mathrm{~Hz}), 3.87(1 \mathrm{H}, \mathrm{dd}, J=$ 10.4, $10.4 \mathrm{~Hz}), 3.11$ (2H, brs), $2.12(1 \mathrm{H}, \mathrm{d}, J=2.3 \mathrm{~Hz}), 2.05(1 \mathrm{H}, \mathrm{dd}, J=10.4 .4 .6 \mathrm{~Hz}), 1.64-1.58$ $(1 \mathrm{H}, \mathrm{m}), 1.56-1.53(2 \mathrm{H}, \mathrm{m}), 1.50(3 \mathrm{H}, \mathrm{s}), 1.46(1 \mathrm{H}, \mathrm{s}), 1.25-1.15(2 \mathrm{H}, \mathrm{m}), 0.91(3 \mathrm{H}, \mathrm{s}), 0.88(3 \mathrm{H}, \mathrm{s})$, $0.84(3 \mathrm{H}, \mathrm{s}) ;{ }^{13} \mathrm{C}-\mathrm{NMR}\left(125 \mathrm{MHz}, \mathrm{CDCl}_{3}\right) \delta: 149.9,120.3,118.4\left(\mathrm{q}, J_{\mathrm{CF} 3}=320 \mathrm{~Hz}\right), 73.7,59.9,59.6$, 54.3, 40.2, 38.9, 36.8, 32.7, 32.4, 21.7, 20.3, 18.0, 15.4; HRMS (FAB-DF) calcd for $\mathrm{C}_{16} \mathrm{H}_{25} \mathrm{~F}_{3} \mathrm{O}_{5} \mathrm{SNa}$ $[\mathrm{M}+\mathrm{Na}]^{+}:$409.1273, found 409.1281.

\section{Aldehyde 2b}<smiles>CC1(C)CCC[C@]2(C)C1=C[C@@](C)(O)[C@@H](O)[C@H]2C=O</smiles>

2-Iodoxybezoic acid $(147 \mathrm{mg}, 0.528 \mathrm{mmol})$ was added to a solution of compound 9 (102 $\mathrm{mg}, 0.264 \mathrm{mmol})$ in DMSO $(1.3 \mathrm{~mL})$ at room temperature under $\mathrm{N}_{2}$ atmosphere. The mixture was stirred at room temperature for $8 \mathrm{~h}$. Saturated $\mathrm{NaHCO}_{3}$ aq. was added to the solution, and the resulting mixture was extracted with EtOAc. The combined organic layer was dried over $\mathrm{Na}_{2} \mathrm{SO}_{4}$, filtered, and concentrated under reduced pressure. The residue was purified by column chromatography on silica gel using $n$-hexane-EtOAc (5:1) to give aldehyde $2 \mathbf{b}$ (95.0 $\mathrm{mg}, 0.247$ mmol, 94\%) as a pale yellow oil; $[\alpha]_{\mathrm{D}}^{28}=-28.9\left(\mathrm{c} 0.95, \mathrm{CHCl}_{3}\right) ;{ }^{1} \mathrm{H}-\mathrm{NMR}\left(500 \mathrm{MHz}, \mathrm{C}_{6} \mathrm{D}_{6}\right) \delta: 9.61$ $(1 \mathrm{H}, \mathrm{d}, J=3.2 \mathrm{~Hz}), 5.76(1 \mathrm{H}, \mathrm{d}, J=2.3 \mathrm{~Hz}), 2.30(1 \mathrm{H}, \mathrm{brs}), 2.17(1 \mathrm{H}, \mathrm{d}, J=3.2 \mathrm{~Hz}), 1.59(1 \mathrm{H}, \mathrm{d}, J$ $=2.3 \mathrm{~Hz}), 1.55-1.52(1 \mathrm{H}, \mathrm{m}), 1.37-1.30(1 \mathrm{H}, \mathrm{m}), 1.28(3 \mathrm{H}, \mathrm{s}), 1.18-1.13(2 \mathrm{H}, \mathrm{m}), 0.86(3 \mathrm{H}, \mathrm{s})$, 0.83-0.80 (1H, m), 0.73-0.67 (1H, m), $0.64(3 \mathrm{H}, \mathrm{s}), 0.56(3 \mathrm{H}, \mathrm{s}) . ;{ }^{13} \mathrm{C}-\mathrm{NMR}\left(125 \mathrm{MHz}, \mathrm{C}_{6} \mathrm{D}_{6}\right) \delta$ : 201.9, 150.1, 120.3, 119.1 (q, $\left.J_{\mathrm{CF} 3}=320 \mathrm{~Hz}\right), 71.7,70.1,53.2,40.2,39.4,36.0,32.4,32.1,21.7,21.6$, 17.8, 15.9; HRMS (FAB-DF) calcd for $\mathrm{C}_{16} \mathrm{H}_{23} \mathrm{~F}_{3} \mathrm{O}_{5} \mathrm{SNa}[\mathrm{M}+\mathrm{Na}]^{+}$: 407.1116, found 407.1109. 


\section{Compound 10a and 10b}

TMSOTf $(9.5 \mu \mathrm{L}, 0.0525 \mathrm{mmol})$ was added dropwise to a mixture of alcohol 3 (52.4 $\mathrm{mg}, 0.315$ mmol), aldehyde $2 \mathbf{b}(40.3 \mathrm{mg}, 0.105 \mathrm{mmol})$ and MS4A $(60 \mathrm{mg})$ in $\mathrm{CH}_{2} \mathrm{Cl}_{2}(0.40 \mathrm{~mL})$ at $-78{ }^{\circ} \mathrm{C}$ under $\mathrm{N}_{2}$ atmosphere. After stirring at $-20{ }^{\circ} \mathrm{C}$ for $24 \mathrm{~h}$, saturated $\mathrm{NaHCO}_{3}$ aq. was added to the resulting mixture, and the mixture was extracted with $\mathrm{CH}_{2} \mathrm{Cl}_{2}$. The combined organic layer was dried over $\mathrm{Na}_{2} \mathrm{SO}_{4}$, filtered, and concentrated under reduced pressure. The residue was purified by flush column chromatography on silica gel using $n$-hexane-EtOAc (5:1) to give compound 10a (21.0 $\mathrm{mg}$, $0.0394 \mathrm{mmol}, 38 \%)$ as a colorless solid, and compound $\mathbf{1 0 b}(6.71 \mathrm{mg}, 0.0126 \mathrm{mmol}, 12 \%)$ as a colorless solid.

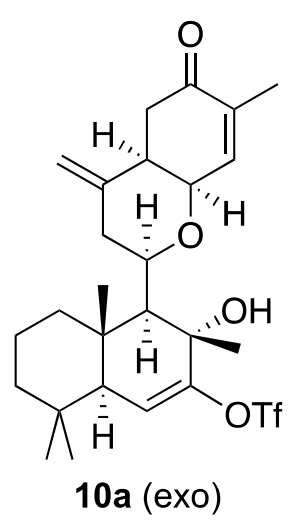

10a: MP $136-139{ }^{\circ} \mathrm{C} ;[\alpha]_{\mathrm{D}}^{23}=-12.5\left(\mathrm{c} 0.47, \mathrm{CHCl}_{3}\right) ;{ }^{1} \mathrm{H}-\mathrm{NMR}(500 \mathrm{MHz}$, $\left.\mathrm{CDCl}_{3}\right) \delta: 6.63(1 \mathrm{H}, \mathrm{dd}, J=5.8,1.8 \mathrm{~Hz}), 5.77(1 \mathrm{H}, \mathrm{d}, J=1.7 \mathrm{~Hz}), 4.86(1 \mathrm{H}, \mathrm{s})$, $4.80(1 \mathrm{H}, \mathrm{s}), 3.90-3.88(2 \mathrm{H}, \mathrm{m}), 2.87-2.73(3 \mathrm{H}, \mathrm{m}), 2.29(1 \mathrm{H}, \mathrm{dd}, J=14.9,2.9$ $\mathrm{Hz}), 2.10-2.06(2 \mathrm{H}, \mathrm{m}), 1.99-1.96(1 \mathrm{H}, \mathrm{m}), 1.84(3 \mathrm{H}, \mathrm{s}), 1.79(1 \mathrm{H}, \mathrm{s})$, 1.72-1.69 (2H, m), 1.55-1.47 (2H, m), $1.50(3 \mathrm{H}, \mathrm{s}), 1.41-1.35(1 \mathrm{H}, \mathrm{m})$, 1.25-1.14 (1H, m), $1.14(3 \mathrm{H}, \mathrm{s}), 0.91(3 \mathrm{H}, \mathrm{s}), 0.85(3 \mathrm{H}, \mathrm{s}) ;{ }^{13} \mathrm{C}-\mathrm{NMR}(125$ $\left.\mathrm{MHz}, \mathrm{CDCl}_{3}\right) \delta: 199.5,150.5,145.3,139.6,138.4,120.1,118.4\left(\mathrm{q}, J_{\mathrm{CF} 3}=320\right.$ $\mathrm{Hz}), 111.2,78.8,73.6,72.6,61.8,55.4,42.2,41.4,40.4,39.0,37.4,37.2,32.9$, 32.7, 21.9, 21.4, 18.1, 16.2, 15.8; HRMS (MALDI-TOF) calcd for $\mathrm{C}_{26} \mathrm{H}_{35} \mathrm{~F}_{3} \mathrm{O}_{6} \mathrm{SNa}[\mathrm{M}+\mathrm{Na}]^{+}:$555.1999, found 555.1986.<smiles>CCCOC1=CC2C(C)(C)CCC[C@]2(C)[C@H](C2C=C(C)[C@@H]3CC(=O)C(C)=C[C@H]3O2)[C@H]1O</smiles>

found 555.1999 . 10b: MP 182-184 ${ }^{\circ} \mathrm{C} ;[\alpha]_{\mathrm{D}}^{26}=-7.9\left(\mathrm{c} \quad 0.26, \mathrm{CHCl}_{3}\right) ;{ }^{1} \mathrm{H}-\mathrm{NMR}(500 \mathrm{MHz}$, $\left.\mathrm{CDCl}_{3}\right) \delta: 6.61(1 \mathrm{H}, \mathrm{dd}, J=5.4,1.4 \mathrm{~Hz}), 5.76(1 \mathrm{H}, \mathrm{d}, J=1.7 \mathrm{~Hz}), 5.51(1 \mathrm{H}, \mathrm{s})$, $4.75(1 \mathrm{H}, \mathrm{s}), 4.03(1 \mathrm{H}, \mathrm{t}, J=4.3 \mathrm{~Hz}), 2.61-2.49(2 \mathrm{H}, \mathrm{m}), 2.33-2.31(1 \mathrm{H}, \mathrm{m})$, $2.15(1 \mathrm{H}, \mathrm{brs}), 2.04(1 \mathrm{H}, \mathrm{d}, J=1.7 \mathrm{~Hz}), 1.84(3 \mathrm{H}, \mathrm{s}), 1.84-1.77(2 \mathrm{H}, \mathrm{m}), 1.71$ $(3 \mathrm{H}, \mathrm{s}), 1.67-1.58(1 \mathrm{H}, \mathrm{m}), 1.54(3 \mathrm{H}, \mathrm{s}), 1.49-1.43(2 \mathrm{H}, \mathrm{m}), 1.21-1.14(2 \mathrm{H}, \mathrm{m})$, $1.14(3 \mathrm{H}, \mathrm{s}), 0.88(3 \mathrm{H}, \mathrm{s}), 0.83(3 \mathrm{H}, \mathrm{s}) ;{ }^{13} \mathrm{C}-\mathrm{NMR}\left(125 \mathrm{MHz}, \mathrm{CDCl}_{3}\right) \delta: 199.5$, $150.7,139.7,138.2,132.2,127.5,120.1,118.4\left(\mathrm{q}, J_{\mathrm{CF} 3}=320 \mathrm{~Hz}\right), 76.0,73.7$, 70.3, 62.6, 55.5, 41.4, 40.4, 37.6, 37.3, 37.2, 32.8, 32.7, 21.9, 20.9, 18.0, 16.2, 15.8; HRMS (MALDI-TOF) calcd for $\mathrm{C}_{26} \mathrm{H}_{35} \mathrm{~F}_{3} \mathrm{O}_{6} \mathrm{SNa}[\mathrm{M}+\mathrm{Na}]^{+}$: 555.1999, 


\section{Compound $11^{6}$}<smiles>C=C1CC(C2[C@@]3(C)CCCC(C)(C)C3C=C[C@@]2(C)O)OC2C=C(C)C(=O)CC12</smiles>

$\mathrm{Et}_{3} \mathrm{~N}(110 \mu \mathrm{L}, 0.789 \mathrm{mmol})$ and $\mathrm{HCO}_{2} \mathrm{H}(20 \mu \mathrm{L}, 0.530 \mathrm{mmol})$ was added to a solution of compound 10a $(34.3 \mathrm{mg}, 0.0644 \mathrm{mmol}), \mathrm{Pd}(\mathrm{OAc})_{2}(1.5 \mathrm{mg}, 6.68$ $\mu \mathrm{mol})$ and $\mathrm{PPh}_{3}(3.8 \mathrm{mg}, 0.0145 \mathrm{mmol})$ in DMF $(0.70 \mathrm{~mL})$. After stirring at $60{ }^{\circ} \mathrm{C}$ for $2.5 \mathrm{~h}$, saturated $\mathrm{NaHCO}_{3}$ aq. was added to the resulting mixture, and the mixture was extracted with EtOAc. The combined organic layer was dried over $\mathrm{Na}_{2} \mathrm{SO}_{4}$, filtered, and concentrated under reduced pressure. The residue was purified by flash column chromatography on silica gel using n-hexane-EtOAc (4:1) to give compound 11 (21.6 mg, $0.0562 \mathrm{mmol}, 87 \%)$ as a colorless solid; ${ }^{1} \mathrm{H}-\mathrm{NMR}\left(500 \mathrm{MHz}, \mathrm{C}_{6} \mathrm{D}_{6}\right) \delta: 6.12(1 \mathrm{H}, \mathrm{dd}, J=5.7,1.7 \mathrm{~Hz}), 5.59(1 \mathrm{H}, \mathrm{dd}, J=10.2$, $1.4 \mathrm{~Hz}), 5.55(1 \mathrm{H}, \mathrm{dd}, J=10.2,2.9 \mathrm{~Hz}), 4.67(1 \mathrm{H}, \mathrm{t}, J=1.7 \mathrm{~Hz}), 4.62(1 \mathrm{H}, \mathrm{t}, J=1.7 \mathrm{~Hz}), 3.91-3.88$ $(1 \mathrm{H}, \mathrm{m}), 3.42-3.41(1 \mathrm{H}, \mathrm{m}), 2.89-2.82(1 \mathrm{H}, \mathrm{m}), 2.67(1 \mathrm{H}, \mathrm{dd}, J=13.8,12.6 \mathrm{~Hz}), 2.32-2.25(2 \mathrm{H}, \mathrm{m})$, $1.99(1 \mathrm{H}, \mathrm{d}, J=11.5 \mathrm{~Hz}), 1.88(1 \mathrm{H}, \mathrm{dd}, J=14.4,2.3 \mathrm{~Hz}), 1.72(1 \mathrm{H}, \mathrm{s}), 1.67(3 \mathrm{H}, \mathrm{s}), 1.60-1.51(1 \mathrm{H}$, m), 1.43-1.42 (1H, m), $1.42(3 \mathrm{H}, \mathrm{s}), 1.32-1.27(2 \mathrm{H}, \mathrm{m}), 1.21(3 \mathrm{H}, \mathrm{s}), 1.21-1.14(2 \mathrm{H}, \mathrm{m}), 1.08-1.02$ $(1 \mathrm{H}, \mathrm{m}), 0.86(3 \mathrm{H}, \mathrm{s}), 0.79(3 \mathrm{H}, \mathrm{s}) \cdot{ }^{13} \mathrm{C}-\mathrm{NMR}\left(125 \mathrm{MHz}, \mathrm{C}_{6} \mathrm{D}_{6}\right) \delta: 197.8,146.9,139.2,138.3,135.5$, $127.3,110.2,79.7,72.9,72.8,62.4,56.7,42.5,41.7,41.3,39.5,38.4,38.2,33.2,32.7,25.4,21.8$, 18.6, 16.6, 15.8; HRMS (MALDI-TOF) calcd for $\mathrm{C}_{25} \mathrm{H}_{36} \mathrm{O}_{3} \mathrm{Na}[\mathrm{M}+\mathrm{Na}]^{+}: 407.2557$, found 407.2557.

Ansellone A (1) $)^{7,8}$<smiles>CC(=O)OCC1=CC(C2[C@](C)(O)C=CC3C(C)(C)CCC[C@]32C)OC2C=C(C)C(=O)C[C@@H]12</smiles>

Bromoacetoxylation: NBS (21.4 $\mathrm{mg}, 0.120 \mathrm{mmol})$ was added to a solution of compound 11 (18.4 mg, $0.0478 \mathrm{mmol})$ and DABCO (20.3 mg, 0.181 mmol) in $\mathrm{CCl}_{4} / \mathrm{AcOH}(10 / 1,1.00 \mathrm{~mL})$ at $0{ }^{\circ} \mathrm{C}$. After stirring at room temperature for $24 \mathrm{~h}$, saturated $\mathrm{NaHCO}_{3}$ aq. was added to the resulting mixture, and the mixture was extracted with $\mathrm{CH}_{2} \mathrm{Cl}_{2}$. The combined organic layer was dried over $\mathrm{Na}_{2} \mathrm{SO}_{4}$, filtered, and concentrated under reduced pressure. The residue was purified by flash column chromatography on silica gel using $n$-hexane-EtOAc (9:2) to give compound $\mathbf{1 2}^{8}$ as a crude product $(14.3 \mathrm{mg})$.

HBr Elimination: $\mathrm{NaOAc}(33.4 \mathrm{mg}, 0.407 \mathrm{mmol})$ was added to a solution of crude 12 (14.3 $\mathrm{mg})$ in DMF $(0.50 \mathrm{~mL})$. After stirring at $120^{\circ} \mathrm{C}$ for $2 \mathrm{~h}$, the mixture was cooled to room temperature. The resulting mixture was diluted with EtOAc, and washed with $\mathrm{H}_{2} \mathrm{O}$. The organic layer was dried over $\mathrm{Na}_{2} \mathrm{SO}_{4}$, filtered, and concentrated under reduced pressure. The residue was purified by flash column chromatography on silica gel using $n$-hexane-EtOAc (3:1 to 2:1) to give ansellone A (1) (4.8 mg, $0.0108 \mathrm{mmol}, 23 \%$ in 2 steps) as a colorless solid. $[\alpha]_{\mathrm{D}}^{30}=-23.1$ (c $\left.0.05, \mathrm{MeOH}\right) ;{ }^{1} \mathrm{H}-\mathrm{NMR}(400$ $\left.\mathrm{MHz}, \mathrm{C}_{6} \mathrm{D}_{6}\right) \delta: 6.14(1 \mathrm{H}, \mathrm{dd}, J=5.5,1.4 \mathrm{~Hz}), 5.71(1 \mathrm{H}, \mathrm{brs}), 5.60(1 \mathrm{H}, \mathrm{dd}, J=10.2,1.4 \mathrm{~Hz}), 5.53$ $(1 \mathrm{H}, \mathrm{dd}, J=10.2,3.0 \mathrm{~Hz}), 4.78(1 \mathrm{H}, \mathrm{brs}), 4.42(1 \mathrm{H}, \mathrm{d}, J=12.6 \mathrm{~Hz}), 4.27(1 \mathrm{H}, \mathrm{d}, J=12.6 \mathrm{~Hz}), 3.44$ 
$(1 \mathrm{H}, \mathrm{t}, J=4.1 \mathrm{~Hz}), 2.67(2 \mathrm{H}, \mathrm{d}, J=8.7 \mathrm{~Hz}), 2.12-2.07(1 \mathrm{H}, \mathrm{m}), 1.81(1 \mathrm{H}, \mathrm{brd}, 12.4 \mathrm{~Hz}), 1.70-1.69$ $(1 \mathrm{H}, \mathrm{m}), 1.69(3 \mathrm{H}, \mathrm{s}), 1.67(3 \mathrm{H}, \mathrm{s}), 1.56-1.50(1 \mathrm{H}, \mathrm{m}), 1.50(3 \mathrm{H}, \mathrm{s}), 1.46(1 \mathrm{H}, \mathrm{s}), 1.36-1.35(1 \mathrm{H}, \mathrm{m})$, 1.35-1.29 (1H, m), $1.20(3 \mathrm{H}, \mathrm{s}), 1.08(1 \mathrm{H}, \mathrm{dd}, \mathrm{J}=14.0,4.4 \mathrm{~Hz}), 1.01(1 \mathrm{H}, \mathrm{dd}, J=13.3,3.7 \mathrm{~Hz}), 0.90$ (1H, brs), $0.86(3 \mathrm{H}, \mathrm{s}), 0.78(3 \mathrm{H}, \mathrm{s}) ;{ }^{13} \mathrm{C}-\mathrm{NMR}\left(100 \mathrm{MHz}, \mathrm{C}_{6} \mathrm{D}_{6}\right) \delta: 197.4,169.8,139.0,138.2,135.3$, 134.4, 131.0, 127.6, 76.5, 72.7, 70.5, 65.7, 63.4, 56.6, 41.8, 41.3, 38.5, 38.2, 34.4, 33.2, 32.7, 26.1, 21.8, 20.4, 18.5, 16.4, 15.9; HRMS (MALDI-TOF) calcd for $\mathrm{C}_{27} \mathrm{H}_{38} \mathrm{O}_{5} \mathrm{Na}[\mathrm{M}+\mathrm{Na}]^{+}: 465.2611$, found 465.2614 . 
Table S1. ${ }^{1} \mathrm{H}$-NMR Comparison of natural and synthetic ansellone A

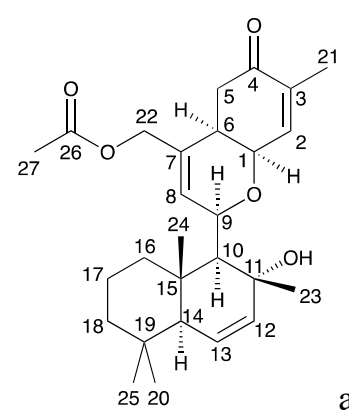

ansellone A (1)

\begin{tabular}{|c|c|c|c|}
\hline \multirow{2}{*}{$\begin{array}{l}\text { C } \\
\text { No. }\end{array}$} & \multicolumn{3}{|c|}{${ }^{1} \mathrm{H}-\mathrm{NMR}\left(\mathrm{C}_{6} \mathrm{D}_{6}\right)$} \\
\hline & $\begin{array}{c}\text { natural ansellone } \mathrm{A}(600 \mathrm{MHz}) \\
\text { ref. } 7\end{array}$ & $\begin{array}{c}\text { Tong's synthetic ansellone A (400 } \\
\text { MHz) ref. } 8\end{array}$ & $\begin{array}{l}\text { our synthetic ansellone A (400 } \\
\text { MHz) }\end{array}$ \\
\hline 1 & $3.44(1 \mathrm{H}$, brt, $J=4.8 \mathrm{~Hz})$ & $3.45(1 \mathrm{H}, \mathrm{t}, J=4.0 \mathrm{~Hz})$ & $3.44(1 \mathrm{H}, \mathrm{t}, J=4.1 \mathrm{~Hz})$ \\
\hline 2 & $6.14(1 \mathrm{H}, \mathrm{d}, J=4.8 \mathrm{~Hz})$ & $6.14(1 \mathrm{H}, \mathrm{dd}, J=5.5,1.4 \mathrm{~Hz})$ & $6.14(1 \mathrm{H}, \mathrm{dd}, J=5.5,1.4 \mathrm{~Hz})$ \\
\hline 3 & - & - & - \\
\hline 4 & - & - & - \\
\hline 5 & $2.67(2 \mathrm{H}, \mathrm{d}, J=9 \mathrm{~Hz})$ & $2.67(2 \mathrm{H}, \mathrm{d}, J=9 \mathrm{~Hz})$ & $2.67(2 \mathrm{H}, \mathrm{d}, J=8.7 \mathrm{~Hz})$ \\
\hline 6 & $2.10(1 \mathrm{H}, \mathrm{tt}, J=3 \mathrm{~Hz}, 9 \mathrm{~Hz})$ & $2.10(1 \mathrm{H}, \mathrm{tt}, J=2.8,8.8 \mathrm{~Hz})$ & $2.12-2.07(1 \mathrm{H}, \mathrm{m})$ \\
\hline 7 & - & - & - \\
\hline 8 & $5.70(1 \mathrm{H}$, brs $)$ & $5.70(1 \mathrm{H}, \mathrm{brs})$ & $5.71(1 \mathrm{H}, \mathrm{brs})$ \\
\hline 9 & $4.77(1 \mathrm{H}, \mathrm{brs})$ & $4.77(1 \mathrm{H}, \mathrm{brs})$ & $4.78(1 \mathrm{H}, \mathrm{brs})$ \\
\hline 10 & $1,46(1 \mathrm{H}, \mathrm{brs})$ & $1.47(1 \mathrm{H}, \mathrm{s})$ & $1.46(1 \mathrm{H}, \mathrm{s})$ \\
\hline 11 & - & - & - \\
\hline 12 & $5.52(1 \mathrm{H}, \mathrm{dd}, \mathrm{d}, J=3,10 \mathrm{~Hz})$ & $5.52(1 \mathrm{H}, \mathrm{dd}, J=10.1,3.0 \mathrm{~Hz})$ & $5.53(1 \mathrm{H}, \mathrm{dd}, J=10.2,3.0 \mathrm{~Hz})$ \\
\hline 13 & $5.59(1 \mathrm{H}$, brd, $J=10 \mathrm{~Hz})$ & $5.60(1 \mathrm{H}, \mathrm{dd}, J=10.2,1.5 \mathrm{~Hz})$ & $5.60(1 \mathrm{H}, \mathrm{dd}, J=10.2,1.4 \mathrm{~Hz})$ \\
\hline 14 & $1.71(1 \mathrm{H}, \mathrm{m})$ & $1.73-1.70(1 \mathrm{H}, \mathrm{m})$ & $1.70-1.69(1 \mathrm{H}, \mathrm{m})$ \\
\hline 15 & - & - & - \\
\hline 16 & $1.02(1 \mathrm{H}, \mathrm{m})$ & $1.00(1 \mathrm{H}, \mathrm{dd}, \mathrm{J}=13.2,4.0 \mathrm{~Hz})$ & $1.01(1 \mathrm{H}, \mathrm{dd}, J=13.3,3.7 \mathrm{~Hz})$ \\
\hline $16^{\prime}$ & $1.82(1 \mathrm{H}$, brd, $J=13 \mathrm{~Hz})$ & $1.81(1 \mathrm{H}, \mathrm{d}, J=12.3 \mathrm{~Hz})$ & $1.81(1 \mathrm{H}$, brd, $J=12.4 \mathrm{~Hz})$ \\
\hline 17 & $1.33(1 \mathrm{H}, \mathrm{m})$ & $1.33-1.25(1 \mathrm{H}, \mathrm{m})$ & $1.36-1.35(1 \mathrm{H}, \mathrm{m})$ \\
\hline $17^{\prime}$ & $1.53(1 \mathrm{H}, \mathrm{dt}, J=3.5,13 \mathrm{~Hz})$ & $1.54(1 \mathrm{H}, \mathrm{dt}, J=13.7,3.2 \mathrm{~Hz})$ & $1.56-1.50(1 \mathrm{H}, \mathrm{m})$ \\
\hline 18 & $1.04(1 \mathrm{H}, \mathrm{m})$ & $1.08(1 \mathrm{H}, \mathrm{dd}, J=13.9,4.3 \mathrm{~Hz})$ & $1.08(1 \mathrm{H}, \mathrm{dd}, J=14.0,4.4 \mathrm{~Hz})$ \\
\hline $18^{\prime}$ & $1.29(1 \mathrm{H}, \mathrm{m})$ & $1.40-1.33(1 \mathrm{H}, \mathrm{m})$ & $1.35-1.29(1 \mathrm{H}, \mathrm{m})$ \\
\hline 19 & - & - & - \\
\hline 20 & $0.86(3 \mathrm{H}, \mathrm{s})$ & $0.86(3 \mathrm{H}, \mathrm{s})$ & $0.86(3 \mathrm{H}, \mathrm{s})$ \\
\hline 21 & $1.69(3 \mathrm{H}, \mathrm{s})$ & $1.69(3 \mathrm{H}, \mathrm{s})$ & $1.69(3 \mathrm{H}, \mathrm{s})$ \\
\hline 22 & $4.27(1 \mathrm{H}$, brd, $J=12 \mathrm{~Hz})$ & $4.27(1 \mathrm{H}, \mathrm{d}, J=12.6 \mathrm{~Hz})$ & $4.27(1 \mathrm{H}, \mathrm{d}, J=12.6 \mathrm{~Hz})$ \\
\hline $22^{\prime}$ & $4.42(1 \mathrm{H}$, brd, $J=12 \mathrm{~Hz})$ & $4.42(1 \mathrm{H}, \mathrm{d}, J=12.6 \mathrm{~Hz})$ & $4.42(1 \mathrm{H}, \mathrm{d}, J=12.6 \mathrm{~Hz})$ \\
\hline 23 & $1.50(3 \mathrm{H}, \mathrm{s})$ & $1.50(3 \mathrm{H}, \mathrm{s})$ & $1.50(3 \mathrm{H}, \mathrm{s})$ \\
\hline 24 & $1.20(3 \mathrm{H}, \mathrm{s})$ & $1.20(3 \mathrm{H}, \mathrm{s})$ & $1.20(3 \mathrm{H}, \mathrm{s})$ \\
\hline 25 & $0.78(3 \mathrm{H}, \mathrm{s})$ & $0.78(3 \mathrm{H}, \mathrm{s})$ & $0.78(3 \mathrm{H}, \mathrm{s})$ \\
\hline 26 & - & - & - \\
\hline 27 & $1.67(3 \mathrm{H}, \mathrm{s})$ & $1.67(3 \mathrm{H}, \mathrm{s})$ & $1.67(3 \mathrm{H}, \mathrm{s})$ \\
\hline
\end{tabular}


Table S2. ${ }^{13} \mathrm{C}-\mathrm{NMR}$ Comparison of natural and synthetic ansellone $\mathrm{A}$

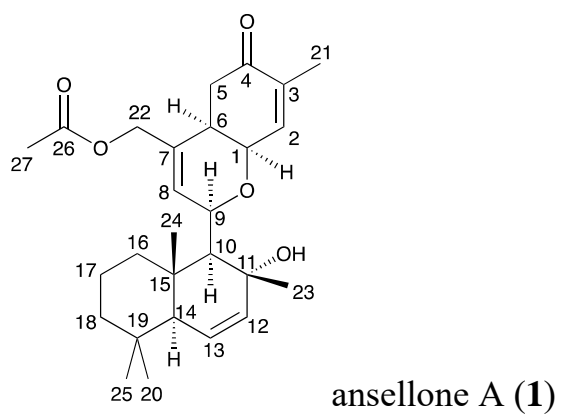

\begin{tabular}{|c|c|c|c|}
\hline \multirow{2}{*}{$\begin{array}{c}\mathrm{C} \\
\text { No. }\end{array}$} & \multicolumn{3}{|c|}{${ }^{13} \mathrm{C}-\mathrm{NMR}\left(\mathrm{C}_{6} \mathrm{D}_{6}\right)$} \\
\hline & $\begin{array}{c}\text { natural ansellone } \mathrm{A}(150 \mathrm{MHz}) \\
\text { ref. } 7\end{array}$ & $\begin{array}{l}\text { Tong's synthetic ansellone A (100 } \\
\text { MHz) ref. } 8\end{array}$ & $\begin{array}{c}\text { our synthetic ansellone A (100 } \\
\text { MHz) }\end{array}$ \\
\hline 1 & 70.9 & 70.5 & 70.5 \\
\hline 2 & 139.4 & 139.0 & 139.0 \\
\hline 3 & 138.6 & 138.2 & 138.2 \\
\hline 4 & 197.7 & 197.3 & 197.4 \\
\hline 5 & 38.6 & 38.3 & 38.2 \\
\hline 6 & 34.8 & 34.5 & 34.4 \\
\hline 7 & 131.4 & 131.0 & 131.0 \\
\hline 8 & 134.8 & 134.4 & 134.4 \\
\hline 9 & 76.9 & 76.6 & 76.5 \\
\hline 10 & 63.8 & 63.4 & 63.4 \\
\hline 11 & 73.1 & 72.7 & 72.7 \\
\hline 12 & 135.7 & 135.3 & 135.3 \\
\hline 13 & 128.0 & 127.4 & 127.6 \\
\hline 14 & 57.0 & 56.7 & 56.6 \\
\hline 15 & 42.1 & 41.8 & 41.8 \\
\hline 16 & 38.9 & 38.6 & 38.5 \\
\hline 17 & 18.9 & 18.5 & 18.5 \\
\hline 18 & 41.7 & 41.4 & 41.3 \\
\hline 19 & 33.1 & 32.7 & 32.7 \\
\hline 20 & 33.6 & 33.2 & 33.2 \\
\hline 21 & 16.3 & 15.9 & 15.9 \\
\hline 22 & 66.1 & 65.7 & 65.7 \\
\hline 23 & 26.5 & 26.1 & 26.1 \\
\hline 24 & 16.8 & 16.4 & 16.4 \\
\hline 25 & 22.2 & 21.8 & 21.8 \\
\hline 26 & 170.2 & 169.8 & 169.8 \\
\hline 27 & 20.8 & 20.4 & 20.4 \\
\hline
\end{tabular}




\section{Synthesis of ansellone $A$ analogs}

\section{Compound 13}

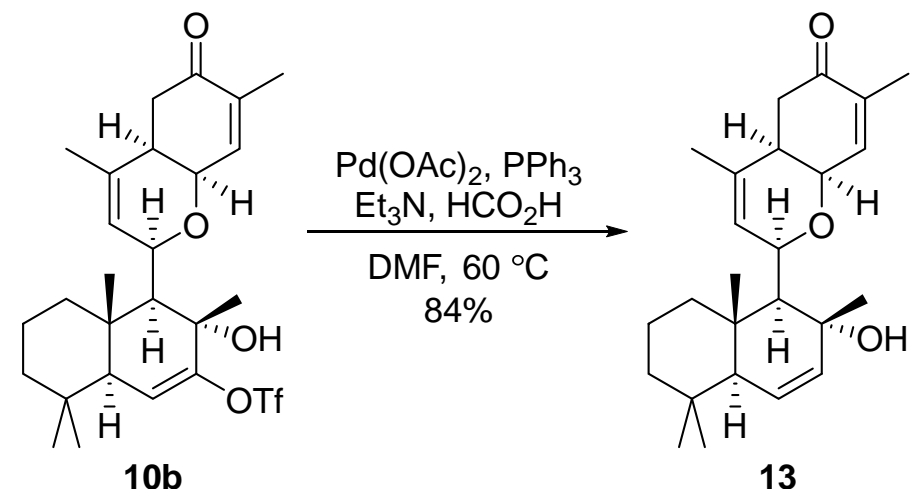

$\mathrm{Et}_{3} \mathrm{~N}(130 \mu \mathrm{L}, 0.933 \mathrm{mmol})$ and $\mathrm{HCO}_{2} \mathrm{H}(24.0 \mu \mathrm{L}, 0.636 \mathrm{mmol})$ was added to a solution of compound 10b (42.3 mg, $0.0794 \mathrm{mmol}), \mathrm{Pd}(\mathrm{OAc})_{2}(2.0 \mathrm{mg}, 0.00891 \mathrm{mmol})$ and $\mathrm{PPh} 3(4.7 \mathrm{mg}$, $0.0179 \mathrm{mmol})$ in DMF $(0.80 \mathrm{~mL})$ at room temperature under $\mathrm{N}_{2}$ atmosphere. After stirring at $60{ }^{\circ} \mathrm{C}$ for $2 \mathrm{~h}$, the resulting solution was cooled to room temperature and added saturated $\mathrm{NaHCO}_{3}$ aq., and the resulting mixture was extracted with $\mathrm{CH}_{2} \mathrm{Cl}_{2}$. The combined organic layer was dried over $\mathrm{Na}_{2} \mathrm{SO}_{4}$, filtered, and concentrated under reduced pressure. The residue was purified by flash column chromatography on silica gel using $n$-hexane-EtOAc (3:1) to give compound $\mathbf{1 3}$ (25.8 $\mathrm{mg}, 0.0671$ mmol, 84\%) as a colorless solid. MP 151-154 ${ }^{\circ} \mathrm{C} ;[\alpha]_{\mathrm{D}}^{25}=+7.9\left(\mathrm{c} 0.11, \mathrm{CH}_{2} \mathrm{Cl}_{2}\right) ;{ }^{1} \mathrm{H}-\mathrm{NMR}(300 \mathrm{MHz}$, $\left.\mathrm{C}_{6} \mathrm{D}_{6}\right) \delta: 6.19(1 \mathrm{H}, \mathrm{dd}, J=5.5,1.4 \mathrm{~Hz}), 5.62(1 \mathrm{H}, \mathrm{dd}, J=10.2,1.4 \mathrm{~Hz}), 5.55(1 \mathrm{H}, \mathrm{dd}, J=10.2,2.9$ $\mathrm{Hz}), 5.33(1 \mathrm{H}, \mathrm{d}, J=1.0 \mathrm{~Hz}), 4.78(1 \mathrm{H}, \mathrm{s}), 3.54(1 \mathrm{H}, \mathrm{t}, J=4.3 \mathrm{~Hz}), 2.67-2.53(2 \mathrm{H}, \mathrm{m}), 1.91-1.86$ $(1 \mathrm{H}, \mathrm{m}), 1.81-1.71(2 \mathrm{H}, \mathrm{m}), 1.71(3 \mathrm{H}, \mathrm{s}), 1.59-1.50(2 \mathrm{H}, \mathrm{m}), 1.54(3 \mathrm{H}, \mathrm{s}), 1.40(3 \mathrm{H}, \mathrm{s}), 1.36-1.28$ $(2 \mathrm{H}, \mathrm{m}), 1.23(3 \mathrm{H}, \mathrm{s}), 1.15-1.00(3 \mathrm{H}, \mathrm{m}), 0.87(3 \mathrm{H}, \mathrm{s}), 0.79(3 \mathrm{H}, \mathrm{s}) ;{ }^{13} \mathrm{C}-\mathrm{NMR}\left(125 \mathrm{MHz}, \mathrm{C}_{6} \mathrm{D}_{6}\right) \delta$ : 197.9, 1394, 138.1, 135.5, 131.4, 129.4, 127.5, 76.8, 72.8, 70.6, 63.4, 56.8, 41.8, 41.4, 38.4, 37.9, 37.5, 33.2, 32.7, 26.1, 21.8, 20.7, 18.5, 16.5, 15.9; HRMS (MALDI-TOF) calcd for $\mathrm{C}_{25} \mathrm{H}_{36} \mathrm{O}_{3} \mathrm{Na}$ $[\mathrm{M}+\mathrm{Na}]^{+}:$407.2557, found 407.2552. 


\section{Compound $14^{8}$}<smiles>CC=CC1CC(=O)C(C)=CC1OC1C=C(COC(C)=O)C2C=C[C@](C)(O)[C@@]1(C)CCCC2(C)C</smiles>

1

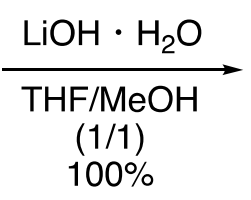

14

Lithium hydroxide monohydrate $(2.7 \mathrm{mg}, 0.0643 \mathrm{mmol})$ was added to a solution of compound $\mathbf{1}$ (9.7 $\mathrm{mg}, 0.0219 \mathrm{mmol})$ in THF $(2.0 \mathrm{~mL})$ and $\mathrm{MeOH}(2.0 \mathrm{~mL})$ at room temperature under $\mathrm{N}_{2}$ atmosphere. After stirring for $1 \mathrm{~h}$, the resulting solution was added $\mathrm{H}_{2} \mathrm{O}$, and the resulting mixture was extracted with EtOAc. The combined organic layer was dried over $\mathrm{Na}_{2} \mathrm{SO}_{4}$, filtered, and concentrated under reduced pressure. The residue was purified by flash column chromatography on silica gel using $n$-hexane-EtOAc (1:2) to give compound $\mathbf{1 4}\left(9.0 \mathrm{mg}\right.$, quantitative) as a colorless oil. $[\alpha]_{\mathrm{D}}^{30}=+13.8(\mathrm{c}$ 0.12, $\left.\mathrm{CH}_{2} \mathrm{Cl}_{2}\right) ;{ }^{1} \mathrm{H}-\mathrm{NMR}\left(500 \mathrm{MHz}, \mathrm{CDCl}_{3}\right) \delta: 6.65(1 \mathrm{H}, \mathrm{dd}, J=5.7,1.7 \mathrm{~Hz}), 5.90(1 \mathrm{H}, \mathrm{d}, J=1.1$ $\mathrm{Hz}), 5.72(1 \mathrm{H}, \mathrm{dd}, J=10.0,1.8 \mathrm{~Hz}), 5.55(1 \mathrm{H}, \mathrm{dd}, J=10.0,2.9 \mathrm{~Hz}), 4.84(1 \mathrm{H}, \mathrm{d}, J=1.7 \mathrm{~Hz}), 4.11$ $(2 \mathrm{H}, \mathrm{d}, J=4.0 \mathrm{~Hz}), 4.05-4.04(1 \mathrm{H}, \mathrm{m}), 2.65-2.60(3 \mathrm{H}, \mathrm{m}), 1.90(1 \mathrm{H}, \mathrm{s}), 1.84(3 \mathrm{H}, \mathrm{s}), 1.84-1.83(2 \mathrm{H}$, m), 1.76-1.73 (1H, m), 1.64-1.61 (1H, m), $1.42(3 \mathrm{H}, \mathrm{s}), 1.42-1.39(3 \mathrm{H}, \mathrm{m}), 1.18-1.12(2 \mathrm{H}, \mathrm{m}), 1.09$ $(3 \mathrm{H}, \mathrm{s}), 0.89$ (3H, s), $0.81(3 \mathrm{H}, \mathrm{s}) ;{ }^{13} \mathrm{C}-\mathrm{NMR}\left(125 \mathrm{MHz}, \mathrm{CDCl}_{3}\right) \delta: 199.3,139.9,138.1,135.3,134.4$, 129.7, 128.2, 76.7, 73.4, 70.4, 64.3, 63.0, 56.6, 41.3, 41.0, 38.0, 37.9, 33.3, 33.0, 32.6, 25.9, 21.7, 18.3, 16.1, 15.9; HRMS (MALDI-TOF) calcd for $\mathrm{C}_{25} \mathrm{H}_{36} \mathrm{O}_{4} \mathrm{Na}[\mathrm{M}+\mathrm{Na}]^{+}: 423.2506$, found 423.2501.

\section{Compound 15}

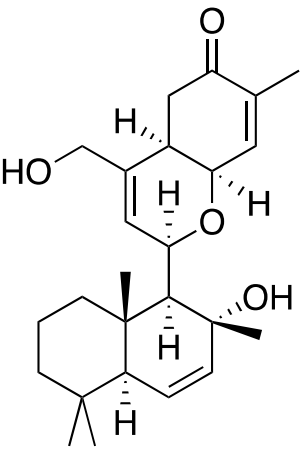

14

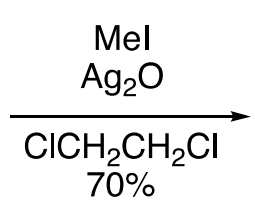<smiles>CC=CC1CC(=O)C(C)=CC1OC1C=C(COC)C2C=C[C@@H](O)[C@](C)(CCCC2(C)C)[C@H]1C</smiles>

15

MeI $(61 \mu \mathrm{L}, 0.980 \mathrm{mmol})$ and $\mathrm{Ag}_{2} \mathrm{O}(46.4 \mathrm{mg}, 0.200 \mathrm{mmol})$ was added to a solution of compound $14(8.0 \mathrm{mg}, 0.020 \mathrm{mmol})$ in 1,2-dichloroethane $(0.56 \mathrm{~mL})$ at room temperature under $\mathrm{N}_{2}$ atmosphere. After stirring for $23 \mathrm{~h}$, the resulting mixture was filtered thorough celite pad, and the filtrate was 
concentrated under reduced pressure. The residue was purified by flash column chromatography on silica gel using $n$-hexane-EtOAc (2:1) to give compound $15(5.8 \mathrm{mg}, 0.014 \mathrm{mmol}, 70 \%)$ as a colorless oil. $[\alpha]_{\mathrm{D}}^{32}=+10.7\left(\mathrm{c} 0.13, \mathrm{CH}_{2} \mathrm{Cl}_{2}\right) ;{ }^{1} \mathrm{H}-\mathrm{NMR}\left(400 \mathrm{MHz}, \mathrm{C}_{6} \mathrm{D}_{6}\right) \delta: 6.18(1 \mathrm{H}, \mathrm{d}, J=5.5 \mathrm{~Hz})$, $5.69(1 \mathrm{H}, \mathrm{s}), 5.61(1 \mathrm{H}, \mathrm{d}, J=10.4 \mathrm{~Hz}), 5.54(1 \mathrm{H}, \mathrm{dd}, J=10.4,3.0 \mathrm{~Hz}), 4.83(1 \mathrm{H}, \mathrm{s}), 3.61-3.49(3 \mathrm{H}$, m), $3.05(3 \mathrm{H}, \mathrm{s}), 2.76-2.67(2 \mathrm{H}, \mathrm{m}), 2.26-2.22(1 \mathrm{H}, \mathrm{m}), 1.91-1.88(1 \mathrm{H}, \mathrm{m}), 1.72-1.70(1 \mathrm{H}, \mathrm{m}), 1.70$ $(3 \mathrm{H}, \mathrm{s}), 1.57-1.49(2 \mathrm{H}, \mathrm{m}), 1.53(3 \mathrm{H}, \mathrm{s}), 1.37-1.28(2 \mathrm{H}, \mathrm{m}), 1.23(3 \mathrm{H}, \mathrm{s}), 1.12-0.99(2 \mathrm{H}, \mathrm{m}), 0.86$ $(3 \mathrm{H}, \mathrm{s}), 0.78(3 \mathrm{H}, \mathrm{s}) ;{ }^{13} \mathrm{C}-\mathrm{NMR}\left(400 \mathrm{MHz}, \mathrm{C}_{6} \mathrm{D}_{6}\right) \delta: 197.7,139.2,138.1,135.4,133.1,131.7,127.6$, 76.6, 74.2, 72.8, 70.7, 63.4, 57.7, 56.7, 41.8, 41.3, 38.5, 38.3, 34.0, 33.2, 32.7, 26.1, 21.8, 18.5, 16.4, 16.0; HRMS (MALDI-TOF) calcd for $\mathrm{C}_{26} \mathrm{H}_{38} \mathrm{O}_{4} \mathrm{Na}[\mathrm{M}+\mathrm{Na}]^{+}: 437.2662$, found 437.2660. 


\section{Study of Prins cyclization with 2a and 2c}

Preparation of 2c<smiles></smiles>

8

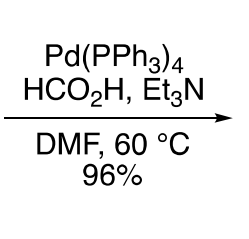

$96 \%$<smiles>CC1(C)CCC[C@]2(C)[C@H]3CO[Si](C(C)(C)C)(C(C)(C)C)O[C@@H]3C=C[C@@H]12</smiles>

S6

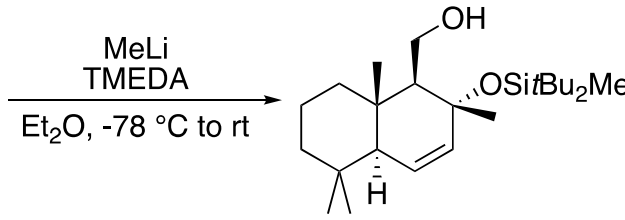

S7

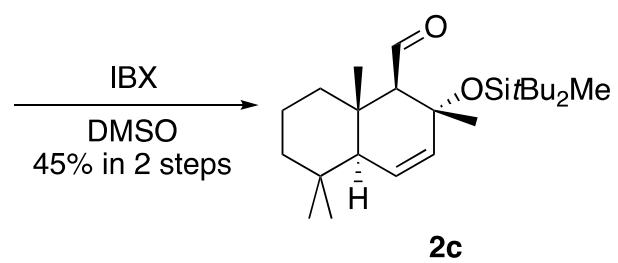

\section{Compound S6}<smiles>CC1(C)CCC[C@@]2(C)[C@H]1C=C[C@]1(C)C[Si](C(C)(C)C)(C(C)(C)C)OC[C@@H]12</smiles>

Triethylamine $(900 \mu \mathrm{L}, 6.45 \mathrm{mmol})$ and formic acid $(170 \mu \mathrm{L}, 4.50 \mathrm{mmol})$ was added to a solution of compound 8 (305 mg, $0.579 \mathrm{mmol}), \mathrm{Pd}\left(\mathrm{PPh}_{3}\right)_{4}$ $(66.0 \mathrm{mg}, 0.0571 \mathrm{mmol})$ in DMF $(4.50 \mathrm{~mL})$ at room temperature under an $\mathrm{N}_{2}$ atmosphere. After stirring at $60{ }^{\circ} \mathrm{C}$ for $24 \mathrm{~h}$, the resulting solution was cooled to room temperature and added saturated $\mathrm{NaHCO}_{3}$ aq., then the resulting mixture was extracted with $\mathrm{CH}_{2} \mathrm{Cl}_{2}$. The combined organic layers were dried over $\mathrm{Na}_{2} \mathrm{SO}_{4}$, filtered, and concentrated under reduced pressure. The residue was purified by flash column chromatography on silica gel using $n$-hexane-EtOAc (30:1) to give compound S7 (210 mg, 0.555 mmol, 96\%) as a colorless oil. $[\alpha]_{\mathrm{D}}^{27}=-51.4\left(\mathrm{c} 0.65, \mathrm{CH}_{2} \mathrm{Cl}_{2}\right)$; ${ }^{1} \mathrm{H}-\mathrm{NMR}\left(400 \mathrm{MHz}, \mathrm{C}_{6} \mathrm{D}_{6}\right) \delta: 5.79$ $(1 \mathrm{H}, \mathrm{dd}, J=10.5,3.2 \mathrm{~Hz}), 5.55(1 \mathrm{H}, \mathrm{d}, J=10.5 \mathrm{~Hz}), 4.13(1 \mathrm{H}, \mathrm{dd}, J=11.6,4.2 \mathrm{~Hz}), 3.98(1 \mathrm{H}, \mathrm{dd}, J$ $=11.6,11.6 \mathrm{~Hz}), 2.64(1 \mathrm{H}, \mathrm{dd}, J=11.6,4.2 \mathrm{~Hz}), 1.94(1 \mathrm{H}, \mathrm{s}), 1.53(3 \mathrm{H}, \mathrm{s}), 1.46-1.37(1 \mathrm{H}, \mathrm{m})$, 1.27-1.15 (21H, m), 1.02-0.91 (2H, m), $0.78(3 \mathrm{H}, \mathrm{s}), 0.73(3 \mathrm{H}, \mathrm{s}), 0.69(3 \mathrm{H}, \mathrm{s}) ;{ }^{13} \mathrm{C}-\mathrm{NMR}(125 \mathrm{MHz}$, $\left.\mathrm{C}_{6} \mathrm{D}_{6}\right) \delta: 135.6,125.3,74.9,61.6,57.9,56.8,41.1,37.9,37.1,32.8,32.6,28.9,28.5,26.9,21.6,21.5$, 21.1, 18.7, 16.8; HRMS (MALDI-TOF) calcd for $\mathrm{C}_{23} \mathrm{H}_{43} \mathrm{O}_{2} \mathrm{Si}[\mathrm{M}+\mathrm{H}]^{+}: 379.3027$, found 379.3024.

\section{Aldehyde 2c}

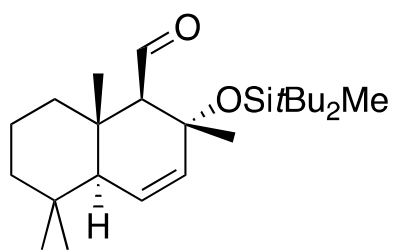

Tetramethylethylenediamine $(1.00 \mathrm{~mL}, 6.85 \mathrm{mmol})$ and $3.1 \mathrm{M} \mathrm{MeLi}$ solution in diethoxymethane $(2.20 \mathrm{~mL}, 6.85 \mathrm{mmol})$ was added to a solution of compound $\mathbf{S 1}(517 \mathrm{mg}, 1.37 \mathrm{mmol})$ in $\mathrm{Et}_{2} \mathrm{O}(7.0 \mathrm{~mL})$ at $-78{ }^{\circ} \mathrm{C}$ under $\mathrm{N}_{2}$ atmosphere. After stirring at room temperature for $2 \mathrm{~h}$, the resulting solution was added saturated $\mathrm{NH}_{4} \mathrm{Cl}$ aq. and the resulting mixture was extracted with EtOAc. The combined organic layer was dried over $\mathrm{Na}_{2} \mathrm{SO}_{4}$, filtered, and concentrated under 
reduced pressure. The residue was purified by flash column chromatography on silica gel using n-hexane-EtOAc (15:1) to give crude product S7 (568 mg). 2-Iodoxybenzoic acid (593 mg, 2.12 mmol) was added to a solution of crude compound $\mathrm{S} 7(568 \mathrm{mg})$ in DMSO $(5.0 \mathrm{~mL})$ at room temperature under an $\mathrm{N}_{2}$ atmosphere. After stirring at room temperature for $8 \mathrm{~h}$, the resulting solution was diluted with EtOAc, then the resulting mixture was washed with $\mathrm{H}_{2} \mathrm{O}$. The combined organic layer was dried over $\mathrm{Na}_{2} \mathrm{SO}_{4}$, filtered, and concentrated under reduced pressure. The residue was purified by flash column chromatography on silica gel using $n$-hexane-EtOAc (30:1) to give compound 2c (267 mg, $0.680 \mathrm{mmol}, 45 \%$ in 2 steps) as a colorless oil. $[\alpha]_{\mathrm{D}}^{24}=-130.6$ (c 0.16 , $\left.\mathrm{CH}_{2} \mathrm{Cl}_{2}\right) ;{ }^{1} \mathrm{H}-\mathrm{NMR}\left(500 \mathrm{MHz}, \mathrm{C}_{6} \mathrm{D}_{6}\right) \delta: 10.05(1 \mathrm{H}, \mathrm{d}, J=3.4 \mathrm{~Hz}), 5.54(1 \mathrm{H}, \mathrm{dd}, J=10.3,1.7 \mathrm{~Hz})$, $5.47(1 \mathrm{H}, \mathrm{dd}, J=10.3,3.4 \mathrm{~Hz}), 2.71(1 \mathrm{H}, \mathrm{d}, J=3.4 \mathrm{~Hz}), 1.84-1.82(1 \mathrm{H}, \mathrm{m}), 1.67-1.66(1 \mathrm{H}, \mathrm{m})$, 1.52-1.44 (1H, m), $1.37(3 \mathrm{H}, \mathrm{s}), 1.25-1.22(2 \mathrm{H}, \mathrm{m}), 1.08(9 \mathrm{H}, \mathrm{s}), 1.04(12 \mathrm{H}, \mathrm{s}), 0.96-0.91(2 \mathrm{H}, \mathrm{m})$, $0.77(3 \mathrm{H}, \mathrm{s}), 0.72(3 \mathrm{H}, \mathrm{s}), 0.12(3 \mathrm{H}, \mathrm{s}) ;{ }^{13} \mathrm{C}-\mathrm{NMR}\left(125 \mathrm{MHz}, \mathrm{C}_{6} \mathrm{D}_{6}\right) \delta: 203.2,134.9,128.7,74.8$, $72.1,54.2,40.9,40.0,37.2,32.7,32.3,28.3,28.2,28.2,21.6,20.8,20.7,18.2,16.1,-5.4$. HRMS (MALDI-TOF) calcd for $\mathrm{C}_{24} \mathrm{H}_{44} \mathrm{O}_{2} \mathrm{NaSi}[\mathrm{M}+\mathrm{Na}]^{+}:$415.3003, found 415.3003 . 


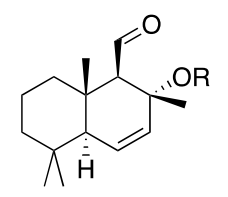

2a: $\mathrm{R}=\mathrm{H}$

2c: $\mathrm{R}=\mathrm{SitBu}_{2} \mathrm{Me}$<smiles>C=C(C)C1CC(=O)C(C)=CC1O</smiles>

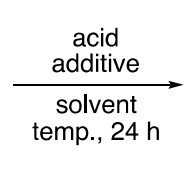

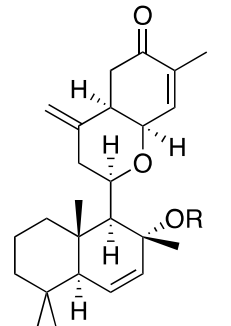

11: $\mathrm{R}=\mathrm{H}$

S8: $\mathrm{R}=\mathrm{SitBu} \mathrm{Me}_{2}$

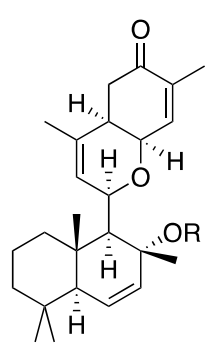

13: $\mathrm{R}=\mathrm{H}$

S9: $\mathrm{R}=\mathrm{SitBu} \mathrm{H}_{2} \mathrm{Me}$

\begin{tabular}{|c|c|c|c|c|c|c|}
\hline entry & aldehyde & acid & additive & solvent & temp. $\left({ }^{\circ} \mathrm{C}\right)$ & $\begin{array}{c}\text { yield } \\
(\%, 11+13 \text { or } \mathbf{S 8}+\mathrm{S} 9)\end{array}$ \\
\hline 1 & $2 \mathbf{a}$ & $\begin{array}{l}\text { TMSOTf } \\
(0.5 \text { eq. })\end{array}$ & - & $\mathrm{CH}_{2} \mathrm{Cl}_{2}$ & -78 & $0^{a}$ \\
\hline 2 & $2 a$ & $\begin{array}{c}\mathrm{BF}_{3} \cdot \mathrm{OEt}_{2} \\
(0.5 \text { eq. })\end{array}$ & - & $\mathrm{CH}_{2} \mathrm{Cl}_{2}$ & -78 & $0^{\mathrm{a}}$ \\
\hline 3 & $2 a$ & $\begin{array}{c}\mathrm{InCl}_{3} \\
\text { (0.5 eq.) }\end{array}$ & - & $\mathrm{CH}_{2} \mathrm{Cl}_{2}$ & -78 & $0^{\mathrm{a}}$ \\
\hline 4 & $2 a$ & $\begin{array}{l}\text { PPTS } \\
\text { (0.5 eq.) }\end{array}$ & - & $\mathrm{CH}_{2} \mathrm{Cl}_{2}$ & -78 & $0^{a}$ \\
\hline 5 & $2 a$ & montmorillonite $\mathrm{K} 10$ & - & $\mathrm{CH}_{2} \mathrm{Cl}_{2}$ & -78 & $0^{\mathrm{a}}$ \\
\hline 6 & $2 a$ & KSF cray & - & $\mathrm{CH}_{2} \mathrm{Cl}_{2}$ & -78 & $0^{\mathrm{a}}$ \\
\hline 7 & $2 a$ & $\begin{array}{c}\mathrm{BF}_{3} \cdot \mathrm{OEt}_{2} \\
(0.5 \text { eq. })\end{array}$ & $\begin{array}{l}\text { 2.6-di-tBu-pyridine } \\
\text { (2.0 eq.) }\end{array}$ & $\mathrm{CH}_{2} \mathrm{Cl}_{2}$ & -78 & $0^{\mathrm{a}}$ \\
\hline 8 & $2 a$ & $\begin{array}{c}\operatorname{lnCl}_{3} \\
(2.0 \text { eq.) }\end{array}$ & $\begin{array}{l}\text { 2.6-di-tBu-pyridine } \\
\text { (2.0 eq.) }\end{array}$ & $\mathrm{CH}_{2} \mathrm{Cl}_{2}$ & -78 & $0^{\mathrm{a}}$ \\
\hline 9 & 2c & $\begin{array}{l}\text { TMSOTf } \\
\text { ( } 0.5 \text { eq.) }\end{array}$ & - & $\mathrm{CH}_{2} \mathrm{Cl}_{2}$ & -78 & multi spots \\
\hline 10 & 2c & $\begin{array}{c}\mathrm{BF}_{3} \cdot \mathrm{OEt}_{2} \\
(0.5 \text { eq. })\end{array}$ & - & $\mathrm{CH}_{2} \mathrm{Cl}_{2}$ & -78 & $0^{\mathrm{a}}$ \\
\hline 11 & 2c & $\begin{array}{c}\mathrm{BF}_{3} \cdot \mathrm{OEt}_{2} \\
(0.5 \text { eq. })\end{array}$ & - & toluene & -78 & $0^{\mathrm{a}}$ \\
\hline 11 & 2c & $\begin{array}{c}\mathrm{BF}_{3} \cdot \mathrm{OEt}_{2} \\
(0.5 \text { eq. })\end{array}$ & $\begin{array}{l}\text { 2,6-lutidine } \\
\text { (2.0 eq.) }\end{array}$ & toluene & 0 to 80 & No reaction \\
\hline
\end{tabular}

a) Dehydrated compounds of aldehyde 2a or 2c were confirmed. 


\section{Optimization of Prins cyclization with 2b}<smiles></smiles>

2b (1.0 eq.)<smiles>C=C(C)C1CC(=O)C(C)=CC1O</smiles>

3 (3.0 eq.)

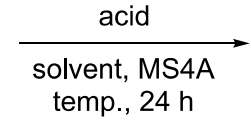

temp., $24 \mathrm{~h}$<smiles>C=C1CC(=O)C(C)=CC(O)C1OC1CC(=C)C2C3CCCC(C)(C)C3C=CC2(C)C1C</smiles>

$10 \mathrm{a}$

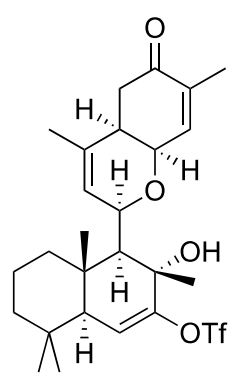

$10 \mathrm{~b}$

\begin{tabular}{|c|c|c|c|c|c|c|}
\hline entry & acid & solvent & MS4A & temp $\left({ }^{\circ} \mathrm{C}\right)$ & $\begin{array}{c}\text { yield }(10 a+10 b, \%)^{a} \\
\quad\left(\text { from }{ }^{1} H-N M R\right)\end{array}$ & $\begin{array}{l}\text { ratio }(10 a: 10 b)^{a} \\
\quad\left(\text { from }{ }^{1} \mathrm{H}-\mathrm{NMR}\right)\end{array}$ \\
\hline 1 & TMSOTf (0.5 eq.) & $\mathrm{CH}_{2} \mathrm{Cl}_{2}$ & No & -78 to -20 & 44 & $61: 39$ \\
\hline 2 & TfOH (0.5 eq.) & $\mathrm{CH}_{2} \mathrm{Cl}_{2}$ & No & -78 to -20 & 44 & $59: 41$ \\
\hline 3 & TFA (0.5 eq. $)$ & $\mathrm{CH}_{2} \mathrm{Cl}_{2}$ & No & -78 to r.t. & $0^{b}$ & - \\
\hline 4 & $\mathrm{TsOH} \cdot \mathrm{H}_{2} \mathrm{O}$ (0.5 eq.) & $\mathrm{CH}_{2} \mathrm{Cl}_{2}$ & No & -78 to r.t. & $0^{b}$ & - \\
\hline 5 & TESOTf (0.5 eq.) & $\mathrm{CH}_{2} \mathrm{Cl}_{2}$ & No & -78 to -20 & multi spots & - \\
\hline 6 & $\mathrm{Yb}(\mathrm{OTf})_{3}$ (0.5 eq.) & $\mathrm{CH}_{2} \mathrm{Cl}_{2}$ & No & -78 to 0 & No reaction & - \\
\hline 7 & TMSOTf (0.5 eq.) & $\mathrm{Et}_{2} \mathrm{O}$ & No & -78 to -20 & 47 & $53: 47$ \\
\hline 8 & TMSOTf (0.5 eq.) & toluene & No & -78 to -20 & 42 & $50: 50$ \\
\hline 9 & TMSOTf (0.5 eq.) & $\mathrm{CH}_{3} \mathrm{CN}$ & No & -78 to -20 & multi spots & - \\
\hline 10 & $\mathrm{TfOH}(0.5$ eq. $)$ & $\mathrm{CH}_{2} \mathrm{Cl}_{2}$ & Yes $^{c}$ & -78 to -20 & 49 & $63: 37$ \\
\hline 11 & $\mathrm{BF}_{3} \cdot \mathrm{OEt}_{2}$ (0.5 eq.) & $\mathrm{CH}_{2} \mathrm{Cl}_{2}$ & Yes $^{c}$ & -78 to 0 & multi spots & - \\
\hline 12 & $\mathrm{Tf}_{2} \mathrm{NH}$ (0.5 eq.) & $\mathrm{CH}_{2} \mathrm{Cl}_{2}$ & Yes $^{c}$ & -78 to -20 & 38 & $66: 34$ \\
\hline 13 & TMSOMs (0.5 eq.) & $\mathrm{CH}_{2} \mathrm{Cl}_{2}$ & Yes $^{c}$ & -78 to $r t$ & No reaction & - \\
\hline 14 & $\mathrm{InCl}_{3}(0.5$ eq. $)$ & $\mathrm{CH}_{2} \mathrm{Cl}_{2}$ & Yes $^{c}$ & -78 to $\mathrm{rt}$ & multi spots & - \\
\hline 15 & TMSOTf (0.5 eq.) & $\mathrm{CH}_{2} \mathrm{Cl}_{2}$ & Yes $^{c}$ & -78 to -20 & 60 & $67: 33$ \\
\hline 16 & TMSOTf (0.2 eq.) & $\mathrm{CH}_{2} \mathrm{Cl}_{2}$ & Yes $^{c}$ & -78 to 0 & No reaction & - \\
\hline 17 & TMSOTf (1.0 eq.) & $\mathrm{CH}_{2} \mathrm{Cl}_{2}$ & Yes $^{c}$ & -78 & trace & - \\
\hline
\end{tabular}

a) Yields and ratios were determined by ${ }^{1} \mathrm{H}-\mathrm{NMR}$ using 1,2,4,5-tetramethylbenzene as an internal standard. b) No desired compound was obtained, but aldehyde $\mathbf{2 b}$ was decomposed. c) $15 \mathrm{mg}$ of MS4A was added for $10 \mathrm{mg}$ of aldehyde $\mathbf{2 b}$. 
6. Tong's synthesis of ansellone A (for comparison) ${ }^{8}$

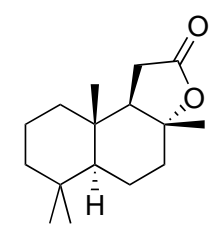

(+)-sclareolide

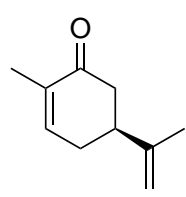

(S)-carvone

10 steps $\downarrow \mid 16 \% \quad 8$ steps $\downarrow \mid 28 \%$<smiles>C=C(CI)[C@H]1C=CC(C)=CC1</smiles>

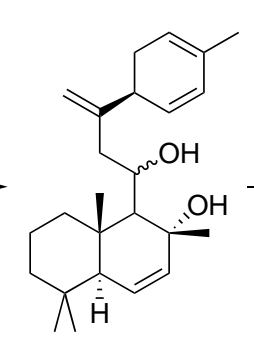

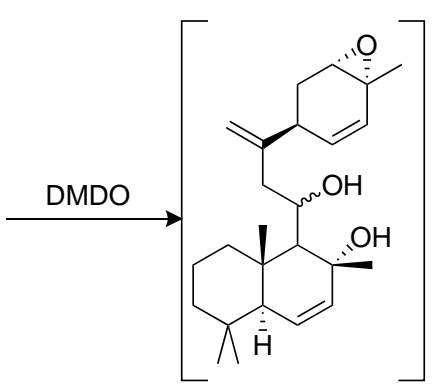

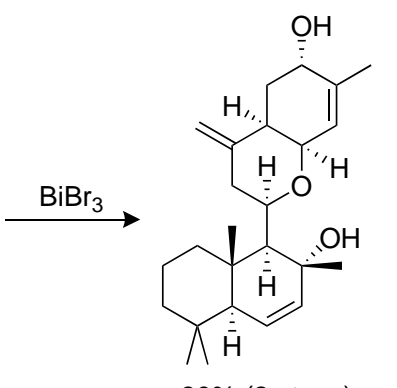

$30 \%$ (2 steps)

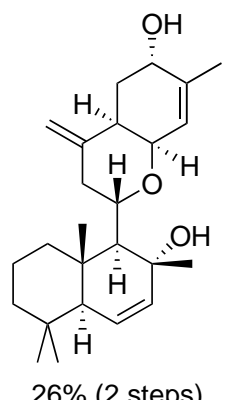

IBX $\downarrow 69 \%$<smiles>C=C1CC(C2C(O)C=CC3C(C)CCCC32C)C2CC(C)C(=O)CC12</smiles>

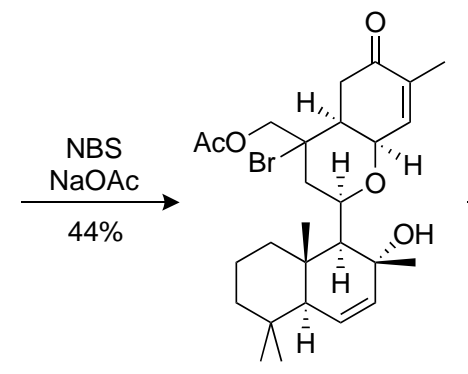<smiles>O=C(O[Na])[Mg][Mg]</smiles><smiles>CC(=O)OCC1=CC2OC3C=C(C)C(=O)CC3C(O)C2CC=CC1C</smiles> 


\section{Computational study}

Structural optimization: Structural optimizations were performed using MacroModel ${ }^{9}$ (ver. 11.8) with none solvent and OPLS3 force field. Each geometry of the generated conformer was optimized employing a Polak-Ribière Conjugate gradient (PRCG) method with a convergence criteria of 0.05 and a maximum of 2500 iterations. The results of these structures were utilized for DFT calculations to obtain thermodynamic energies.

DFT calculations: DFT calculations were performed using the Gaussian 09 software ${ }^{10}$, and the B3LYP hybrid functional. Optimized geometries for each conformer to single point calculations at a B3LYP/6-31G(d, p) level of theory.

B3LYP/6-31G (d, p) Optimized Structure and Energy of compound 16a<smiles>C[C@]1(O)C=CCCC1</smiles>

$16 a$

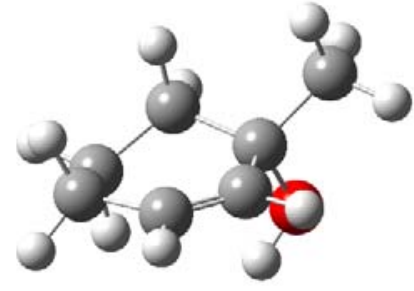

$E(R B 3 L Y P)=-349.196681616$

No imaginary frequencies

\begin{tabular}{cccccc}
\hline $\begin{array}{c}\text { Center } \\
\text { Number }\end{array}$ & Atomic & Atomic & \multicolumn{3}{c}{ Coordinates (Angstroms) } \\
\hline 1 & Number & Type & $\mathrm{X}$ & $\mathrm{Y}$ & $\mathrm{Z}$ \\
\hline 2 & 6 & 0 & -1.445286 & -1.702600 & -1.207625 \\
3 & 6 & 0 & -0.451467 & -0.807015 & -1.206099 \\
4 & 6 & 0 & 0.012532 & -0.055833 & 0.025704 \\
5 & 6 & 0 & -0.555997 & -0.700638 & 1.307232 \\
6 & 6 & 0 & -2.035834 & -1.071396 & 1.158267 \\
7 & 6 & 0 & 1.539588 & 0.018845 & 0.084627 \\
8 & 8 & 0 & -0.415238 & 1.321512 & -0.076785 \\
9 & 1 & 0 & -1.717416 & -2.194104 & -2.140697 \\
10 & 1 & 0 & 0.056799 & -0.555333 & -2.13566 \\
11 & 1 & 0 & -0.405918 & 0.000264 & 2.135127 \\
12 & 1 & 0 & 0.018807 & -1.607593 & 1.538164 \\
13 & 1 & 0 & -2.617186 & -0.165209 & 0.938142 \\
14 & 1 & 0 & -2.431197 & -1.468596 & 2.099375 \\
15 & 1 & 0 & -3.290217 & -2.189694 & -0.229253
\end{tabular}




\begin{tabular}{llllll}
16 & 1 & 0 & -1.90726 & -3.08657 & 0.357239 \\
17 & 1 & 0 & 1.978736 & -0.980385 & 0.155852 \\
18 & 1 & 0 & 1.927777 & 0.511663 & -0.811472 \\
19 & 1 & 0 & 1.851458 & 0.603218 & 0.955881 \\
20 & 1 & 0 & -1.345114 & 1.311152 & -0.339544 \\
\hline
\end{tabular}

B3LYP/6-31G (d, p) Optimized Structure and Energy of compound 17a
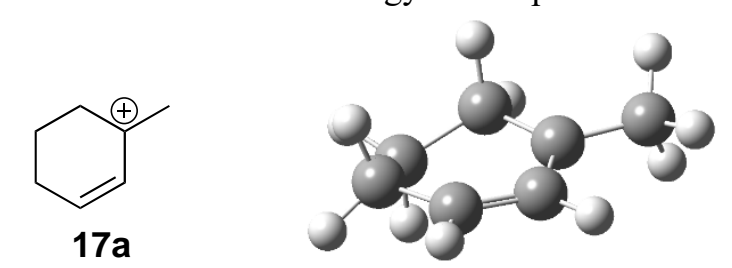

$E(R B 3 L Y P)=-273.111888321$

Zero-point correction $=0.161568$

No imaginary frequencies

\begin{tabular}{cccccc}
\hline $\begin{array}{c}\text { Center } \\
\text { Number }\end{array}$ & $\begin{array}{c}\text { Atomic } \\
\text { Number }\end{array}$ & $\begin{array}{c}\text { Atomic } \\
\text { Type }\end{array}$ & $\mathrm{X}$ & $\mathrm{Y}$ & $\mathrm{Z}$ \\
\hline 1 & 6 & 0 & -2.002435 & -1.060152 & 0.902541 \\
2 & 6 & 0 & -0.678589 & -1.138755 & 0.525252 \\
3 & 6 & 0 & 0.033861 & 0.028696 & 0.200632 \\
4 & 6 & 0 & -0.649375 & 1.353715 & 0.203751 \\
5 & 6 & 0 & -2.165888 & 1.270979 & -0.010795 \\
6 & 6 & 0 & -2.793873 & 0.189762 & 0.876251 \\
7 & 6 & 0 & 1.479599 & -0.026958 & -0.102368 \\
8 & 1 & 0 & -2.486831 & -1.961314 & 1.277155 \\
9 & 1 & 0 & -0.157775 & -2.090381 & 0.560136 \\
10 & 1 & 0 & -0.167052 & 2.023278 & -0.517035 \\
11 & 1 & 0 & -0.41378 & 1.791957 & 1.192328 \\
12 & 1 & 0 & -2.365825 & 1.030422 & -1.06068 \\
13 & 1 & 0 & -2.624576 & 2.242157 & 0.18598 \\
14 & 1 & 0 & -3.826926 & -0.037769 & 0.586547 \\
15 & 1 & 0 & -2.876815 & 0.518864 & 1.930219 \\
16 & 1 & 0 & 1.954285 & -0.956947 & 0.213362 \\
17 & 1 & 0 & 1.584943 & 0.054238 & -1.198006 \\
18 & 1 & 0 & 2.010854 & 0.839209 & 0.306631 \\
\hline
\end{tabular}


<smiles>C[C@@H]1CCCC=C1O</smiles>

16b

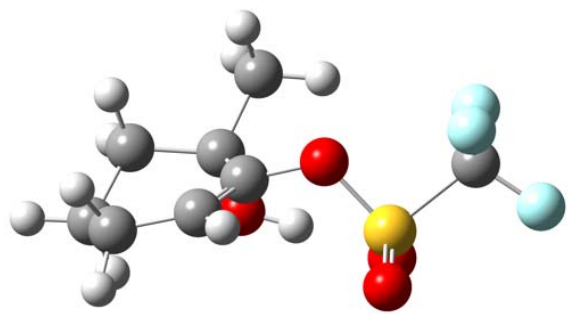

$E(R B 3 L Y P)=-1309.99793481$

Zero-point correction $=0.197841$

No imaginary frequencies

\begin{tabular}{|c|c|c|c|c|c|}
\hline \multirow{2}{*}{$\begin{array}{l}\text { Center } \\
\text { Number }\end{array}$} & \multirow{2}{*}{$\begin{array}{l}\text { Atomic } \\
\text { Number }\end{array}$} & \multirow{2}{*}{$\begin{array}{c}\text { Atomic } \\
\text { Type }\end{array}$} & \multicolumn{3}{|c|}{ Coordinates (Angstroms) } \\
\hline & & & $\mathrm{X}$ & $\mathrm{Y}$ & $\mathrm{Z}$ \\
\hline 1 & 6 & 0 & -3.209899 & 1.210821 & 0.840927 \\
\hline 2 & 6 & 0 & -2.444755 & 2.503548 & 0.523609 \\
\hline 3 & 6 & 0 & -2.168407 & 3.316773 & 1.758416 \\
\hline 4 & 6 & 0 & -2.339602 & 2.824639 & 2.984757 \\
\hline 5 & 6 & 0 & -2.816266 & 1.424706 & 3.344315 \\
\hline 6 & 6 & 0 & -2.648863 & 0.535379 & 2.096053 \\
\hline 7 & 8 & 0 & -1.983667 & 3.658609 & 4.099532 \\
\hline 8 & 16 & 0 & -3.103619 & 4.700893 & 4.664058 \\
\hline 9 & 6 & 0 & -2.157395 & 5.093044 & 6.230818 \\
\hline 10 & 8 & 0 & -3.174269 & 5.901922 & 3.848004 \\
\hline 11 & 8 & 0 & -4.317437 & 3.980186 & 5.048333 \\
\hline 12 & 9 & 0 & -2.874916 & 5.975118 & 6.92268 \\
\hline 13 & 9 & 0 & -1.998656 & 3.981718 & 6.945378 \\
\hline 14 & 9 & 0 & -0.972622 & 5.611689 & 5.927746 \\
\hline 15 & 6 & 0 & -2.037262 & 0.852602 & 4.537712 \\
\hline 16 & 8 & 0 & -4.219773 & 1.417631 & 3.627834 \\
\hline 17 & 1 & 0 & -3.164812 & 0.529242 & -0.014867 \\
\hline 18 & 1 & 0 & -4.264638 & 1.443572 & 1.01898 \\
\hline 19 & 1 & 0 & -2.998711 & 3.117656 & -0.197068 \\
\hline 20 & 1 & 0 & -1.482925 & 2.275794 & 0.038853 \\
\hline 21 & 1 & 0 & -1.800253 & 4.332969 & 1.645276 \\
\hline 22 & 1 & 0 & -3.170106 & -0.405852 & 2.296297 \\
\hline 23 & 1 & 0 & -1.584919 & 0.303677 & 1.961301 \\
\hline 24 & 1 & 0 & -0.960399 & 0.823146 & 4.341953 \\
\hline
\end{tabular}




\begin{tabular}{llllll}
25 & 1 & 0 & -2.20084 & 1.451113 & 5.437588 \\
26 & 1 & 0 & -2.389261 & -0.163822 & 4.732539 \\
27 & 1 & 0 & -4.413229 & 2.108227 & 4.281575 \\
\hline
\end{tabular}

B3LYP/6-31G (d, p) Optimized Structure and Energy of compound 17b
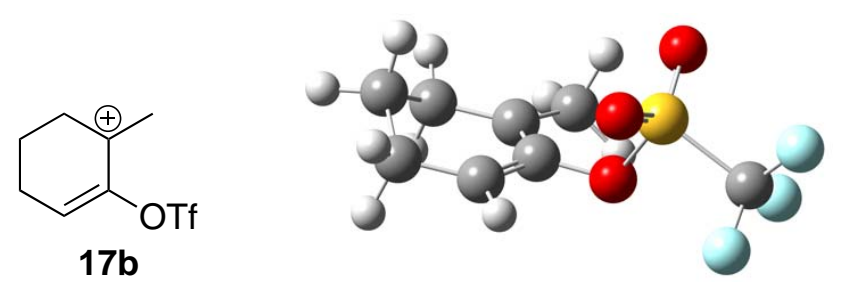

$E($ RB3LYP $)=-1233.89481431$

Zero-point correction $=0.179630$

No imaginary frequencies

\begin{tabular}{|c|c|c|c|c|c|}
\hline \multirow{2}{*}{$\begin{array}{l}\text { Center } \\
\text { Number }\end{array}$} & \multirow{2}{*}{$\begin{array}{l}\text { Atomic } \\
\text { Number }\end{array}$} & \multirow{2}{*}{$\begin{array}{c}\text { Atomic } \\
\text { Type }\end{array}$} & \multicolumn{3}{|c|}{ Coordinates (Angstroms) } \\
\hline & & & $\mathrm{X}$ & $\mathrm{Y}$ & Z \\
\hline 1 & 6 & 0 & -1.049695 & 1.426902 & 0.305822 \\
\hline 2 & 6 & 0 & -0.56411 & 0.212916 & -0.133348 \\
\hline 3 & 6 & 0 & -1.176354 & -0.998917 & 0.248317 \\
\hline 4 & 6 & 0 & -2.428623 & -0.960595 & 1.053777 \\
\hline 5 & 6 & 0 & -3.224146 & 0.34309 & 0.922732 \\
\hline 6 & 6 & 0 & -2.314425 & 1.568733 & 1.058485 \\
\hline 7 & 8 & 0 & 0.632685 & 0.160783 & -0.8299 \\
\hline 8 & 16 & 0 & 0.474118 & 0.507908 & -2.495499 \\
\hline 9 & 6 & 0 & 2.337493 & 0.646067 & -2.796023 \\
\hline 10 & 8 & 0 & -0.056089 & -0.677703 & -3.145674 \\
\hline 11 & 8 & 0 & -0.15792 & 1.812542 & -2.605601 \\
\hline 12 & 9 & 0 & 2.494022 & 0.868888 & -4.087806 \\
\hline 13 & 9 & 0 & 2.802582 & 1.653333 & -2.07816 \\
\hline 14 & 9 & 0 & 2.90278 & -0.493892 & -2.436035 \\
\hline 15 & 6 & 0 & -0.561659 & -2.294016 & -0.097135 \\
\hline 16 & 1 & 0 & -0.442421 & 2.309762 & 0.116266 \\
\hline 17 & 1 & 0 & -2.104264 & -1.134269 & 2.097983 \\
\hline 18 & 1 & 0 & -3.036963 & -1.838898 & 0.808647 \\
\hline 19 & 1 & 0 & -4.018734 & 0.371778 & 1.671076 \\
\hline 20 & 1 & 0 & -3.708308 & 0.366975 & -0.059531 \\
\hline 21 & 1 & 0 & -2.025117 & 1.757184 & 2.110142 \\
\hline
\end{tabular}




\begin{tabular}{llllll}
22 & 1 & 0 & -2.815832 & 2.493924 & 0.748848 \\
23 & 1 & 0 & 0.530609 & -2.250477 & -0.073809 \\
24 & 1 & 0 & -0.94758 & -3.113148 & 0.511201 \\
25 & 1 & 0 & -0.821849 & -2.498171 & -1.151175 \\
\hline
\end{tabular}

B3LYP/6-31G (d, p) Optimized Structure and Energy of compound 16c<smiles>O[C@H]1C=CCCC1</smiles>

$16 \mathrm{c}$

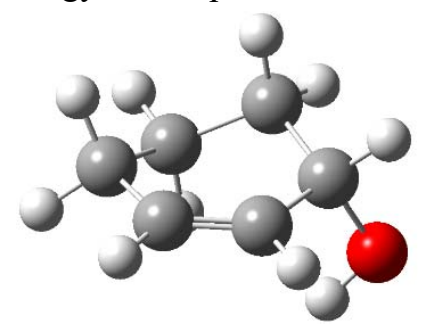

$E(R B 3 L Y P)=-309.875653794$

Zero-point correction $=0.151028$

No imaginary frequencies

\begin{tabular}{cccccc}
\hline $\begin{array}{c}\text { Center } \\
\text { Number }\end{array}$ & $\begin{array}{c}\text { Atomic } \\
\text { Number }\end{array}$ & $\begin{array}{c}\text { Atomic } \\
\text { Type }\end{array}$ & $\mathrm{X}$ & $\mathrm{Y}$ & $\mathrm{Z}$ \\
\hline 1 & 6 & 0 & -2.582859 & 0.406181 & -1.562425 \\
2 & 6 & 0 & -1.295954 & 1.010713 & -2.141192 \\
3 & 6 & 0 & -0.752874 & 0.189544 & -3.284198 \\
4 & 6 & 0 & -1.468449 & -0.729463 & -3.943435 \\
5 & 6 & 0 & -2.903096 & -1.062767 & -3.609451 \\
6 & 6 & 0 & -3.537193 & -0.006724 & -2.689117 \\
7 & 8 & 0 & -2.994528 & -2.387352 & -3.057843 \\
8 & 1 & 0 & -3.06752 & 1.114931 & -0.882533 \\
9 & 1 & 0 & -2.330502 & -0.47738 & -0.959837 \\
10 & 1 & 0 & -0.530856 & 1.110047 & -1.36067 \\
11 & 1 & 0 & -1.489593 & 2.035775 & -2.494148 \\
12 & 1 & 0 & 0.279657 & 0.373412 & -3.578039 \\
13 & 1 & 0 & -1.010593 & -1.30998 & -4.741802 \\
14 & 1 & 0 & -3.488316 & -1.122379 & -4.53497 \\
15 & 1 & 0 & -4.472527 & -0.412325 & -2.29049 \\
16 & 1 & 0 & -3.793342 & 0.877464 & -3.28882 \\
17 & 1 & 0 & -2.313754 & -2.453397 & -2.374632 \\
\hline
\end{tabular}


B3LYP/6-31G (d, p) Optimized Structure and Energy of compound 17c<smiles>[C+]1C=CCCC1</smiles>

$17 \mathrm{c}$

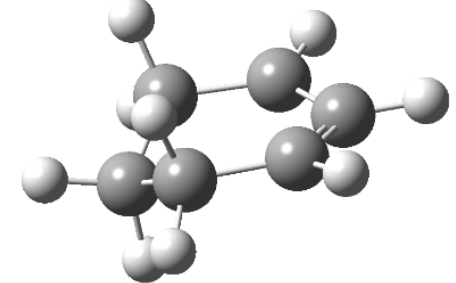

$E(R B 3 L Y P)=-233.773936802$

Zero-point correction $=0.133771$

No imaginary frequencies

\begin{tabular}{cccccc}
\hline $\begin{array}{c}\text { Center } \\
\text { Number }\end{array}$ & $\begin{array}{c}\text { Atomic } \\
\text { Number }\end{array}$ & Atomic & \multicolumn{3}{c}{ Coordinates (Angstroms) } \\
\hline 1 & 6 & 0 & -0.136958 & 1.036791 & -1.070899 \\
2 & 6 & 0 & 0.734066 & -0.210441 & -1.271999 \\
3 & 6 & 0 & 1.07209 & -0.900866 & -0.012903 \\
4 & 6 & 0 & 0.372633 & -0.720478 & 1.17391 \\
5 & 6 & 0 & -0.79051 & 0.039095 & 1.14572 \\
6 & 6 & 0 & -1.246486 & 0.789025 & -0.04019 \\
7 & 1 & 0 & -0.565856 & 1.358608 & -2.021672 \\
8 & 1 & 0 & 0.497917 & 1.854735 & -0.714059 \\
9 & 1 & 0 & 1.655201 & 0.008331 & -1.827361 \\
10 & 1 & 0 & 0.232696 & -0.97772 & -1.896885 \\
11 & 1 & 0 & 1.875389 & -1.637418 & -0.034782 \\
12 & 1 & 0 & 0.65754 & -1.260864 & 2.07017 \\
13 & 1 & 0 & -1.4352 & 0.033716 & 2.024692 \\
14 & 1 & 0 & -2.082179 & 0.190678 & -0.457259 \\
15 & 1 & 0 & -1.733743 & 1.718708 & 0.280816 \\
\hline
\end{tabular}


B3LYP/6-31G (d, p) Optimized Structure and Energy of compound 16d

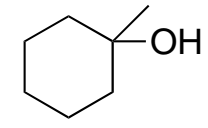

$16 d$

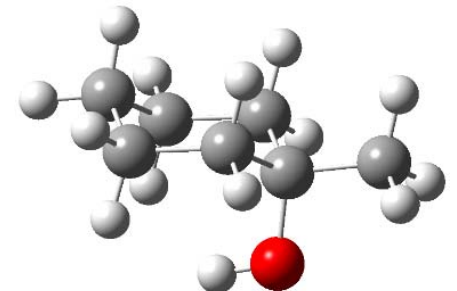

$E(R B 3 L Y P)=-350.430368806$

Zero-point correction $=0.202302$

No imaginary frequencies

\begin{tabular}{|c|c|c|c|c|c|}
\hline \multirow{2}{*}{$\begin{array}{l}\text { Center } \\
\text { Number }\end{array}$} & \multirow{2}{*}{$\begin{array}{l}\text { Atomic } \\
\text { Number }\end{array}$} & \multirow{2}{*}{$\begin{array}{l}\text { Atomic } \\
\text { Type }\end{array}$} & \multicolumn{3}{|c|}{ Coordinates (Angstroms) } \\
\hline & & & $\mathrm{X}$ & $\mathrm{Y}$ & Z \\
\hline 1 & 6 & 0 & -4.72833 & 2.247526 & 1.405689 \\
\hline 2 & 6 & 0 & -4.899057 & 2.425234 & -0.111914 \\
\hline 3 & 6 & 0 & -3.873256 & 3.407598 & -0.719655 \\
\hline 4 & 6 & 0 & -2.440881 & 2.981207 & -0.328309 \\
\hline 5 & 6 & 0 & -2.264371 & 2.804804 & 1.188785 \\
\hline 6 & 6 & 0 & -3.29634 & 1.824456 & 1.766442 \\
\hline 7 & 6 & 0 & -4.024531 & 3.485523 & -2.237888 \\
\hline 8 & 8 & 0 & -4.135683 & 4.746631 & -0.260416 \\
\hline 9 & 1 & 0 & -5.451613 & 1.513654 & 1.779137 \\
\hline 10 & 1 & 0 & -4.970989 & 3.190532 & 1.918193 \\
\hline 11 & 1 & 0 & -5.907913 & 2.782841 & -0.34686 \\
\hline 12 & 1 & 0 & -4.781104 & 1.448254 & -0.599894 \\
\hline 13 & 1 & 0 & -1.736092 & 3.726395 & -0.714107 \\
\hline 14 & 1 & 0 & -2.209499 & 2.029882 & -0.826276 \\
\hline 15 & 1 & 0 & -2.366328 & 3.779631 & 1.688908 \\
\hline 16 & 1 & 0 & -1.245967 & 2.464851 & 1.408908 \\
\hline 17 & 1 & 0 & -3.182979 & 1.746632 & 2.854234 \\
\hline 18 & 1 & 0 & -3.105277 & 0.821299 & 1.359504 \\
\hline 19 & 1 & 0 & -3.844584 & 2.510007 & -2.700024 \\
\hline 20 & 1 & 0 & -5.033736 & 3.816105 & -2.501178 \\
\hline 21 & 1 & 0 & -3.312593 & 4.205372 & -2.652693 \\
\hline 22 & 1 & 0 & -4.053276 & 4.756866 & 0.701615 \\
\hline
\end{tabular}


B3LYP/6-31G (d, p) Optimized Structure and Energy of compound 17d

\begin{tabular}{|c|c|c|c|c|c|}
\hline \multicolumn{6}{|c|}{$\begin{array}{c}\mathrm{E}(\mathrm{RB} 3 \mathrm{LYP})=-274.319101579 \\
\text { Zero-point correction }=0.183788 \\
\text { No imaginary frequencies }\end{array}$} \\
\hline \multirow{2}{*}{$\begin{array}{l}\text { Center } \\
\text { Number }\end{array}$} & \multirow{2}{*}{$\begin{array}{l}\text { Atomic } \\
\text { Number }\end{array}$} & \multirow{2}{*}{$\begin{array}{l}\text { Atomic } \\
\text { Type }\end{array}$} & \multicolumn{3}{|c|}{ Coordinates (Angstroms) } \\
\hline & & & $\mathrm{X}$ & $\mathrm{Y}$ & Z \\
\hline 1 & 6 & 0 & -0.035844 & 0.694611 & -0.613994 \\
\hline 2 & 6 & 0 & 0.808879 & 0.391113 & 0.643043 \\
\hline 3 & 6 & 0 & 0.75763 & -0.987161 & 1.147766 \\
\hline 4 & 6 & 0 & 0.50403 & -2.101888 & 0.225765 \\
\hline 5 & 6 & 0 & -0.338303 & -1.778832 & -1.027998 \\
\hline 6 & 6 & 0 & 0.054158 & -0.433393 & -1.646761 \\
\hline 7 & 6 & 0 & 1.009752 & -1.255601 & 2.567341 \\
\hline 8 & 1 & 0 & 0.300756 & 1.645431 & -1.034079 \\
\hline 9 & 1 & 0 & -1.076022 & 0.840181 & -0.300982 \\
\hline 10 & 1 & 0 & 0.673556 & 1.110831 & 1.458569 \\
\hline 11 & 1 & 0 & 1.888898 & 0.479004 & 0.385263 \\
\hline 12 & 1 & 0 & 0.171817 & -2.992329 & 0.771782 \\
\hline 13 & 1 & 0 & 1.54259 & -2.353045 & -0.088767 \\
\hline 14 & 1 & 0 & -1.395075 & -1.768963 & -0.737699 \\
\hline 15 & 1 & 0 & -0.217825 & -2.595402 & -1.743908 \\
\hline 16 & 1 & 0 & 1.071291 & -0.489287 & -2.055913 \\
\hline 17 & 1 & 0 & -0.60594 & -0.211527 & -2.490035 \\
\hline 18 & 1 & 0 & 1.391234 & -2.261638 & 2.759146 \\
\hline 19 & 1 & 0 & 1.608644 & -0.483464 & 3.056787 \\
\hline 20 & 1 & 0 & 0.005173 & -1.210941 & 3.034275 \\
\hline
\end{tabular}


B3LYP/6-31G (d, p) Optimized Structure and Energy of compound $16 e$

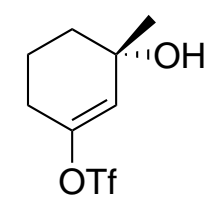

$16 e$

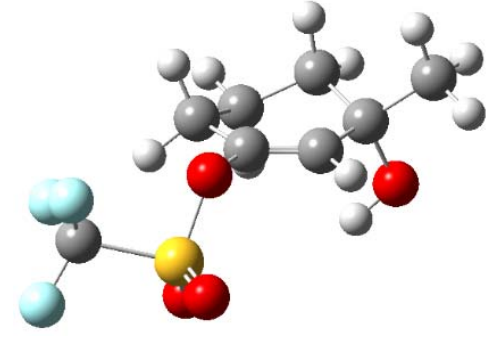

$E(R B 3 L Y P)=-1309.99625141$

Zero-point correction $=0.197329$

No imaginary frequencies

\begin{tabular}{|c|c|c|c|c|c|}
\hline \multirow{2}{*}{$\begin{array}{l}\text { Center } \\
\text { Number }\end{array}$} & \multirow{2}{*}{$\begin{array}{l}\text { Atomic } \\
\text { Number }\end{array}$} & \multirow{2}{*}{$\begin{array}{c}\text { Atomic } \\
\text { Type }\end{array}$} & \multicolumn{3}{|c|}{ Coordinates (Angstroms) } \\
\hline & & & $X$ & $\mathrm{Y}$ & $\mathrm{Z}$ \\
\hline 1 & 6 & 0 & 3.513881 & 4.421464 & -2.074223 \\
\hline 2 & 6 & 0 & 3.081264 & 4.33074 & -3.330964 \\
\hline 3 & 6 & 0 & 2.595989 & 3.025731 & -3.931475 \\
\hline 4 & 6 & 0 & 2.314586 & 1.984978 & -2.826573 \\
\hline 5 & 6 & 0 & 3.420172 & 1.950061 & -1.766062 \\
\hline 6 & 6 & 0 & 3.559103 & 3.311828 & -1.067168 \\
\hline 7 & 6 & 0 & 1.356867 & 3.251074 & -4.800249 \\
\hline 8 & 8 & 0 & 3.602716 & 2.54378 & -4.842026 \\
\hline 9 & 8 & 0 & 3.885516 & 5.707925 & -1.586277 \\
\hline 10 & 16 & 0 & 5.474151 & 6.125665 & -1.607382 \\
\hline 11 & 8 & 0 & 5.600394 & 7.409698 & -2.271624 \\
\hline 12 & 6 & 0 & 5.674657 & 6.436729 & 0.227183 \\
\hline 13 & 8 & 0 & 6.295111 & 4.974801 & -1.957018 \\
\hline 14 & 9 & 0 & 6.920661 & 6.852077 & 0.443236 \\
\hline 15 & 9 & 0 & 4.811838 & 7.365479 & 0.625591 \\
\hline 16 & 9 & 0 & 5.459158 & 5.305368 & 0.901967 \\
\hline 17 & 1 & 0 & 3.106384 & 5.205812 & -3.974594 \\
\hline 18 & 1 & 0 & 2.203774 & 1.00797 & -3.307132 \\
\hline 19 & 1 & 0 & 1.357605 & 2.223368 & -2.343956 \\
\hline 20 & 1 & 0 & 4.375672 & 1.689619 & -2.239544 \\
\hline 21 & 1 & 0 & 3.21975 & 1.170354 & -1.024729 \\
\hline 22 & 1 & 0 & 4.494811 & 3.364176 & -0.502599 \\
\hline 23 & 1 & 0 & 2.748373 & 3.459251 & -0.338931 \\
\hline 24 & 1 & 0 & 0.52611 & 3.643499 & -4.20715 \\
\hline
\end{tabular}




\begin{tabular}{llllll}
25 & 1 & 0 & 1.583872 & 3.957569 & -5.603337 \\
26 & 1 & 0 & 1.049159 & 2.305209 & -5.255684 \\
27 & 1 & 0 & 4.457624 & 2.598274 & -4.393679 \\
\hline
\end{tabular}

B3LYP/6-31G (d, p) Optimized Structure and Energy of compound 17e

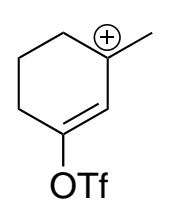

$17 \mathrm{e}$

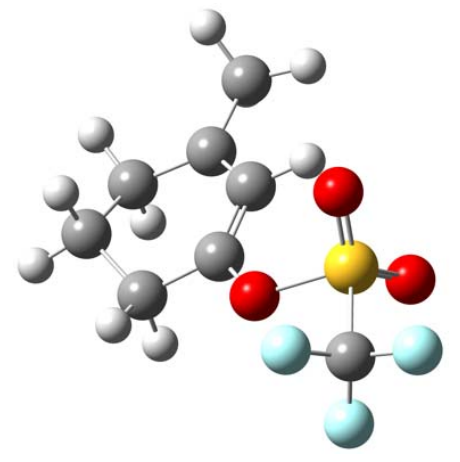

$E(R B 3 L Y P)=-1233.91806276$

Zero-point correction $=0.180981$

\begin{tabular}{cccccc}
\hline $\begin{array}{c}\text { Center } \\
\text { Number }\end{array}$ & $\begin{array}{c}\text { Atomic } \\
\text { Number }\end{array}$ & $\begin{array}{c}\text { Atomic } \\
\text { Type }\end{array}$ & $\mathrm{X}$ & $\mathrm{Y}$ & $\mathrm{Z}$ \\
\hline 1 & 6 & 0 & -2.645477 & 7.303223 & 0.007339 \\
2 & 6 & 0 & -1.922732 & 6.064459 & 0.548674 \\
3 & 6 & 0 & -1.413182 & 5.515311 & -1.882803 \\
4 & 6 & 0 & -2.511147 & 6.249066 & -2.288845 \\
5 & 6 & 0 & -3.369988 & 6.982269 & -1.303804 \\
6 & 6 & 0 & -2.887039 & 6.315238 & -3.72572 \\
7 & 8 & 0 & -0.129005 & 4.669163 & -0.035671 \\
8 & 16 & 0 & 0.962077 & 3.667776 & -1.069996 \\
9 & 8 & 0 & 1.762513 & 4.596422 & -1.837492 \\
10 & 6 & 0 & 1.924219 & 3.027181 & 0.450394 \\
11 & 8 & 0 & 0.138651 & 2.623259 & -1.639134 \\
12 & 9 & 0 & 1.07933 & 2.370161 & 1.218085 \\
13 & 9 & 0 & 2.861177 & 2.234232 & -0.029602 \\
14 & 9 & 0 & 2.440734 & 4.066001 & 1.074052 \\
15 & 6 & 0 & -1.107438 & 5.396363 & -0.514419 \\
16 & 1 & -1.916632 & 8.102535 & -0.164872 \\
17 & 1 & 0 & -3.353406 & 7.670627 & 0.753549 \\
18 & 1 & 0 & -2.643742 & 5.30941 & 0.901908 \\
& & 0 & & &
\end{tabular}




\begin{tabular}{llllll}
19 & 1 & 0 & -1.276567 & 6.292574 & 1.400953 \\
20 & 1 & 0 & -0.81616 & 5.000104 & -2.625815 \\
21 & 1 & 0 & -4.24645 & 6.338051 & -1.117654 \\
22 & 1 & 0 & -3.773515 & 7.886307 & -1.771824 \\
23 & 1 & 0 & -2.314845 & 5.629893 & -4.35195 \\
24 & 1 & 0 & -3.959238 & 6.119646 & -3.84847 \\
25 & 1 & 0 & -2.729439 & 7.341629 & -4.087083 \\
\hline
\end{tabular}

$\underline{\text { Summary of sum of electronic and zero-point energies }}$

alcohol $\mathrm{B3LYP/6-31 \textrm {G } ( \mathrm { d } , \mathrm { p } ) \text { (hartree) }}$




\section{Biological assay}

\section{$<$ Material $>$}

Prostratin was purchased from LC Laboratories. The following reagent was obtained through the NIH AIDS Reagent Program, Division of AIDS, NIAID, NIH: J-Lat Full Length Cells (10.6) from Dr. Eric Verdin (cat\# 9849). Tzm-bl cells from Dr. John C. Kappes, and Dr. Xiaoyun Wu (cat\# $8129)$.

\section{$<$ Method $>$}

\section{HIV-latency reversal with Latency-reversing agents (LRAs)}

The reactivation of HIV from latently-infected cells was determined by quantifying the changes in intracellular GFP expression (J-Lat cells). J-Lat 10.6 cells $\left(5 \times 10^{5}\right.$ cells $\left./ \mathrm{ml}\right)$ were placed in 96 -well plates and incubated with different concentrations of each drug for $24 \mathrm{~h}$. Then, GFP-positive cells were analyzed by flow cytometry (Beckman coulter, CytoFlex). Furthermore, cell viabilities of J-Lat cells were determined using a LIVE/DEAD® Cell Viability Kit (Thermo Fisher Scientific K.K.) at $24 \mathrm{~h}$. $\mathrm{EC}_{50}$ values were calculated from dose-response curves using GraphPad $\AA$ Prism software version. 9.0.

\section{GFP expression}

\begin{tabular}{|l|r|r|r|r|r|r|}
\hline Final conc. $(\mu \mathrm{M})$ & 0 & 0.625 & 1.25 & 2.5 & 5 & 10 \\
\hline prostratin & 1.98 & 36.12 & 57.46 & 73.04 & 76.09 & 78.83 \\
\hline ansellone A (1) & 1.98 & 33.41 & 52.37 & 67.94 & 75.40 & 80.65 \\
\hline $\mathbf{1 1}$ & 1.52 & 1.15 & 1.35 & 1.08 & 1.43 & 2.08 \\
\hline $\mathbf{1 3}$ & 1.52 & 1.17 & 1.20 & 1.45 & 2.13 & 8.24 \\
\hline $\mathbf{1 4}$ & 1.98 & 44.67 & 66.86 & 78.29 & 75.60 & 78.85 \\
\hline $\mathbf{1 5}$ & 1.23 & 0.71 & 0.92 & 0.89 & 1.00 & 1.20 \\
\hline
\end{tabular}

* GFP positive cells (\%).

Cell viabilities

\begin{tabular}{|l|r|r|r|r|r|r|}
\hline Final conc. $(\mu \mathrm{M})$ & 0 & 0.625 & 1.25 & 2.5 & 5 & 10 \\
\hline prostratin & 87.30 & 90.44 & 87.82 & 87.96 & 86.80 & 88.19 \\
\hline ansellone A (1) & 87.90 & 91.42 & 89.73 & 88.27 & 88.66 & 91.01 \\
\hline $\mathbf{1 1}$ & 83.61 & 82.05 & 89.54 & 87.74 & 89.38 & 85.79 \\
\hline $\mathbf{1 3}$ & 83.61 & 87.69 & 93.34 & 93.53 & 94.21 & 86.69 \\
\hline $\mathbf{1 4}$ & 87.30 & 91.55 & 90.35 & 91.78 & 86.58 & 88.19 \\
\hline $\mathbf{1 5}$ & 88.46 & 88.73 & 91.06 & 89.17 & 90.36 & 90.87 \\
\hline
\end{tabular}

* Live cells (\%). 


\section{In vitro expression of LTR-driven luciferase in TZM-bl cells}

TZM-bl cells are derived from a HeLa cell clone that was engineered to contain integrated reporter genes for firefly Luc and E. coli $\beta$-galactosidase under the control of an HIV-1 long terminal repeat. TZM-bl cells $\left(1 \times 10^{5}\right.$ cells $\left./ \mathrm{ml}\right)$ were placed in 96-well plates and incubated with different concentrations of each drug for $24 \mathrm{~h}$. The cells were fixed, and the activation of TZM-bl cells was determined by measuring the LTR-driven luciferase activity in cell lysates.

\begin{tabular}{|l|r|r|r|r|r|r|}
\hline Final conc. $(\mu \mathrm{M})$ & 0 & 0.625 & 1.25 & 2.5 & 5 & 10 \\
\hline prostratin & 1.00 & 1.98 & 2.78 & 3.69 & 4.65 & 6.45 \\
\hline ansellone A $\mathbf{1})$ & 1.00 & 1.96 & 2.71 & 3.61 & 4.80 & 7.02 \\
\hline $\mathbf{1 1}$ & 1.00 & 0.95 & 0.98 & 1.05 & 0.99 & 0.91 \\
\hline $\mathbf{1 3}$ & 1.00 & 1.03 & 1.02 & 1.03 & 1.00 & 1.22 \\
\hline $\mathbf{1 4}$ & 1.00 & 2.29 & 3.51 & 4.84 & 5.84 & 6.58 \\
\hline $\mathbf{1 5}$ & 1.00 & 0.86 & 0.79 & 0.84 & 0.81 & 0.92 \\
\hline
\end{tabular}

* Fold increase HIV LTR Luc. (Relative to DMSO).

In vitro expression of LTR-driven luciferase in TZM-bl cells with ansellone A and its analogs

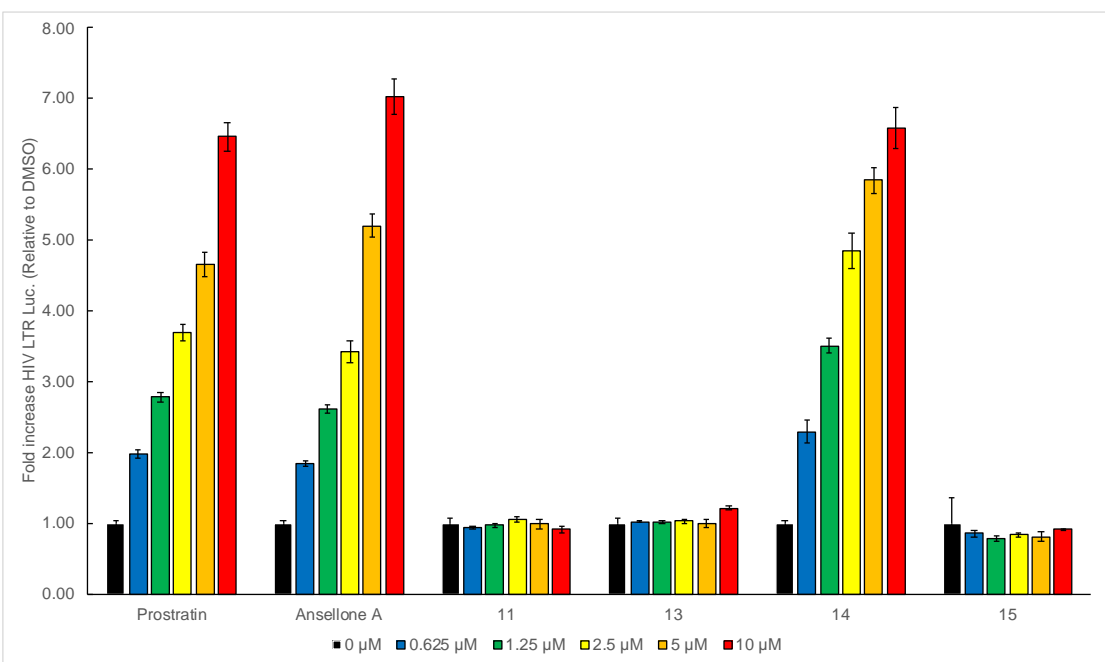




\section{References}

(1) Hubert, J. G.; Furkert, D. P.; Brimble, M. A. Preparation of Cis- $\gamma$-Hydroxycarvone Derivatives for Synthesis of Sester-terpenoid Natural Products: Total Synthesis of Phorbin A. J. Org. Chem. 2015, 80 (4), 2231-2239.

(2) Hamada, H.; Yasumune, H.; Fuchikami, Y.; Hirata, T.; Sattler, I.; Williams, H. J.; Scott, A. I. Biotransformat1on of Geraniol, Nerol and (+)- and (-)-Carvone by Suspension Cultured Cells of Catharanthus Roseus. Phytochemistry 1997, 44 (4), 615-621.

(3) Skiredj, A.; Beniddir, M. A.; Evanno, L.; Poupon, E. Mimicking the Main Events of the Biosynthesis of Drimentines: Synthesis of $\Delta 8^{\prime}$-Isodrimentine A and Related Compounds. Eur. J. Org. Chem. 2016, 2954-2958.

(4) Li, D.; Zhang, S.; Song, Z.; Li, W.; Zhu, F.; Zhang, J.; Li, S. Synthesis and bio-inspired optimization of drimenal: Discovery of chiral drimane fused oxazinones as promising antifungal and antibacterial candidates. Eur. J. Med. Chem. 2018, 143, 558-567.

(5) Kuchkova, K. I.; Aryku, A. N.; Barba, A. N.; Vlad, P. F. Elimination of C-8-Functional Groups

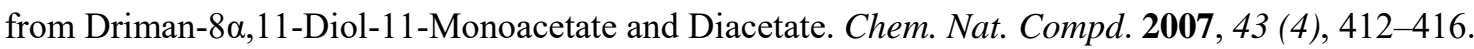

(6) Maturana, H.; Sierra, J.; Lopez, J.; Cortes, M. Synthesis of 1.3 Dioxans Related with Ambergris. Synth. Commun. 1984, 14 (7), 661-674.

(7) Daoust, J.; Fontana, A.; Merchant, C. E.; De Voogd, N. J.; Patrick, B. O.; Kieffer, T. J.; Andersen, R. J. Ansellone A, a Sesterterpenoid Isolated from the Nudibranch Cadlina Luteromarginata and the Sponge Phorbas Sp., Activates the cAMP Signaling Pathway. Org. Lett. 2010, 12 (14), 3208-3211.

(8) Zhang, W.; Yao, H.; Yu, J.; Zhang, Z.; Tong, R. Total Syntheses of Sesterterpenoid Ansellones A and B, and Phorbadione. Angew. Chem. Int. Ed. 2017, 56 (17), 4787-4791.

(9) MacroModel, Version 11.9, Schrödinger, LLC, New York, NY, 2019.

(10) Gaussian 09, Revision A.02, M. J. Frisch, G. W. Trucks, H. B. Schlegel, G. E. Scuseria, M. A. Robb, J. R. Cheeseman, G. Scalmani, V. Barone, B. Mennucci, G. A. Petersson, H. Nakatsuji, M. Caricato, X. Li, H. P. Hratchian, A. F. Izmaylov, J. Bloino, G. Zheng, J. L. Sonnenberg, M. Hada, M. Ehara, K. Toyota, R. Fukuda, J. Hasegawa, M. Ishida, T. Nakajima, Y. Honda, O. Kitao, H. Nakai, T. Vreven, J. A. Montgomery, Jr., J. E. Peralta, F. Ogliaro, M. Bearpark, J. J. Heyd, E. Brothers, K. N. Kudin, V. N. Staroverov, R. Kobayashi, J. Normand, K. Raghavachari, A. Rendell, J. C. Burant, S. S. Iyengar, J. Tomasi, M. Cossi, N. Rega, J. M. Millam, M. Klene, J. E. Knox, J. B. Cross, V. Bakken, C. Adamo, J. Jaramillo, R. Gomperts, R. E. Stratmann, O. Yazyev, A. J. Austin, R. Cammi, C. Pomelli, J. W. Ochterski, R. L. Martin, K. Morokuma, V. G. Zakrzewski, G. A. Voth, P. Salvador, J. J. Dannenberg, S.Dapprich, A. D. Daniels, O. Farkas, J. B. Foresman, J. V. Ortiz, J. Cioslowski, D. J. Fox, Gaussian, Inc., Wallingford CT, 2009. 

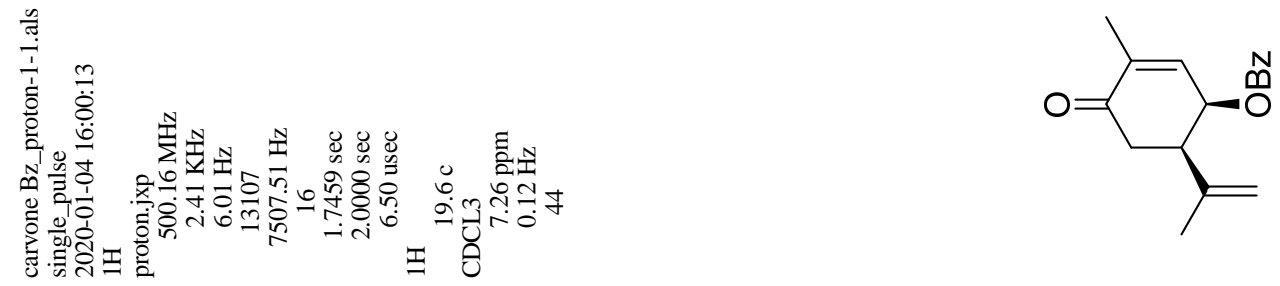

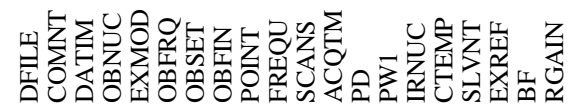

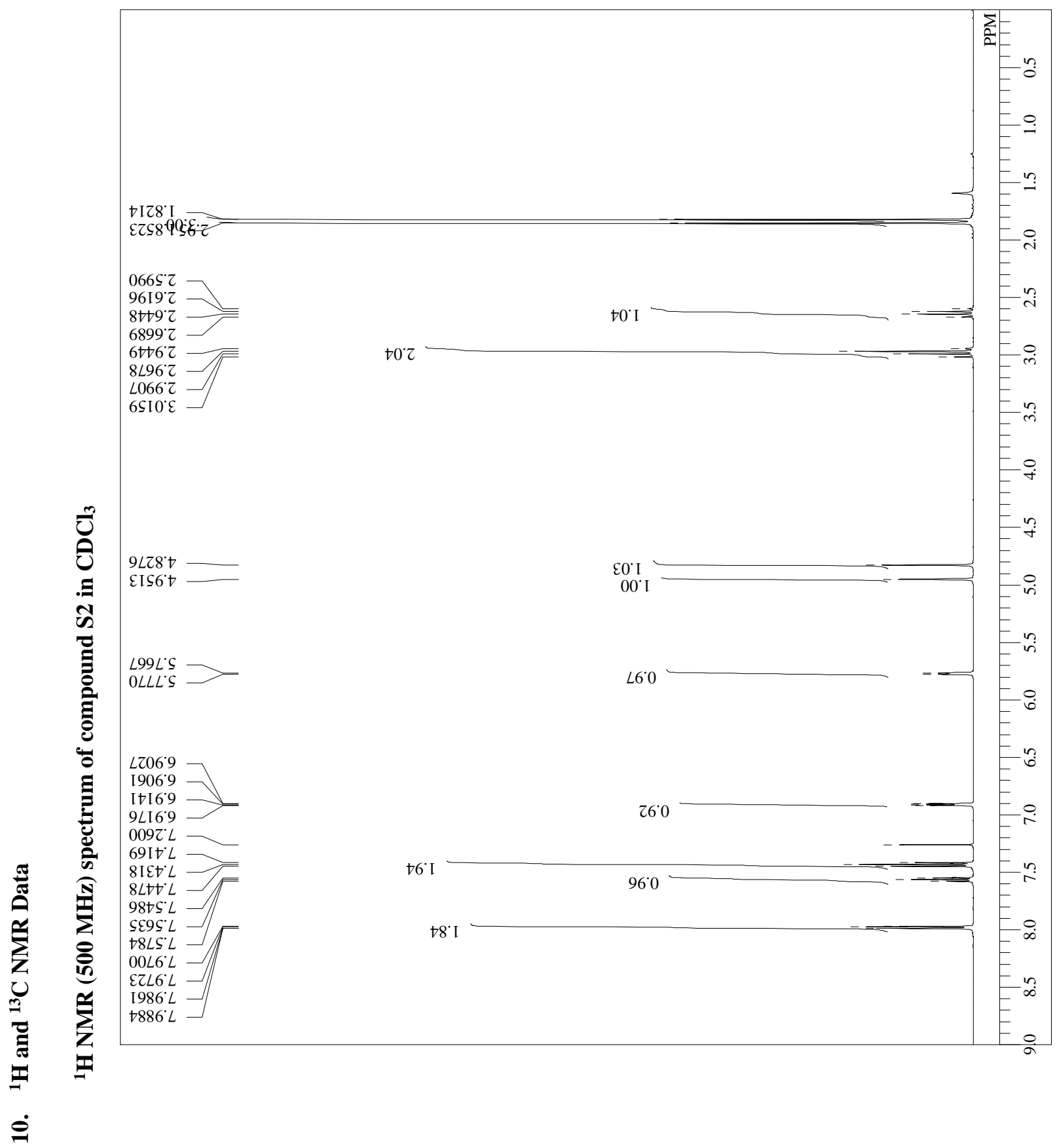




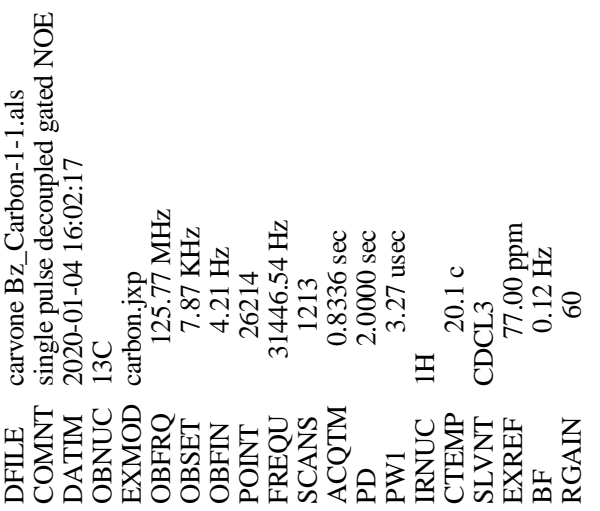
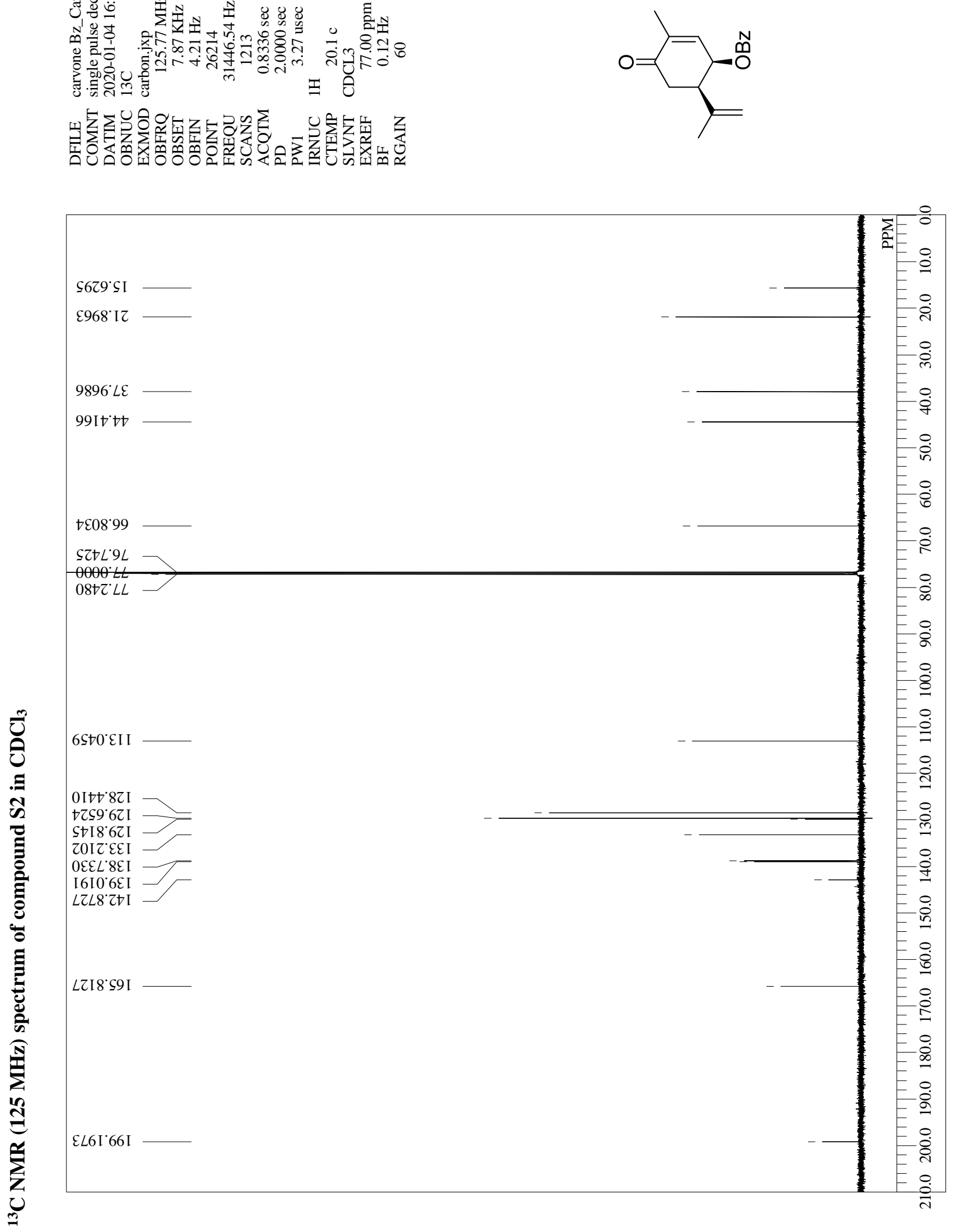

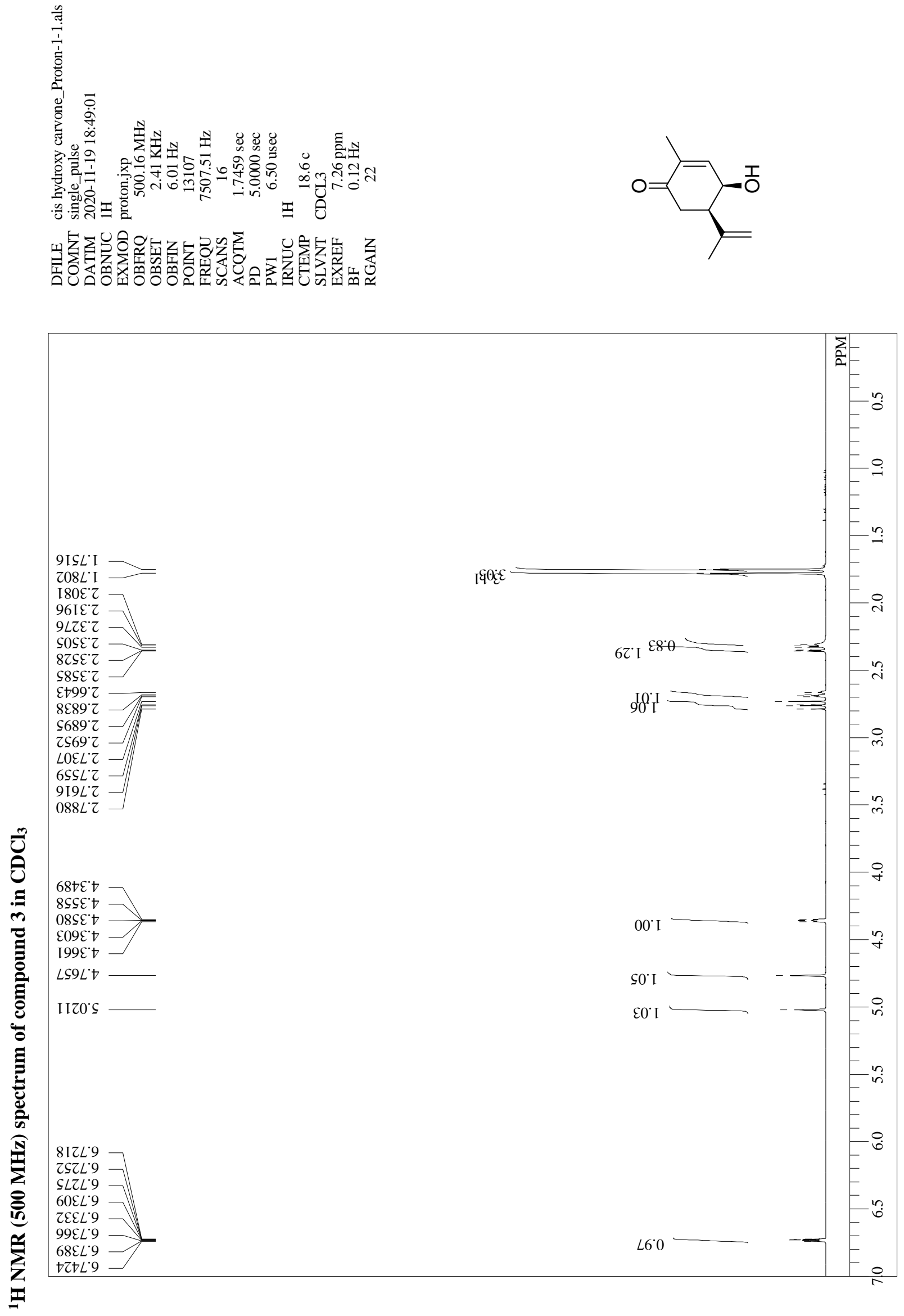
또ํ 됭

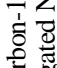

ชี,

官实

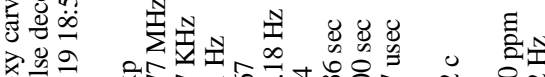

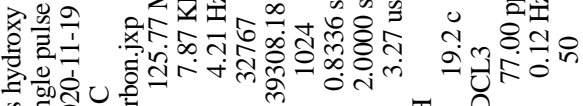

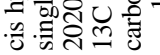

I

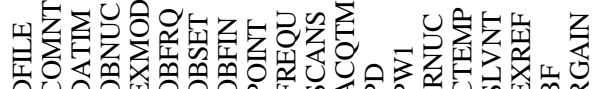

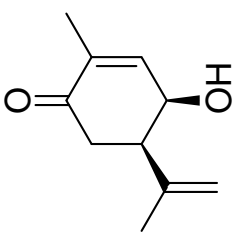

LGEt'SI

$\angle \mathrm{SZG}{ }^{\circ} \mathrm{IZ}$

096 L'9ع

26I8'st

9๕t๋ $\varepsilon 9$

$\mathrm{SZt} \angle{ }^{\circ} 9 \angle$

$0000^{\circ} \angle L$

$08 \nabla Z " L L$

ZtLZ゙ELI

ช

2tzeti

를

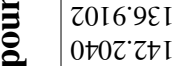

히 $z S z 99^{\circ} \varepsilon t I$

U⿺辶寸

IE98*66I - 

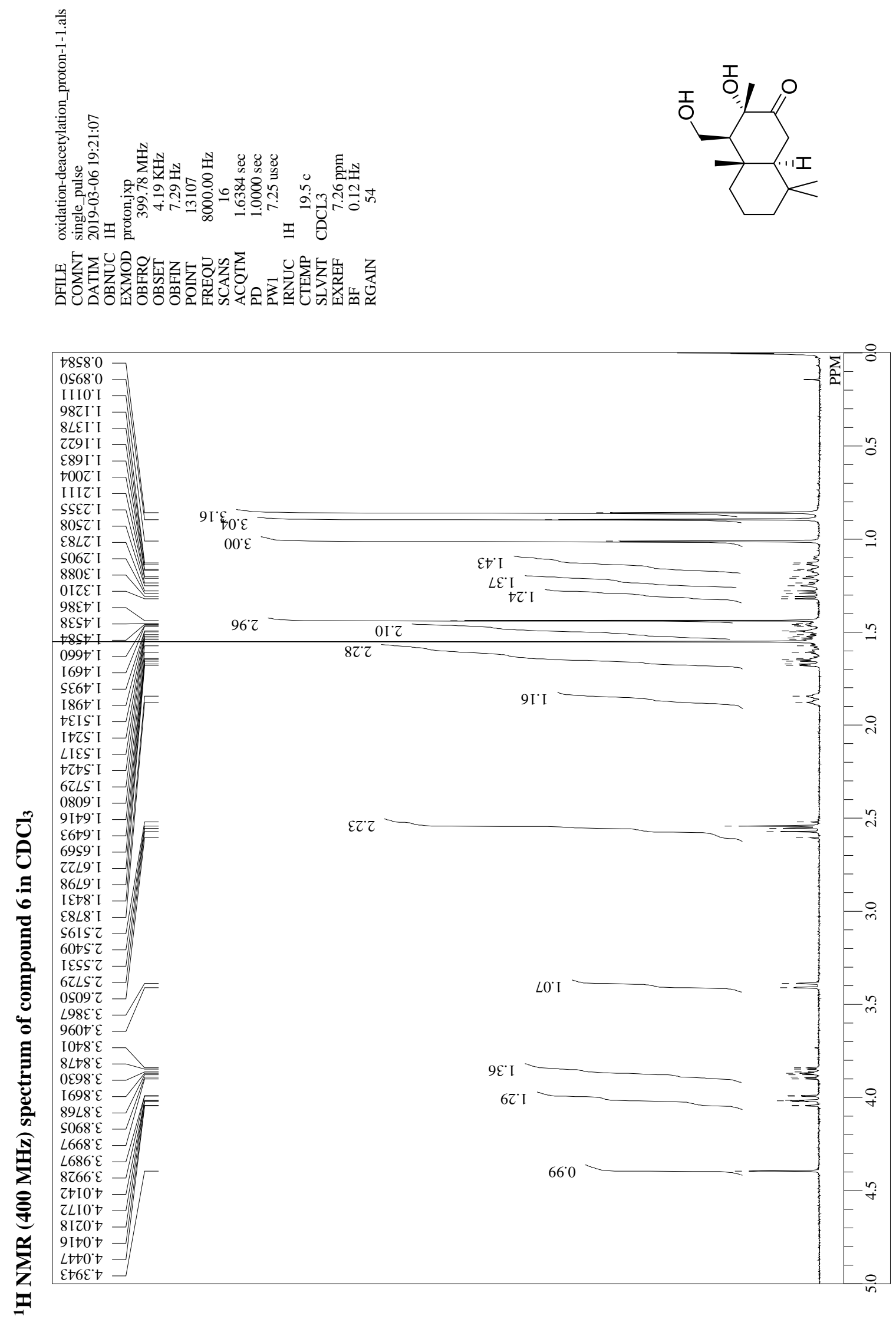

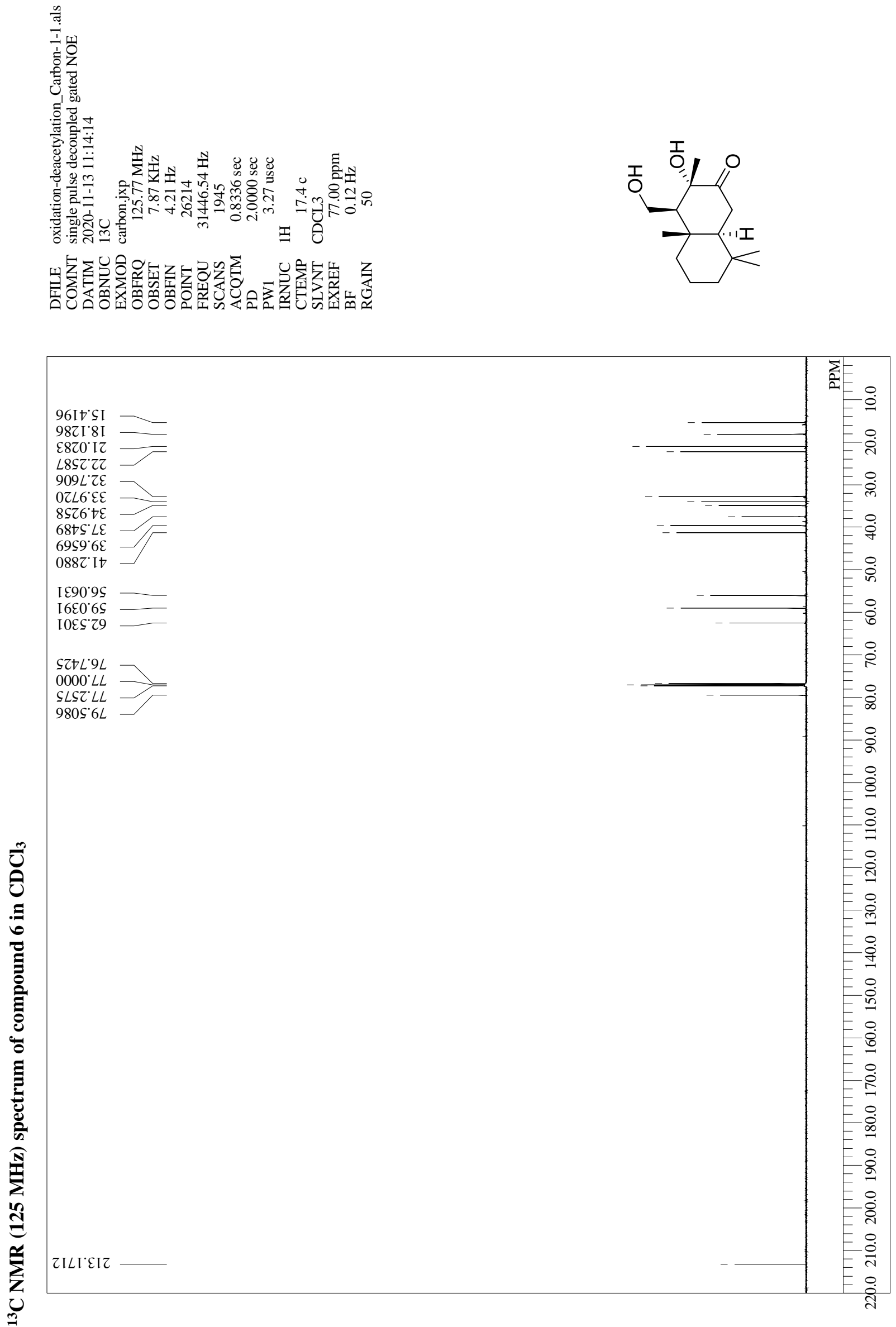

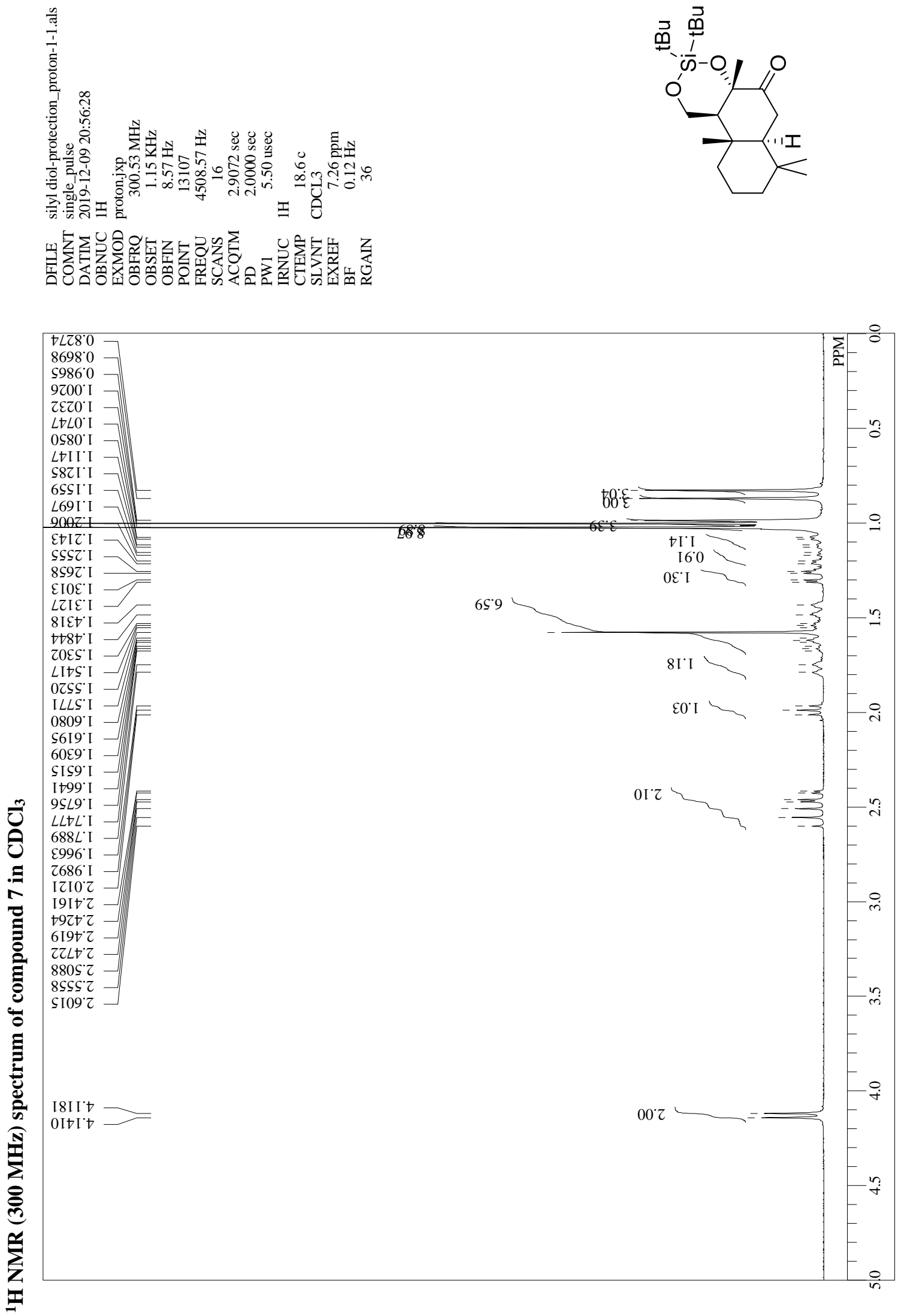


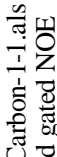

히류

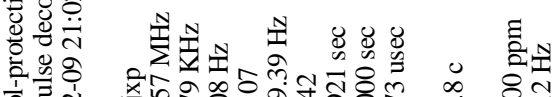

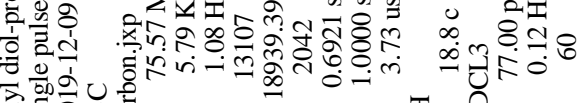

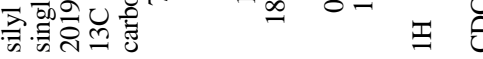

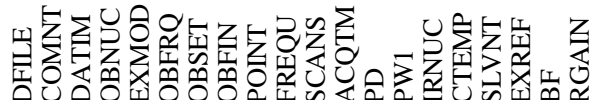
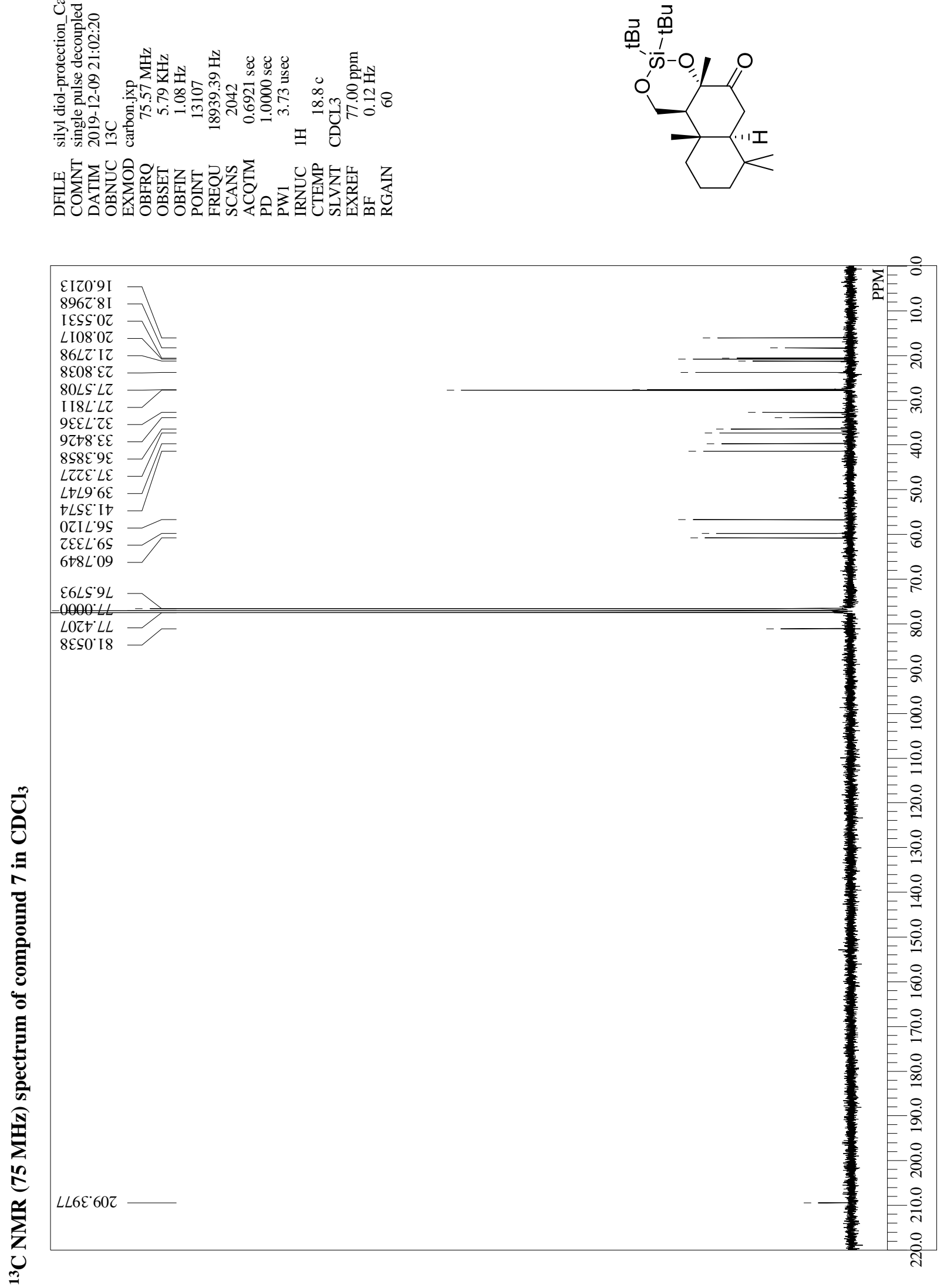

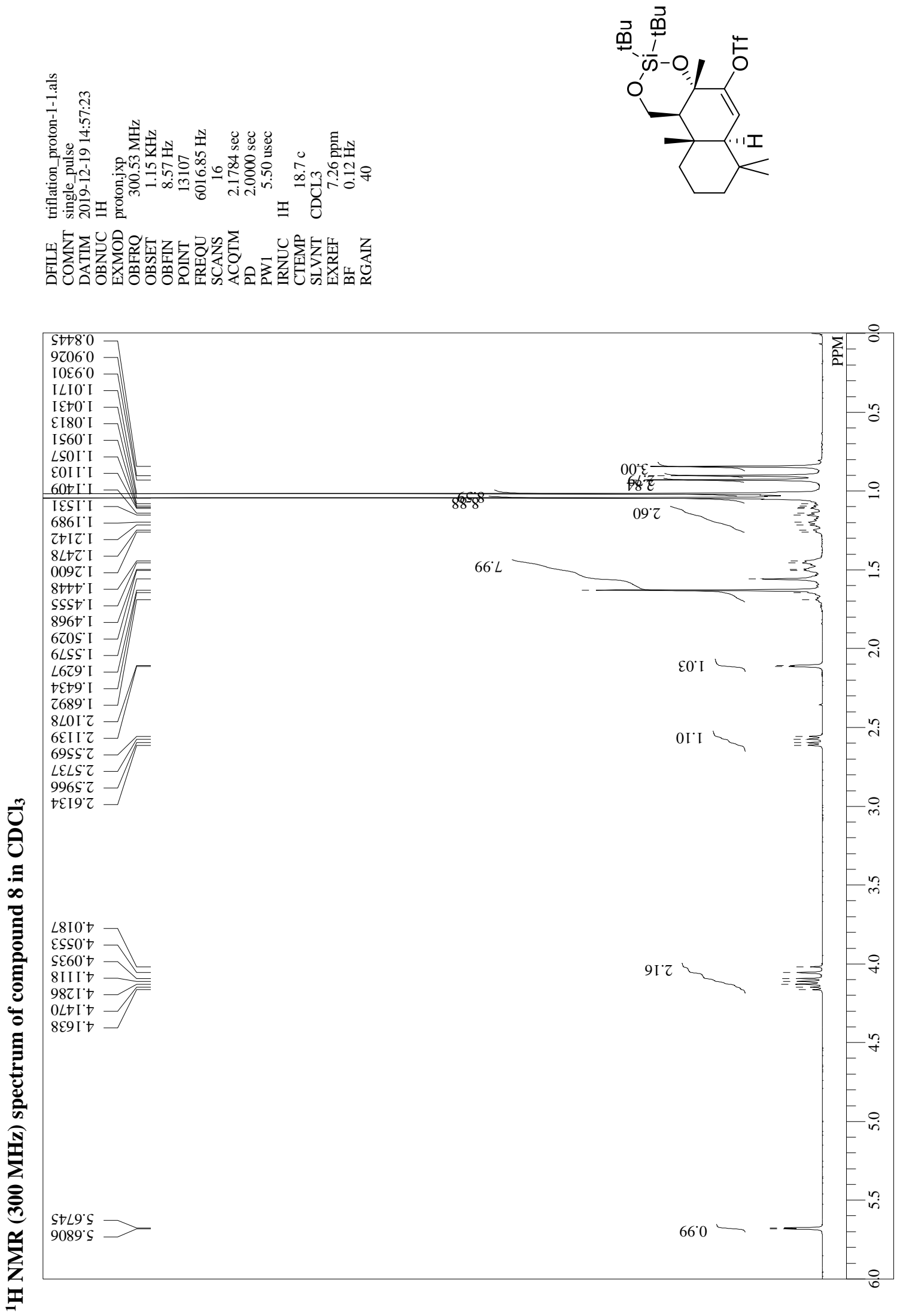

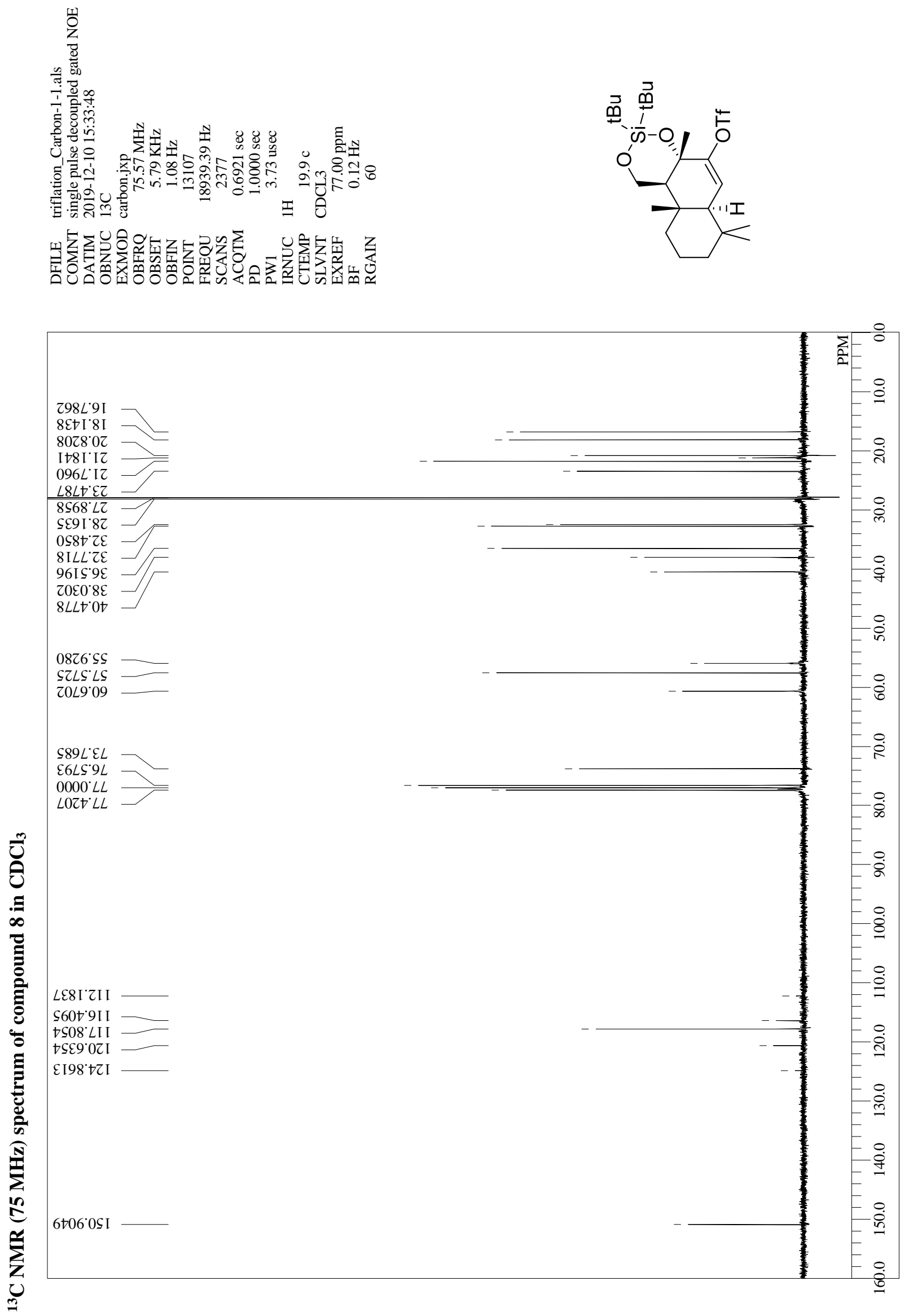

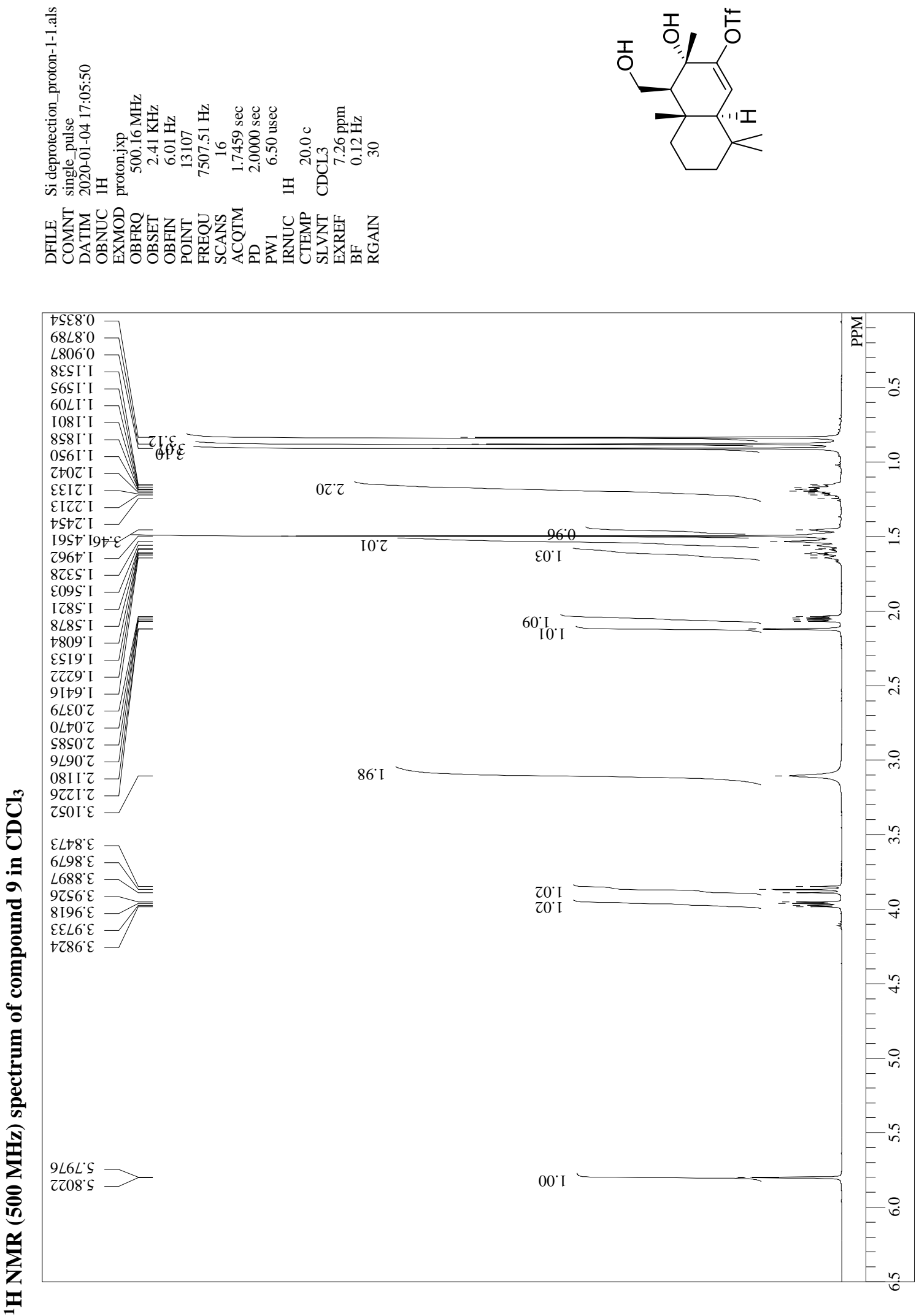

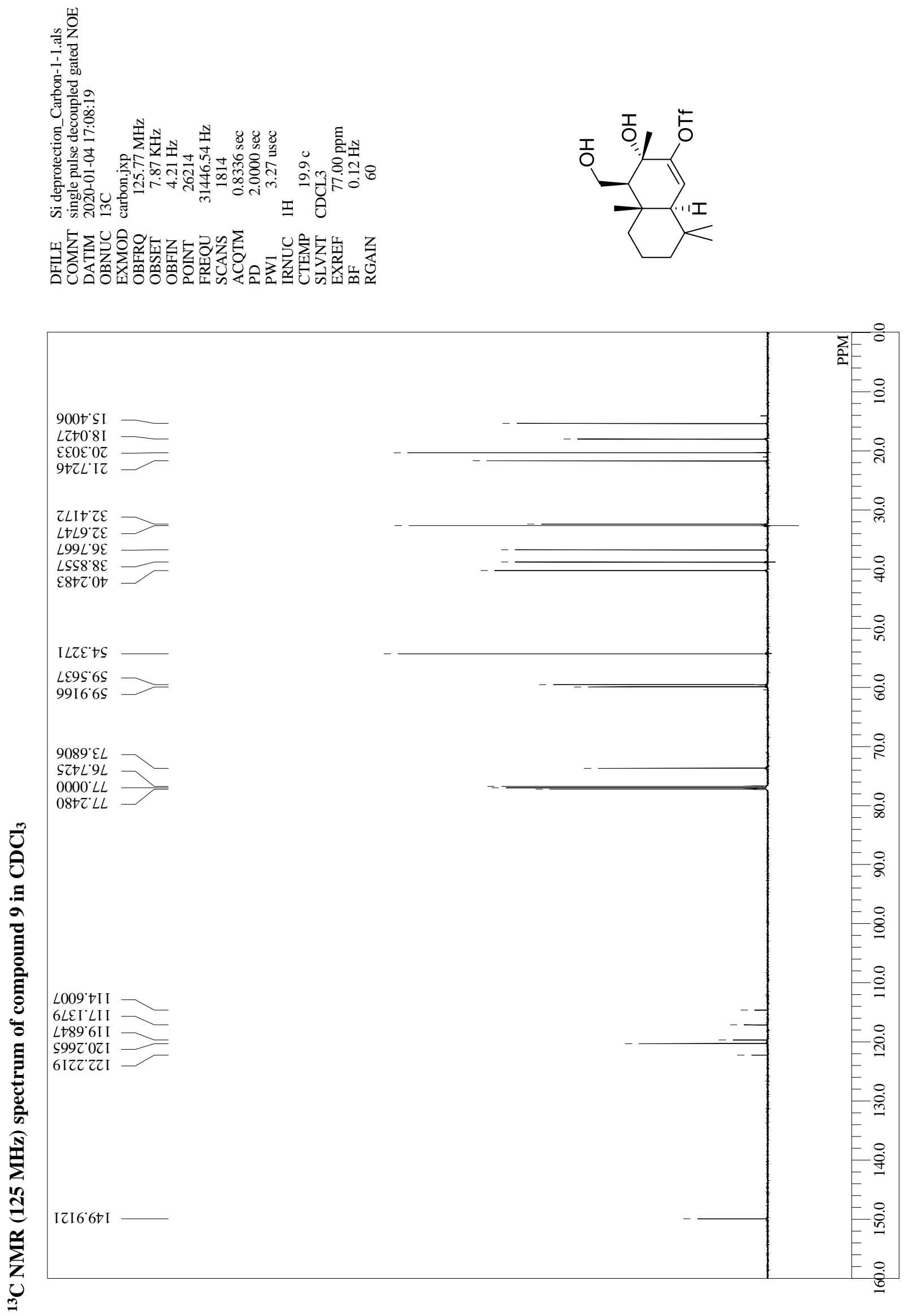
节

蒿

菅

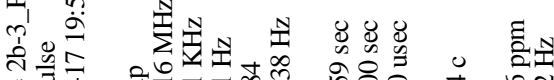

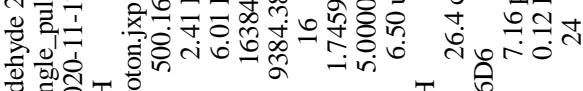

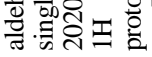

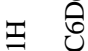

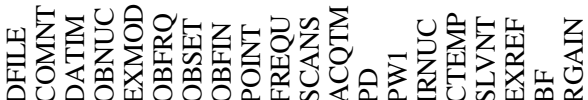
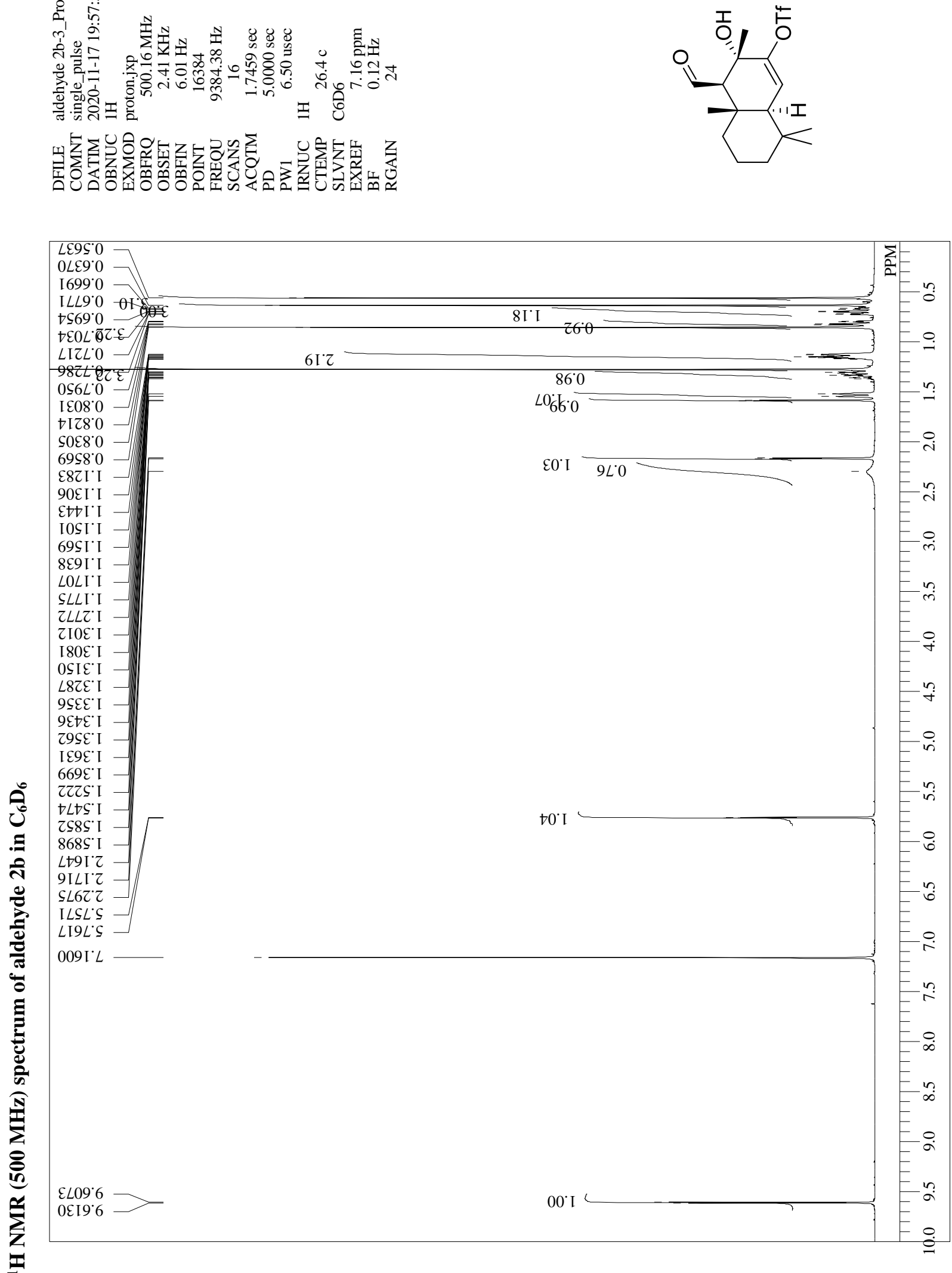


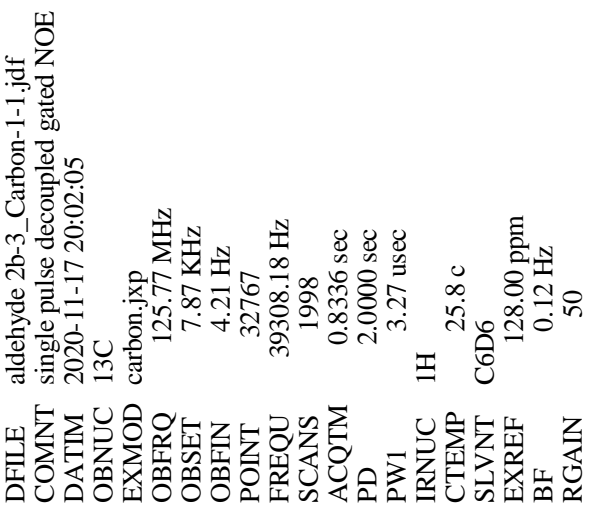
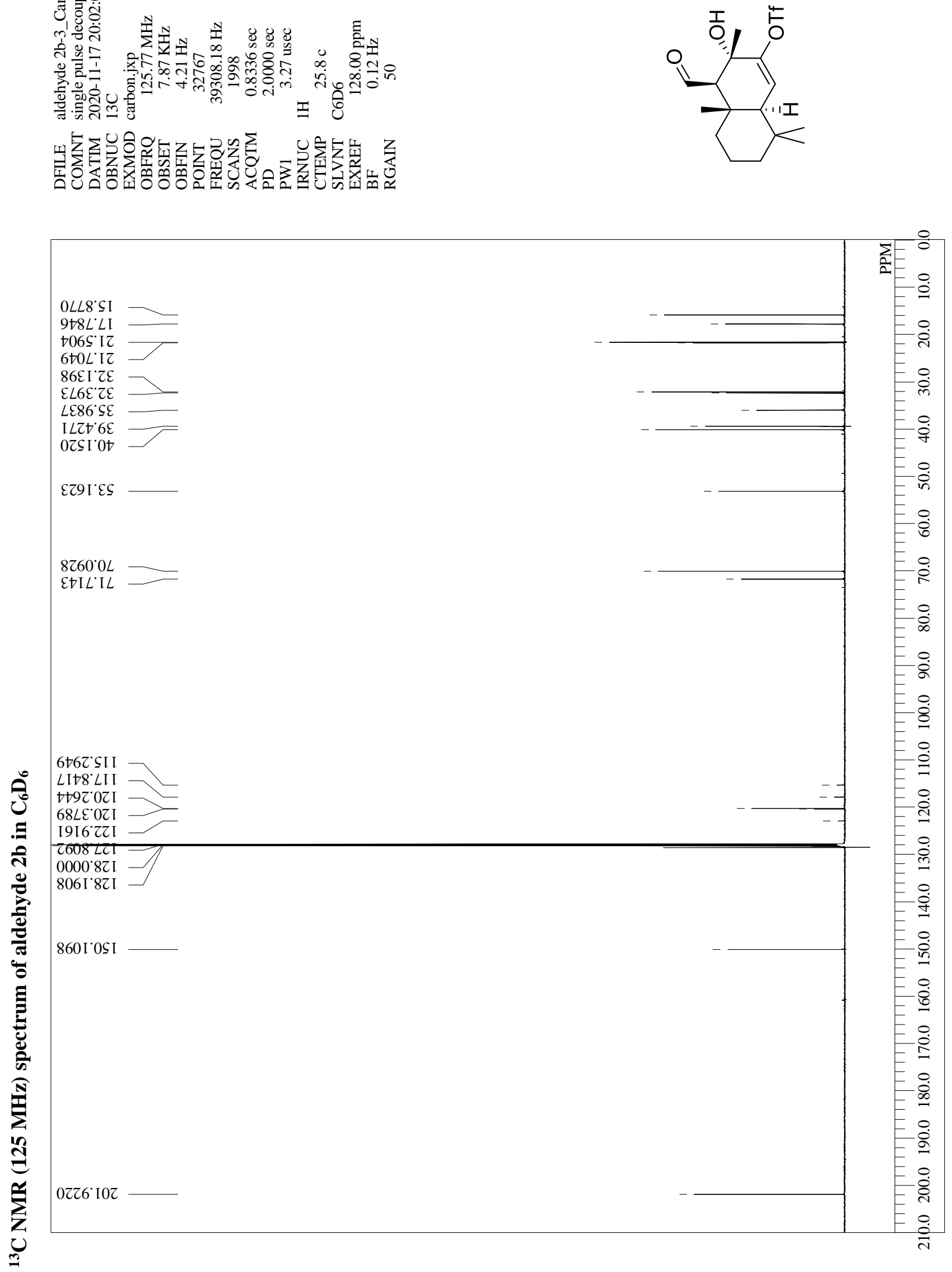


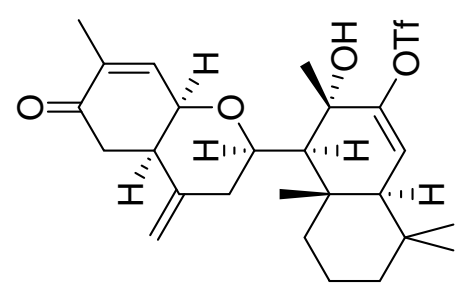

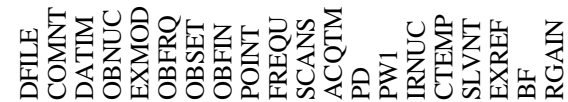

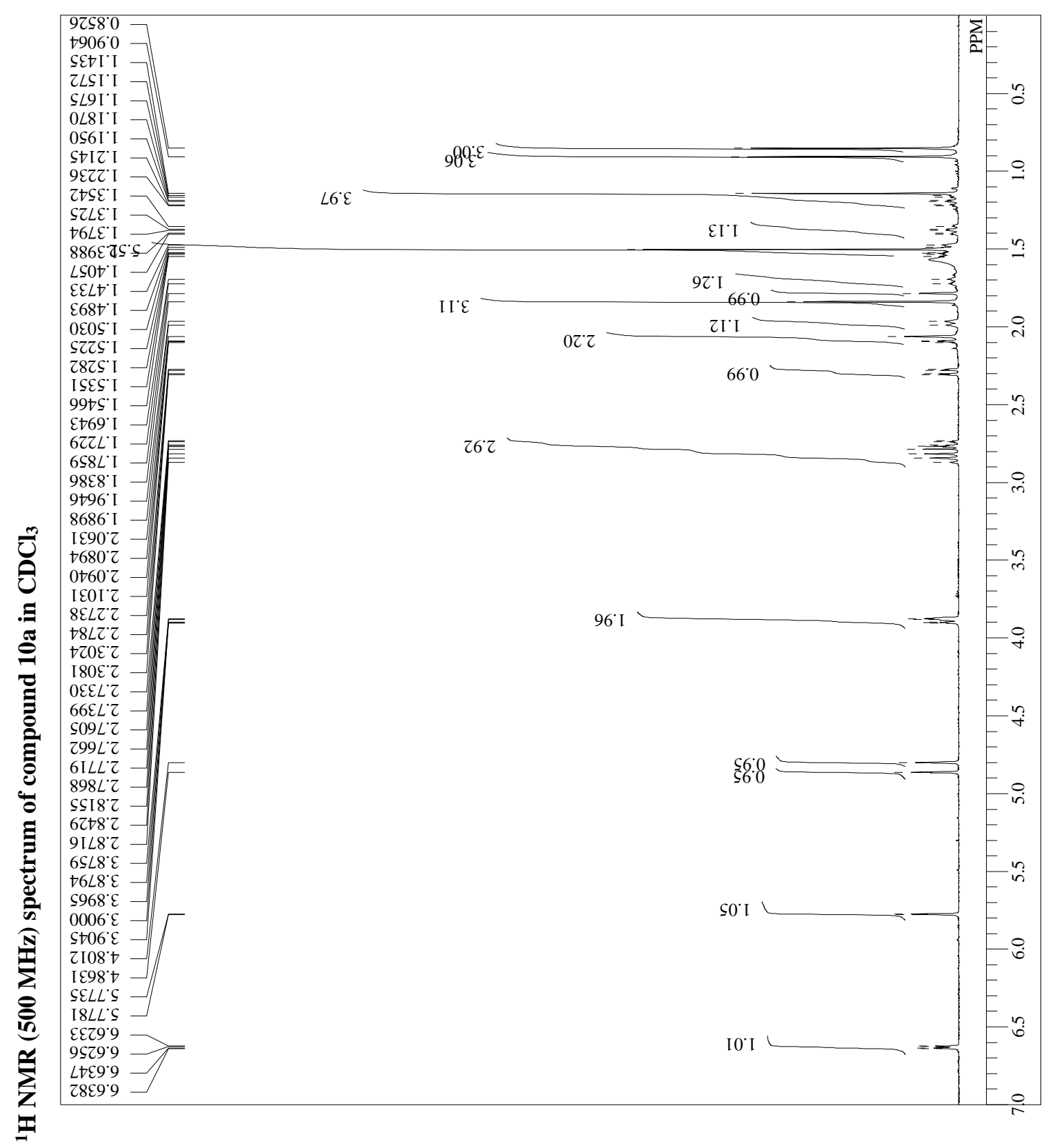



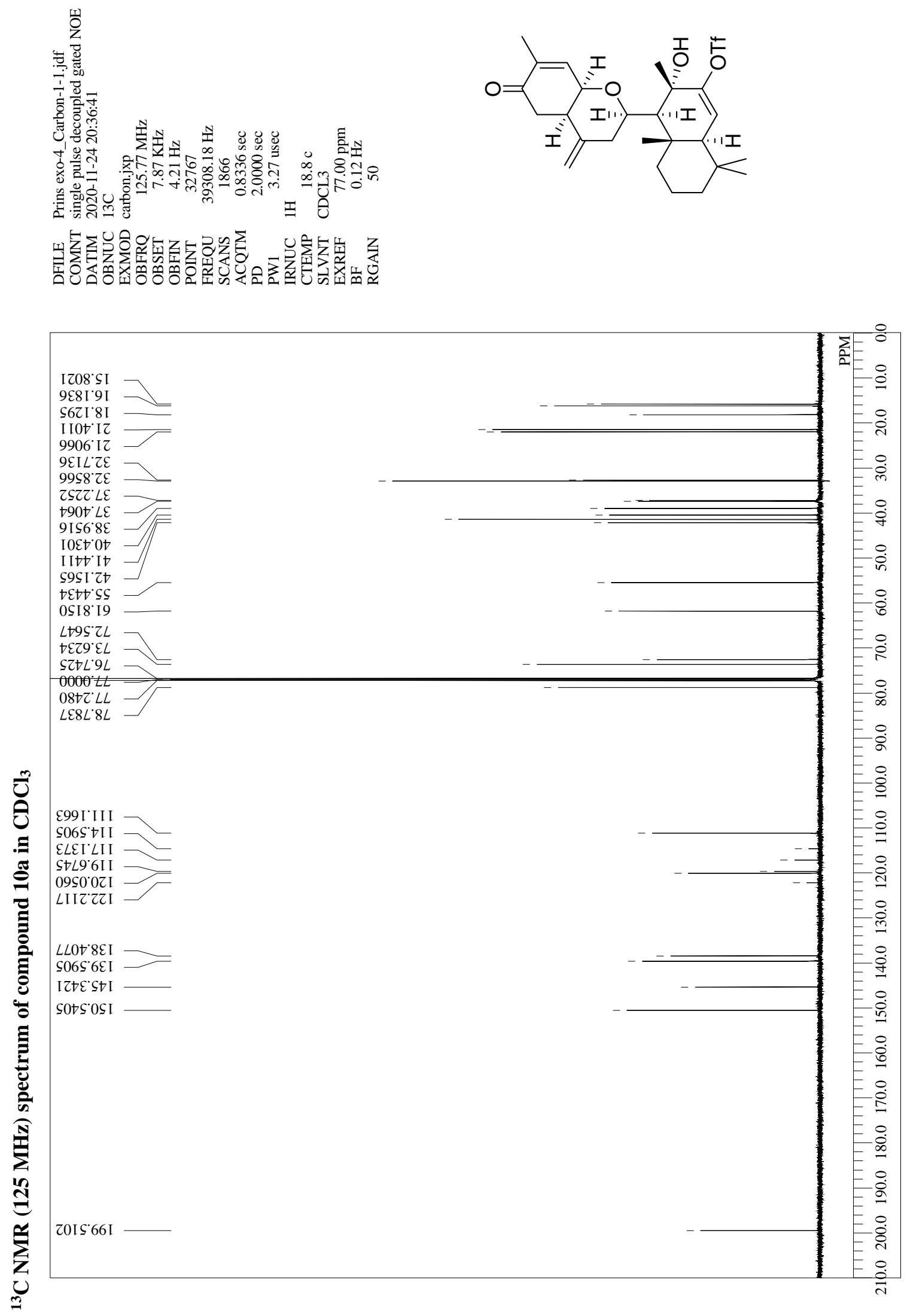


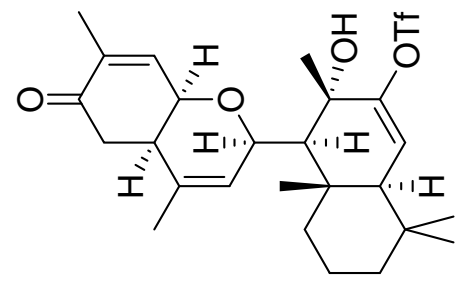

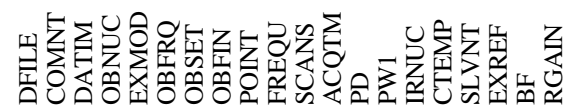

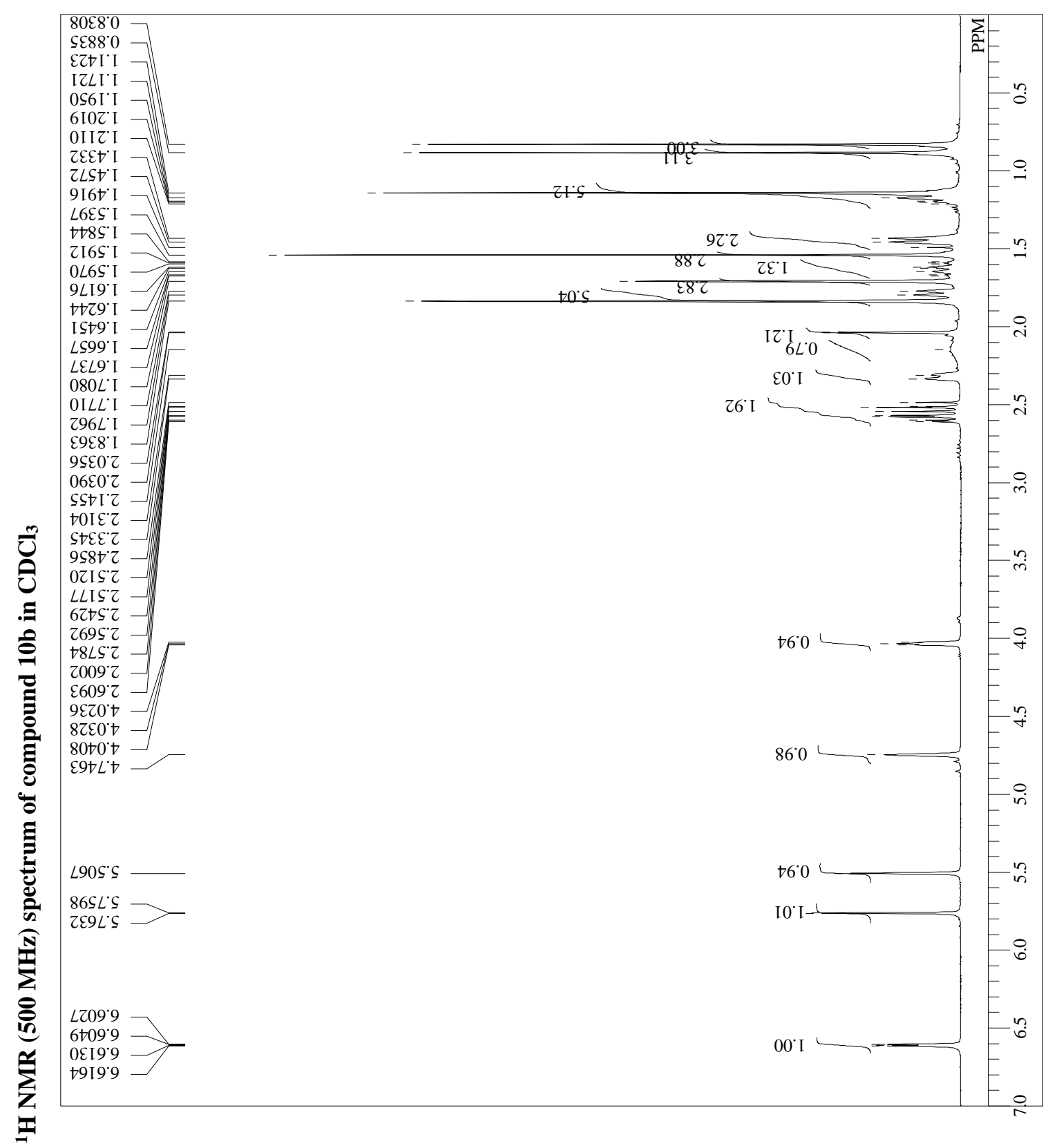



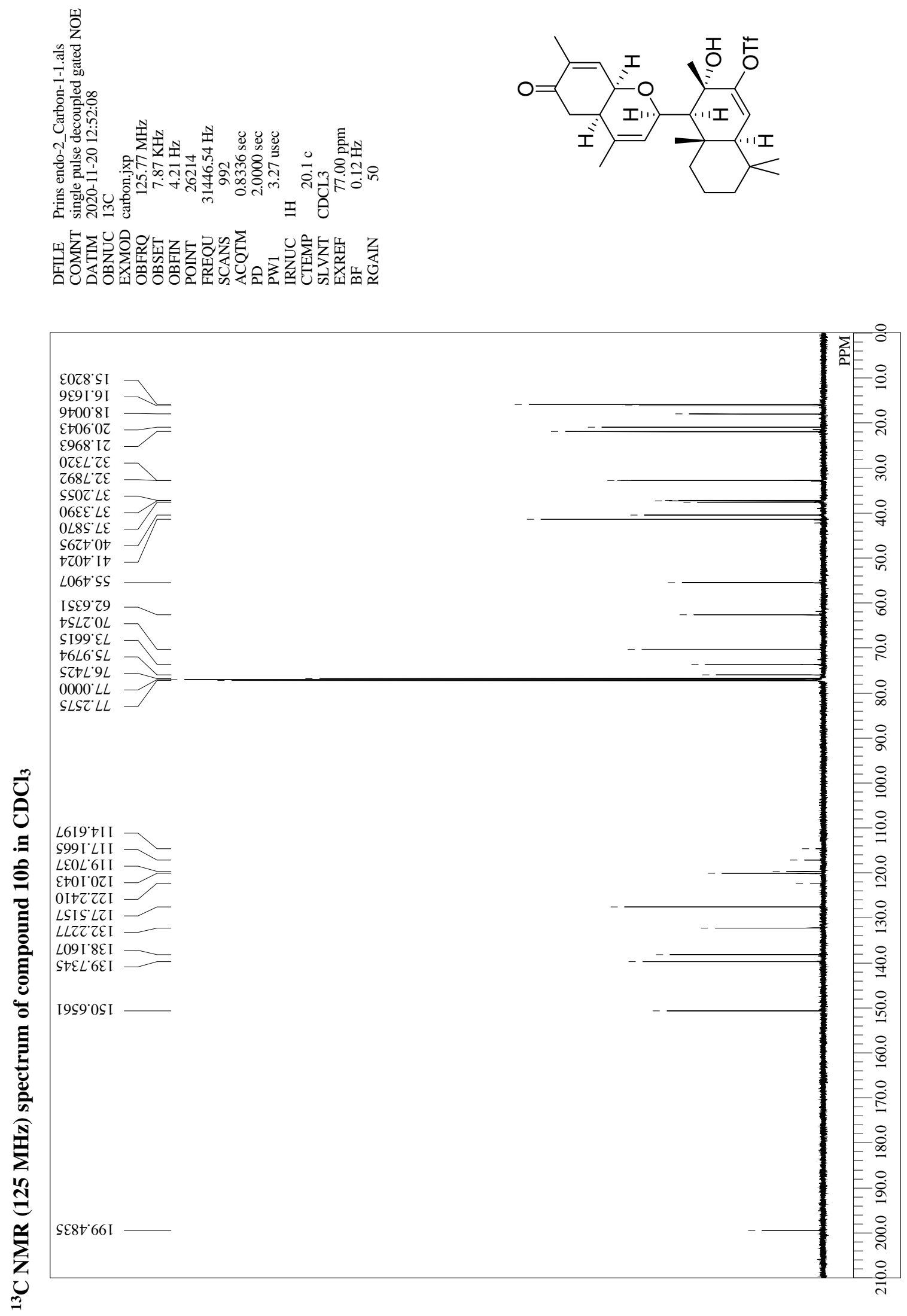

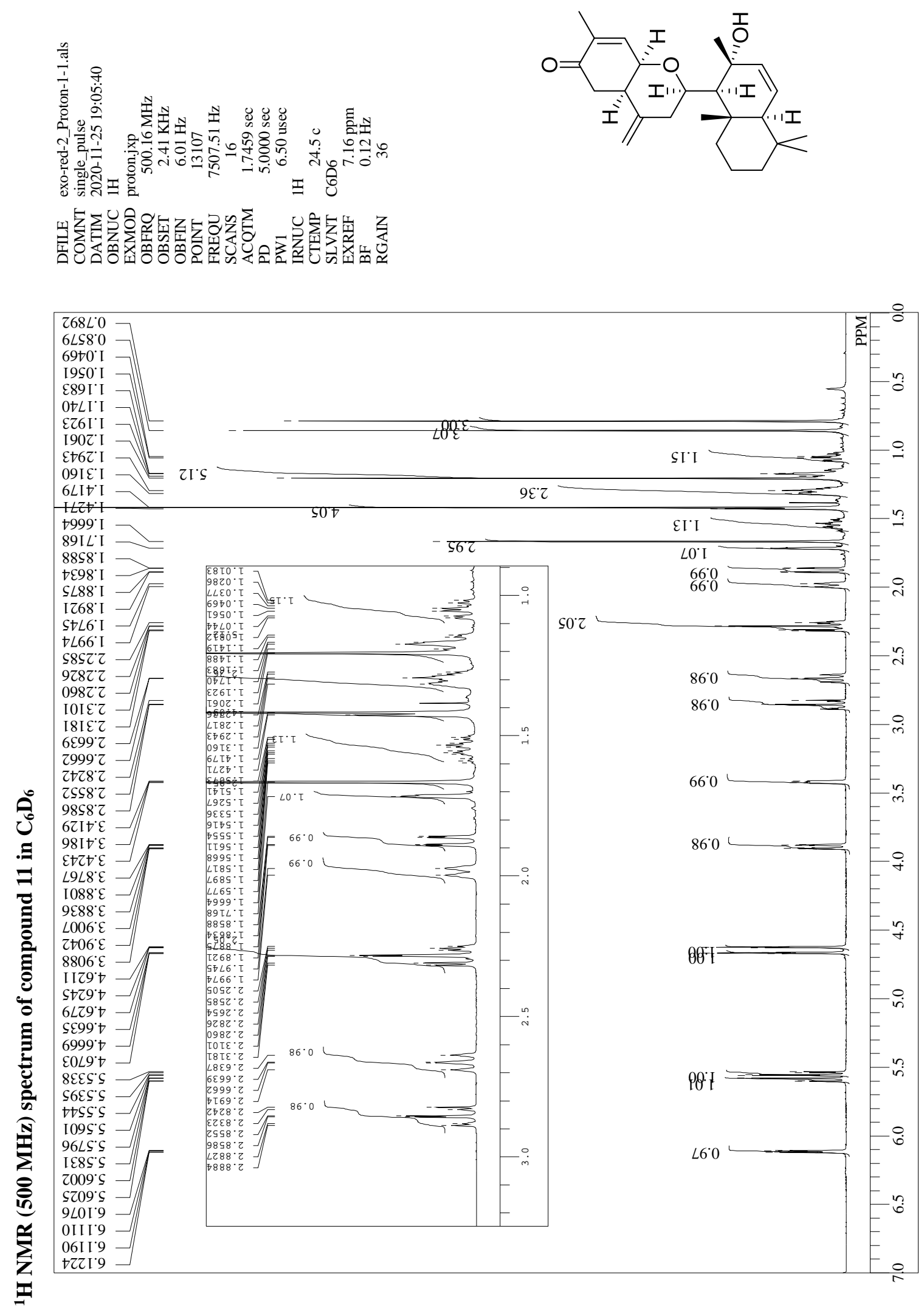

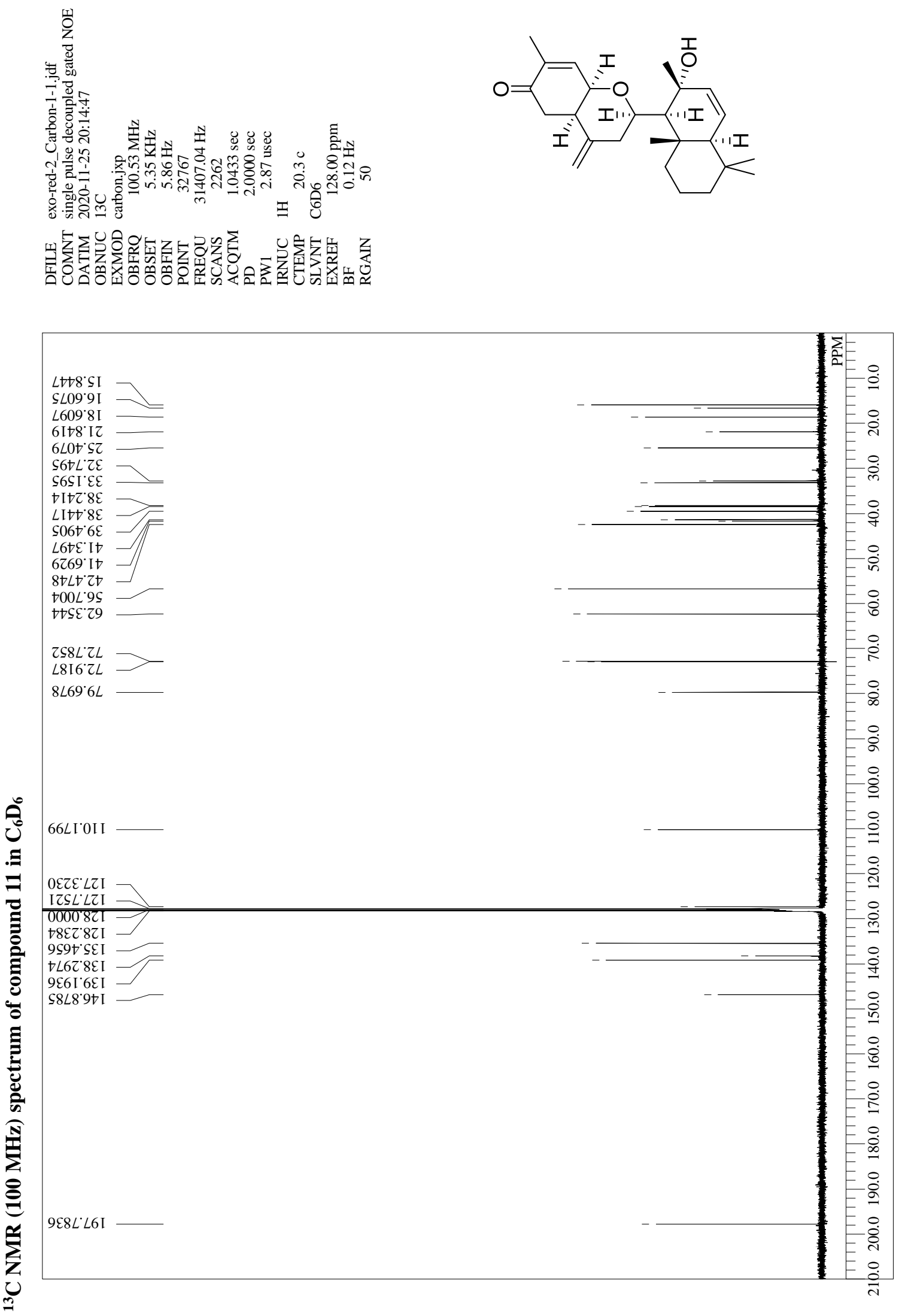

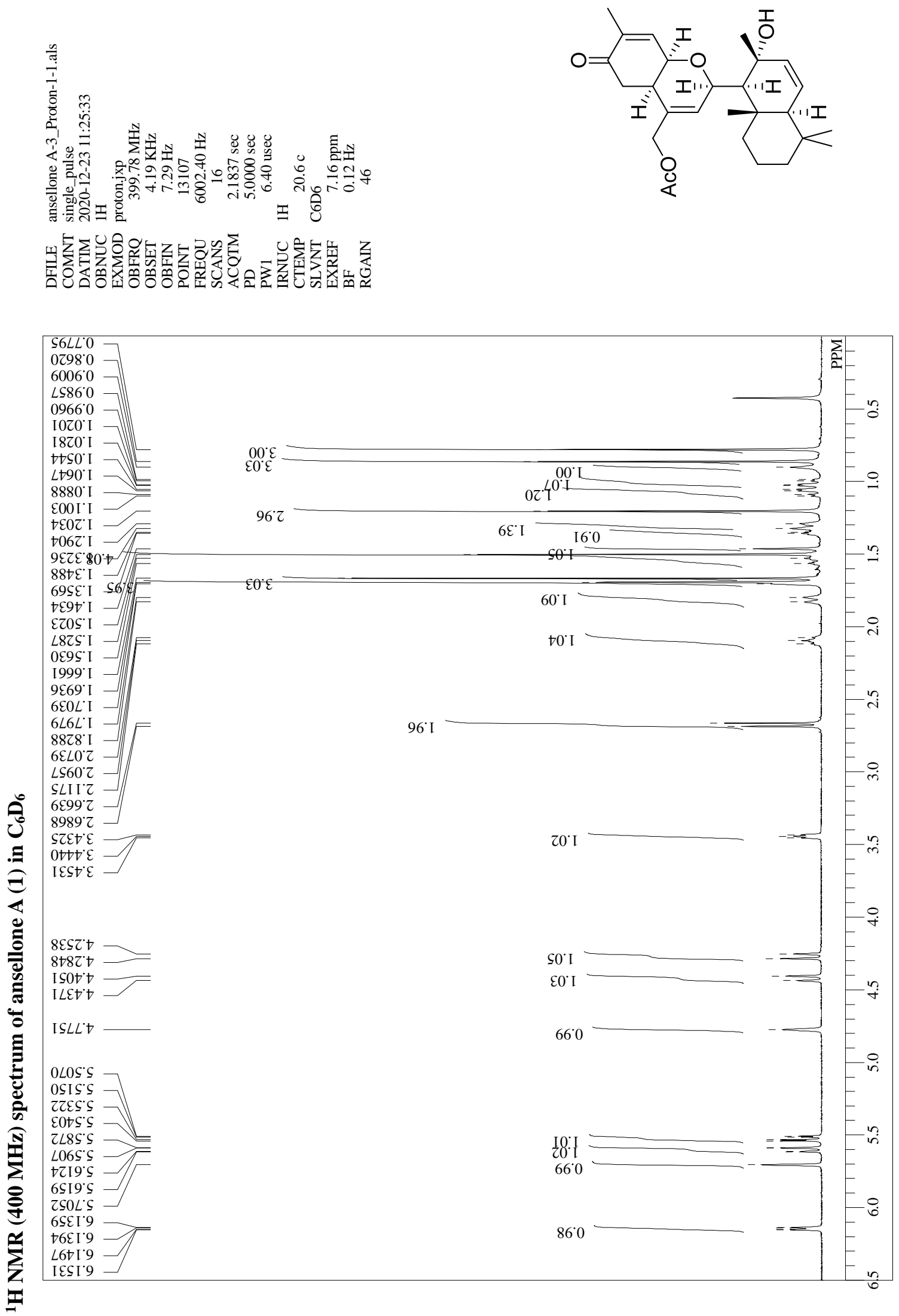
氜

总气

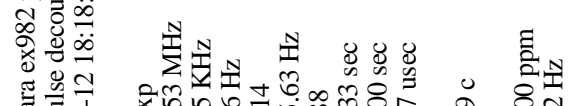

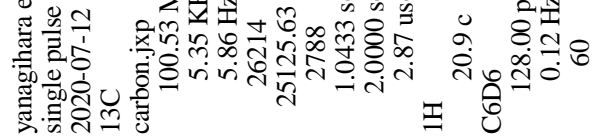

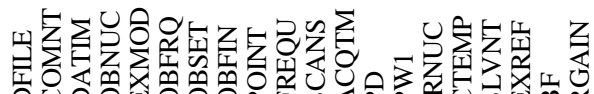
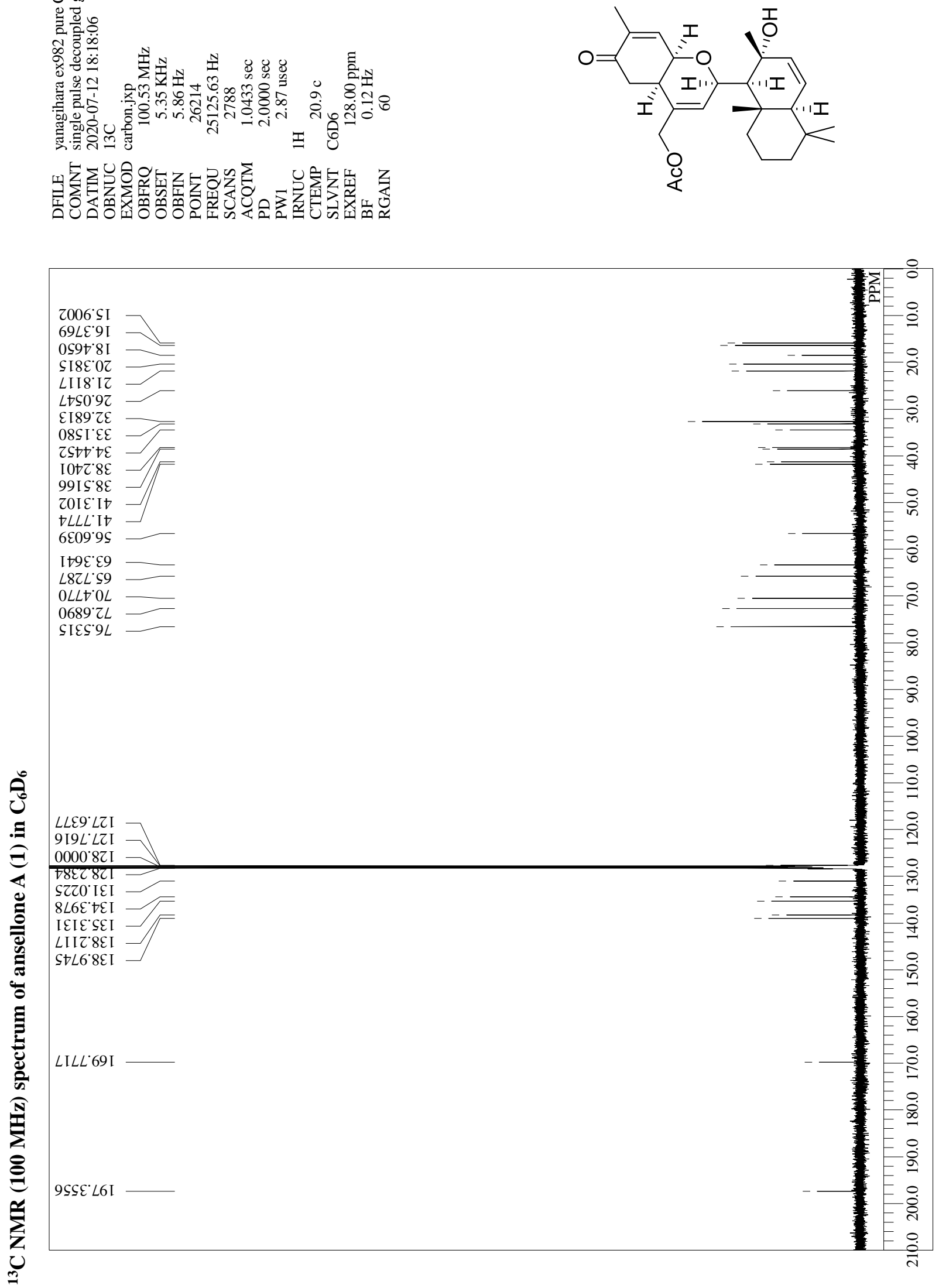

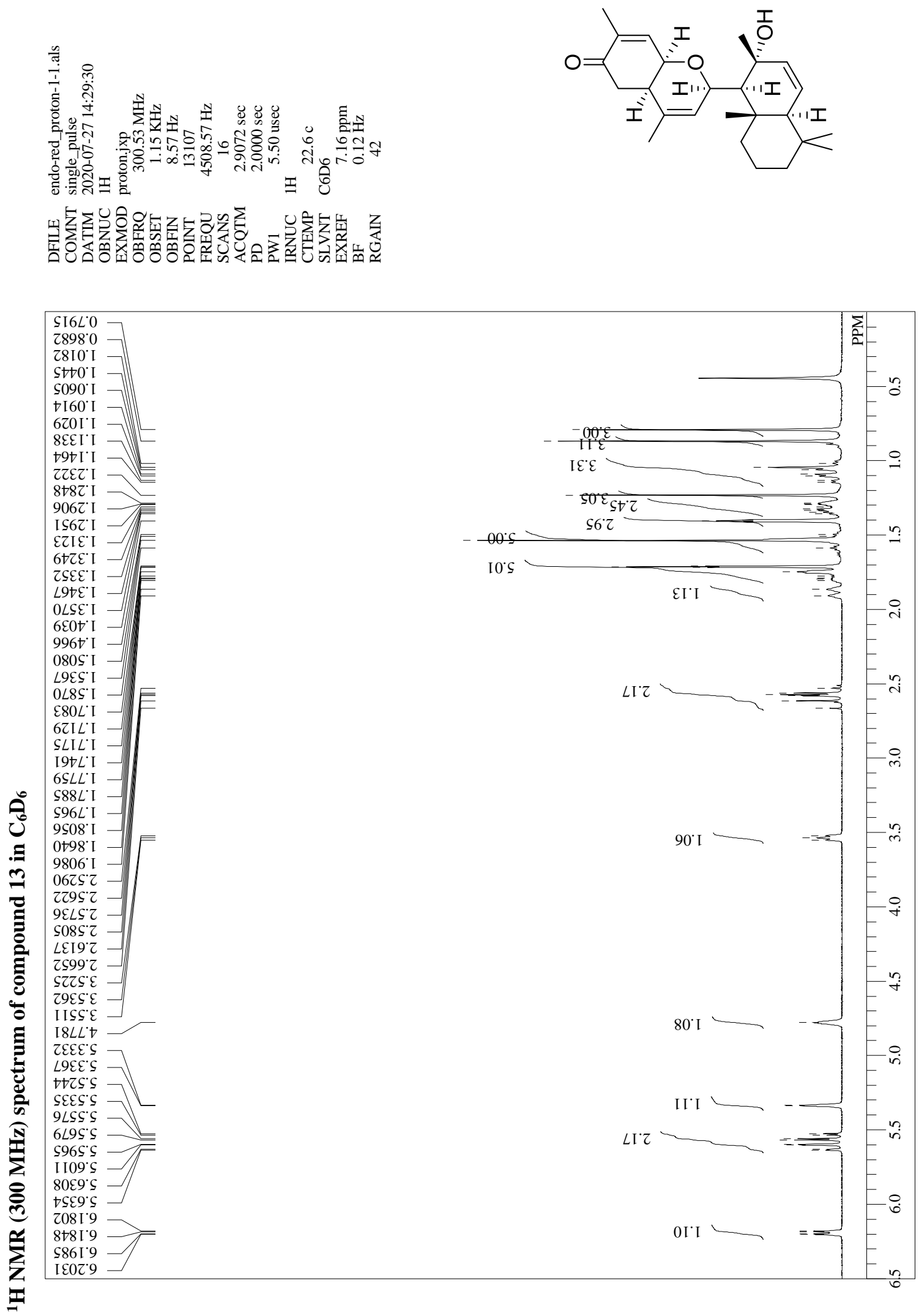

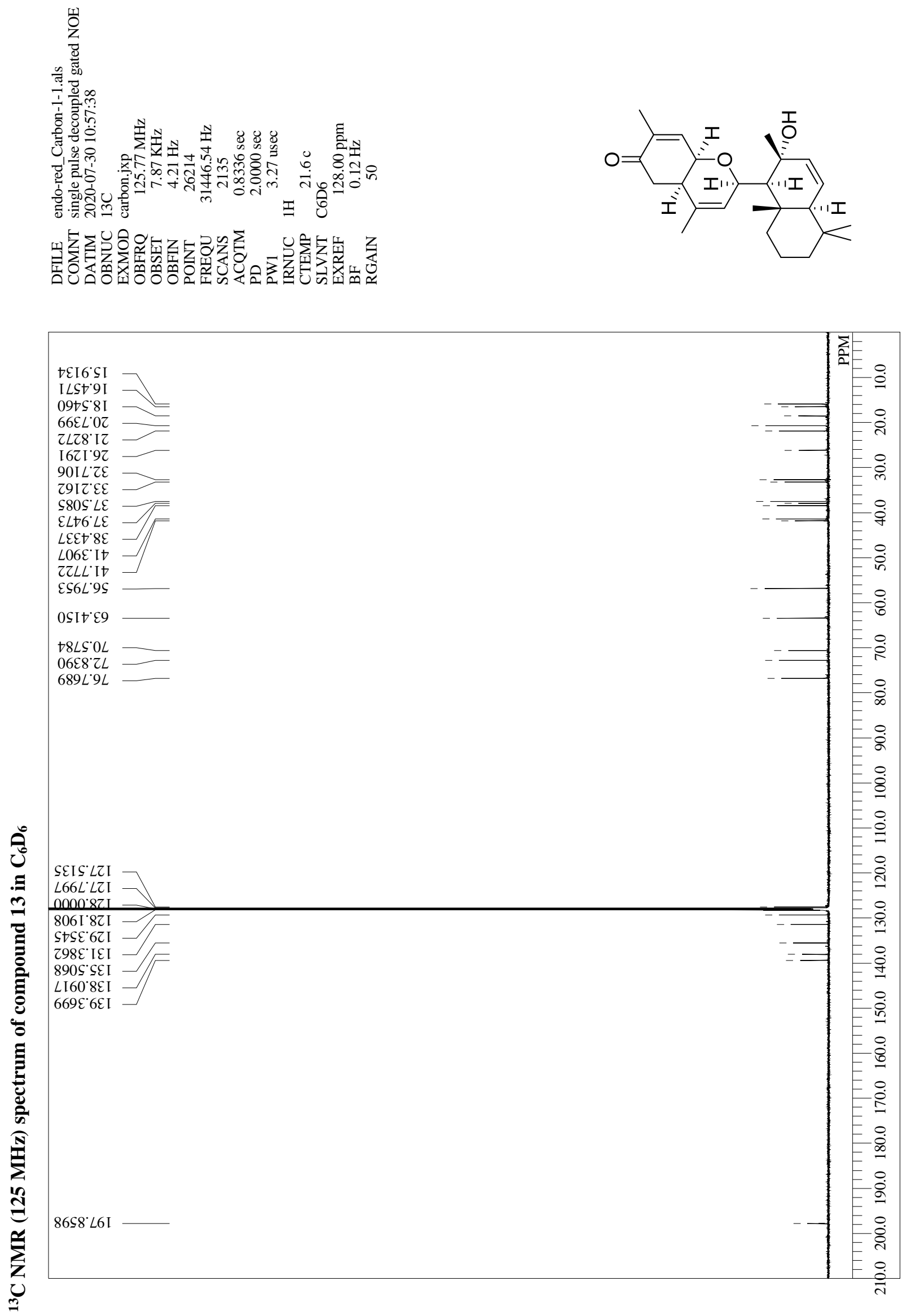

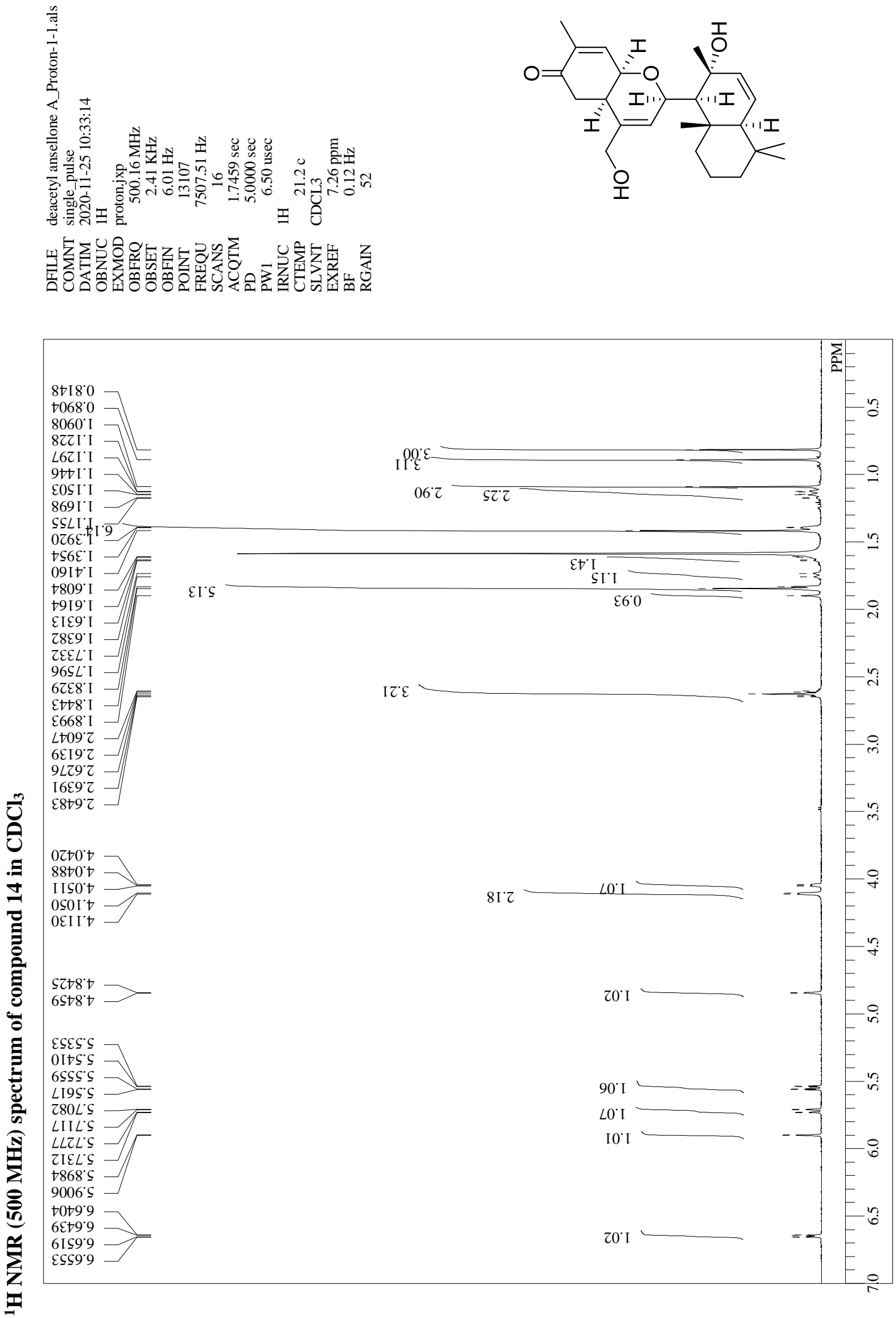

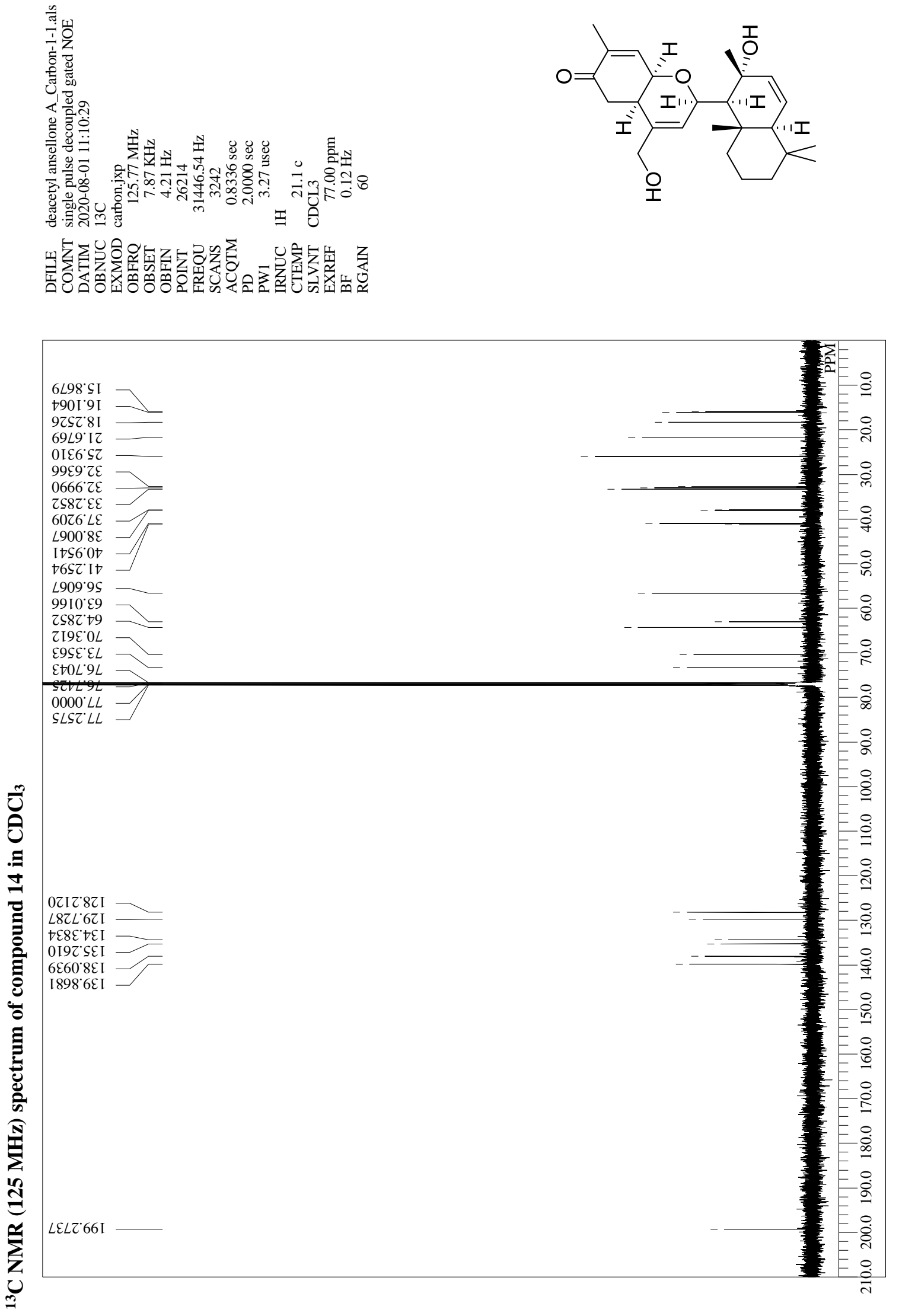

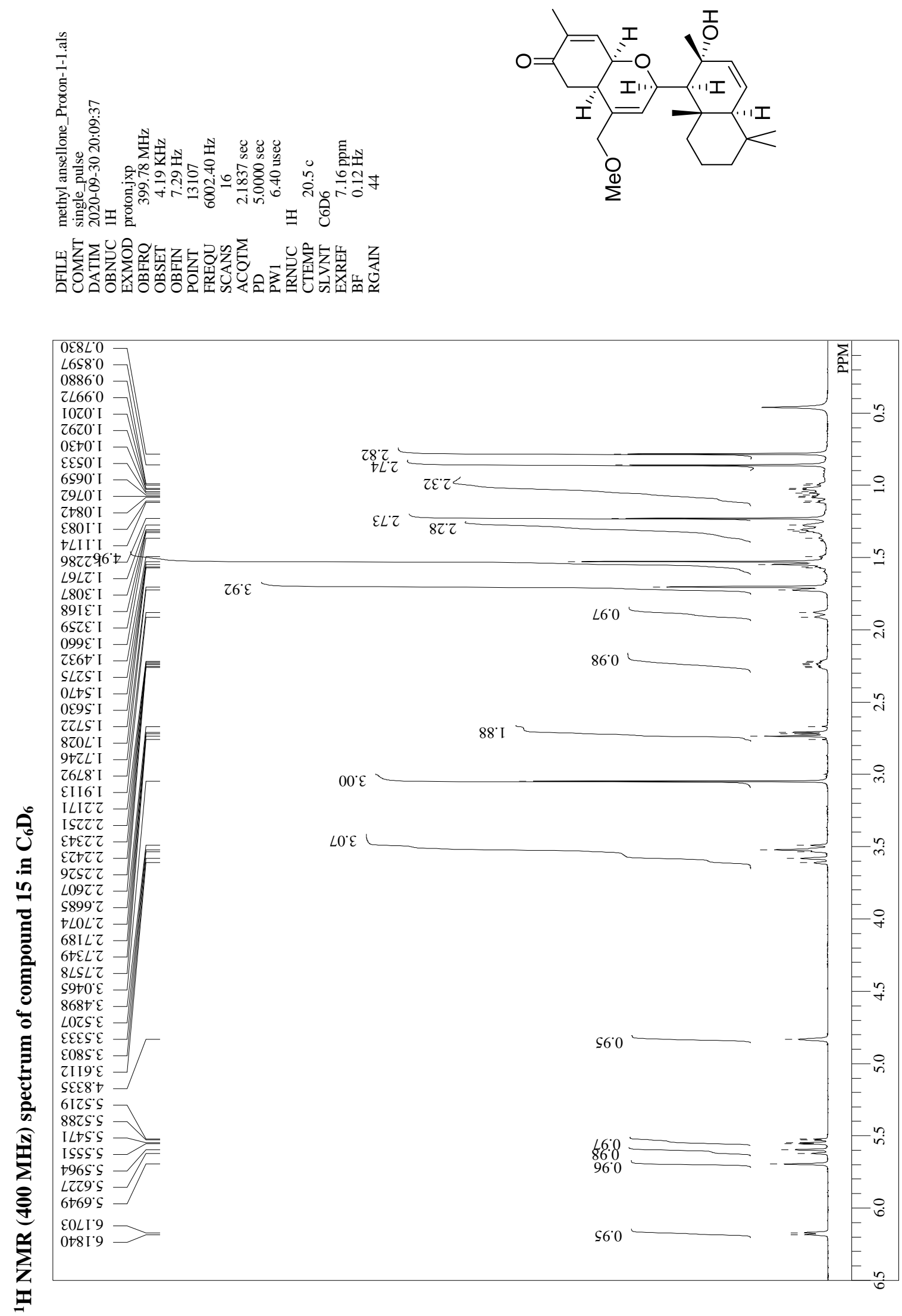


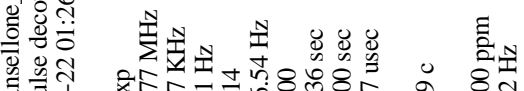

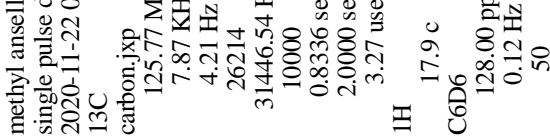

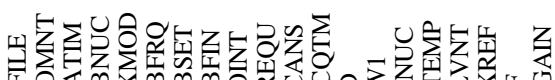

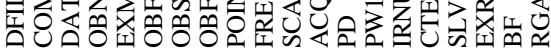
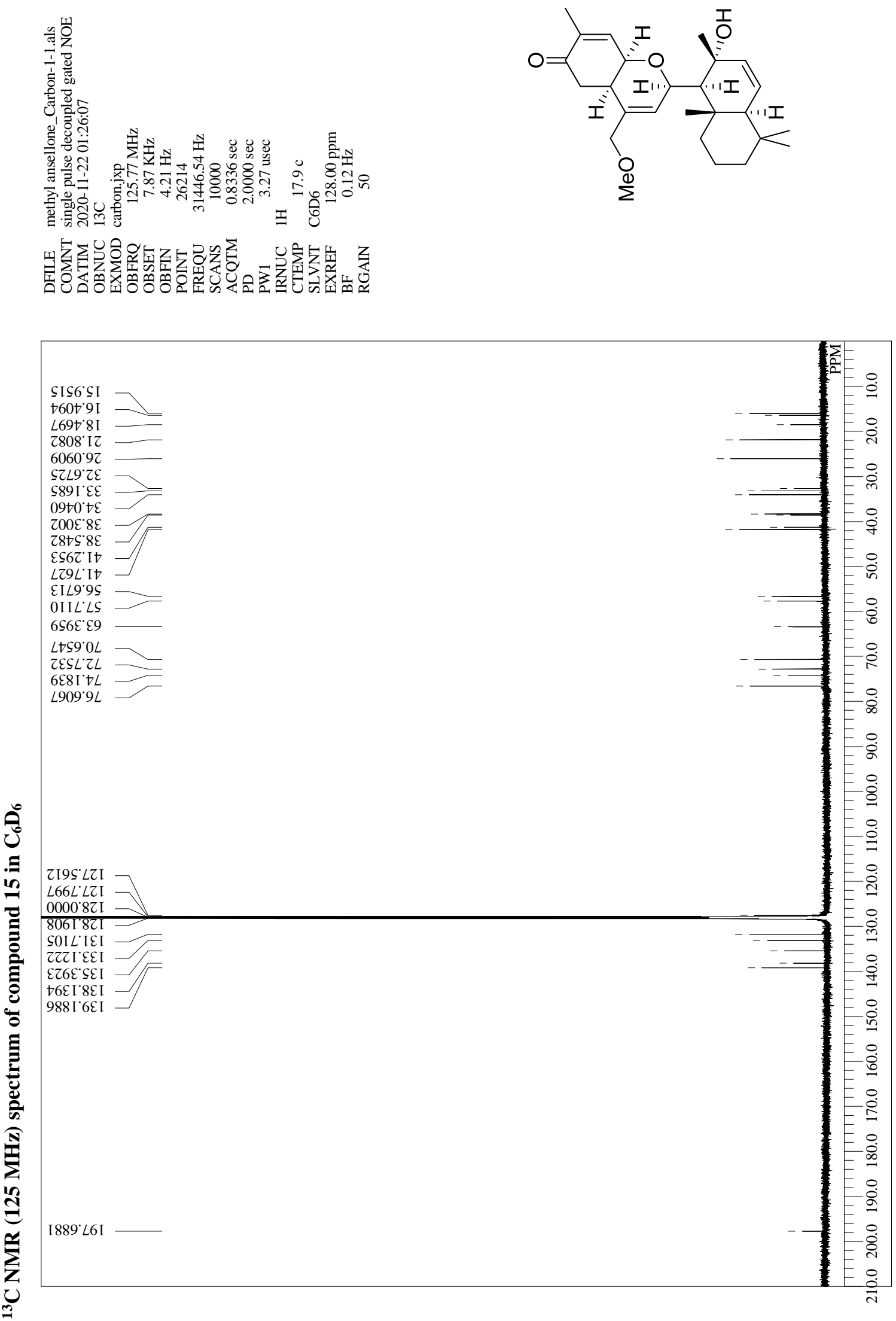


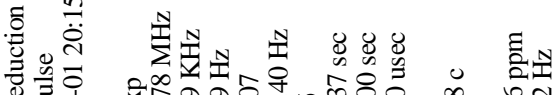

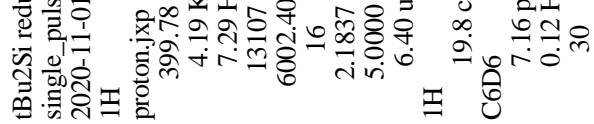

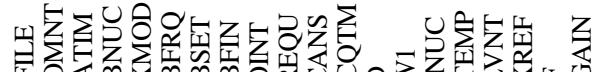

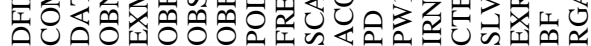
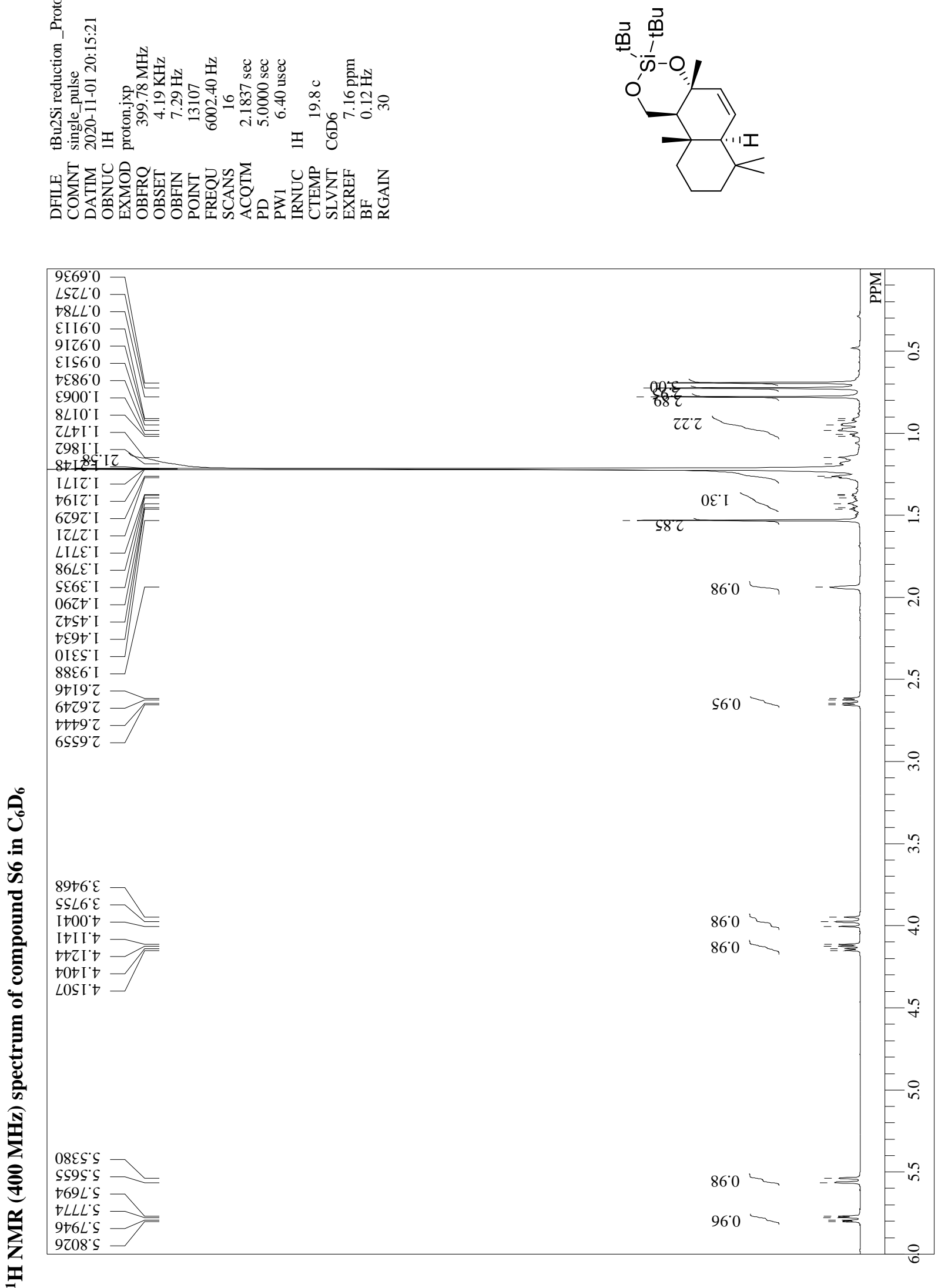
ㄸํㅇ

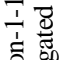

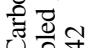

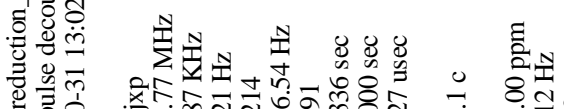

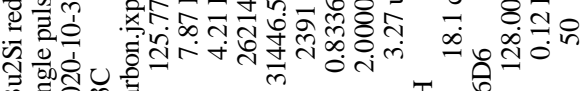

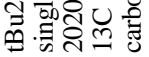

I

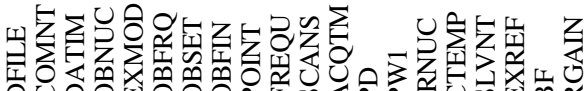

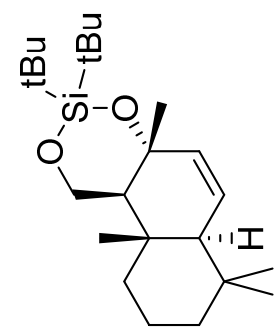

98E8 9 I

9869.8I

จIZI'TZ

SZIS"IZ

$6979^{\circ}$ IZ

EII6"92

z七0९: 82

9998.82

$8 \div 79 \cdot z \varepsilon$

$6 \angle 9 \angle Z Z \varepsilon$

$\varepsilon 6 \angle 0^{\circ} \angle \varepsilon$

$\angle L E 6^{\circ} \angle \varepsilon$

E990' It

Z9LL'9S

ItS8: $\angle S$

IE6S" โ9

9IS8 $\bullet L$

คి

$6679^{\circ} \mathrm{SEL}$

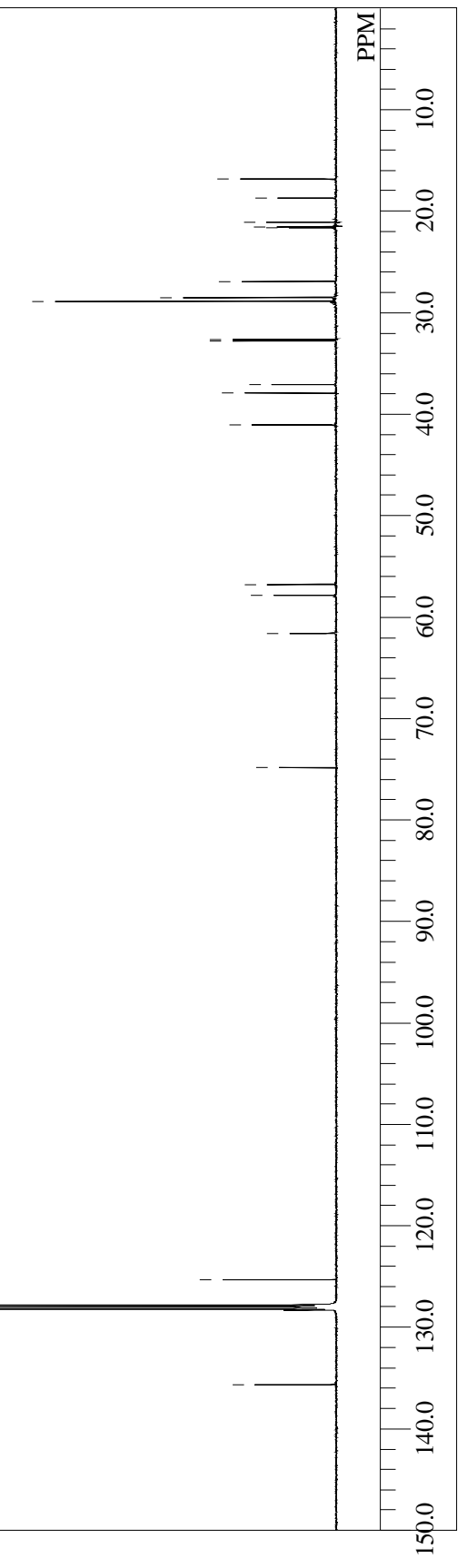



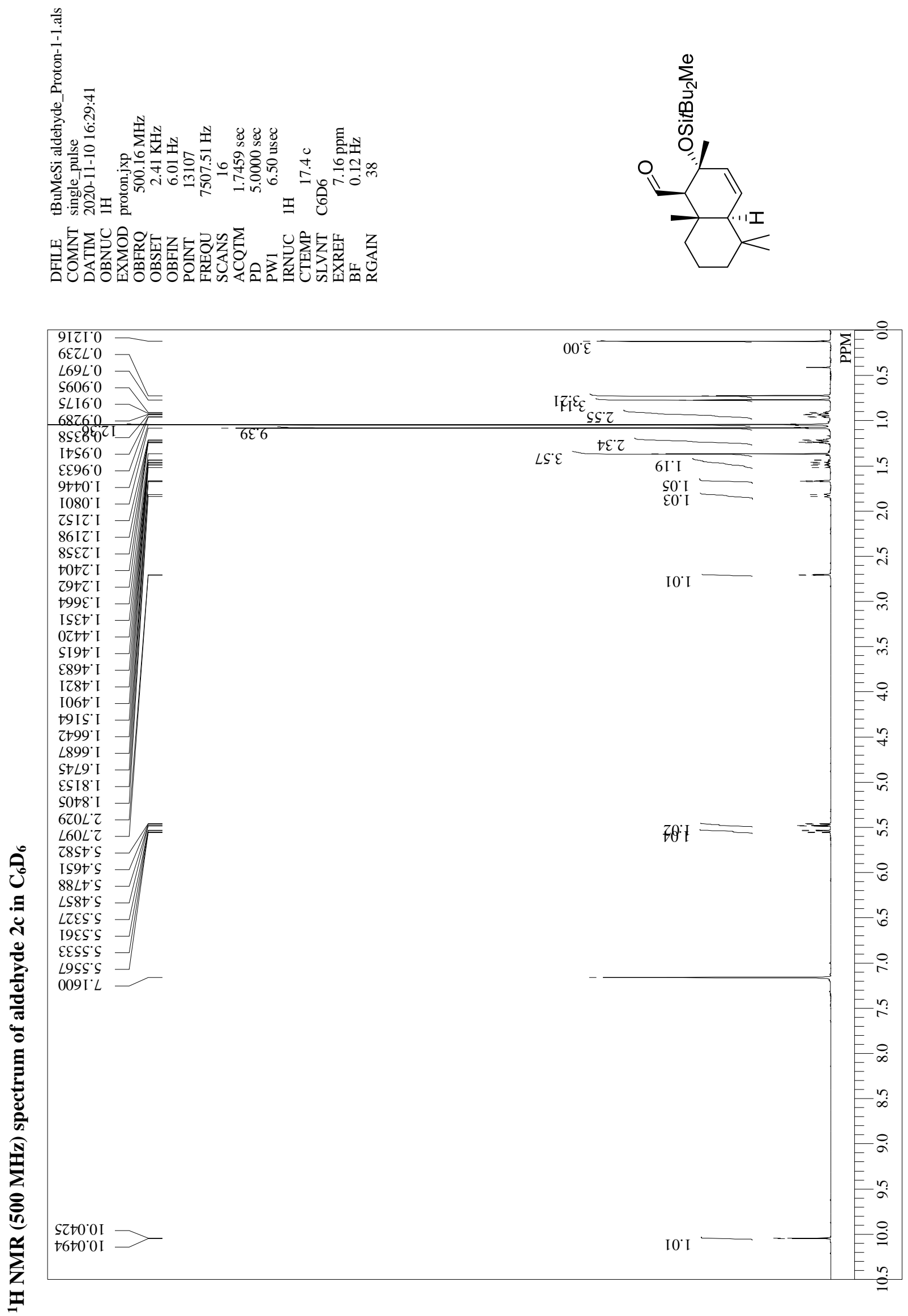
뚭 뜅

要

U⿺辶寸

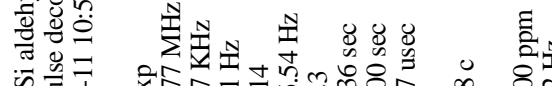

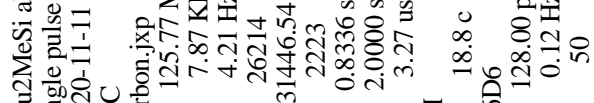

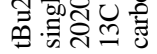

I

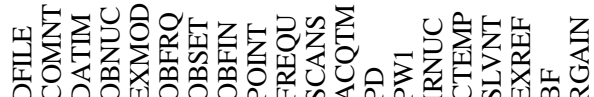
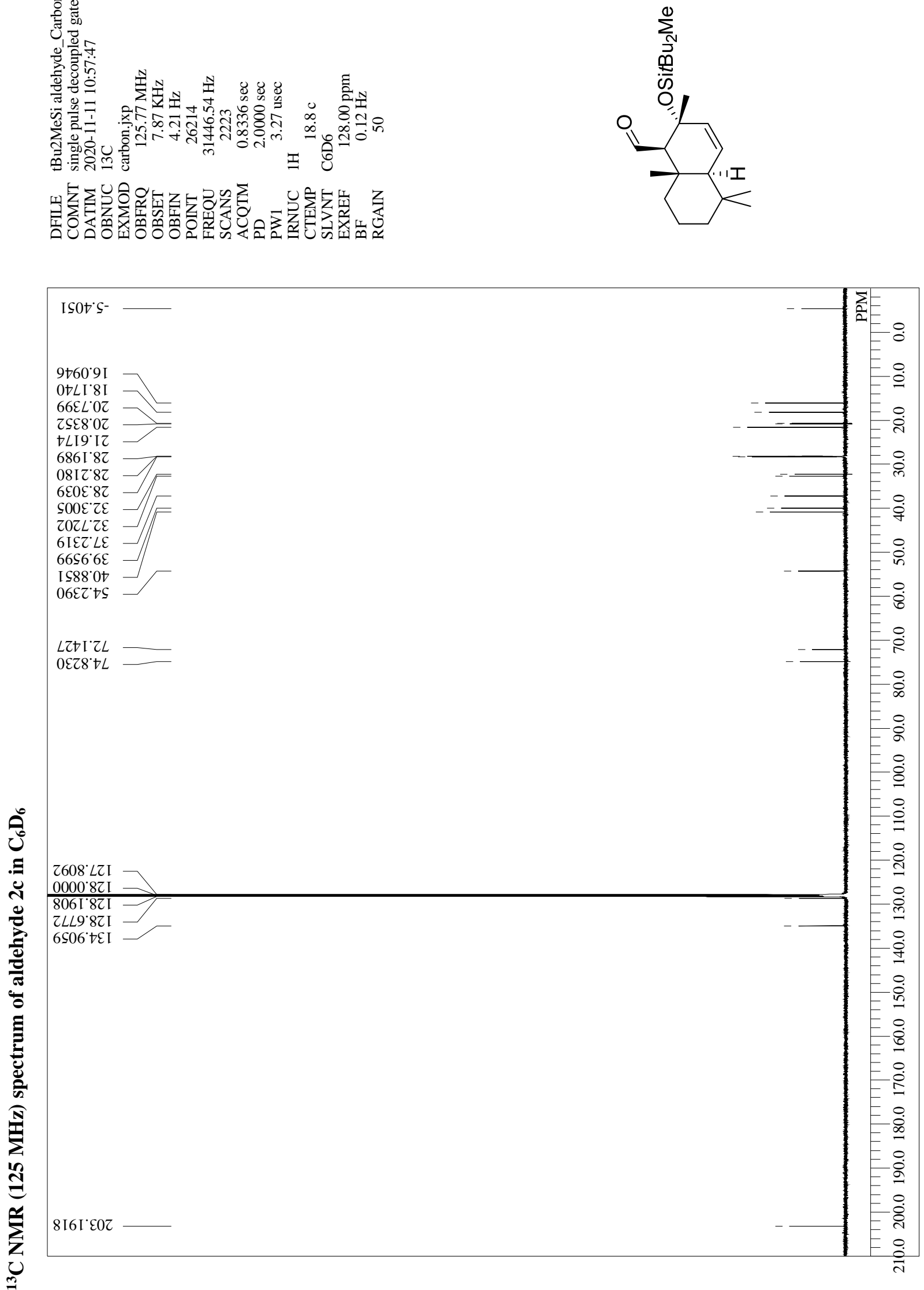